University of Rhode Island

DigitalCommons@URI

Open Access Dissertations

1976

\title{
Agency/Communion Balance and its Relationship to Sex Role Stereotyping
}

Dorothy Thompson

University of Rhode Island

Follow this and additional works at: https://digitalcommons.uri.edu/oa_diss

\section{Recommended Citation}

Thompson, Dorothy, "Agency/Communion Balance and its Relationship to Sex Role Stereotyping" (1976). Open Access Dissertations. Paper 1092.

https://digitalcommons.uri.edu/oa_diss/1092

This Dissertation is brought to you for free and open access by DigitalCommons@URI. It has been accepted for inclusion in Open Access Dissertations by an authorized administrator of DigitalCommons@URI. For more information, please contact digitalcommons-group@uri.edu. 


\section{AGENCY/CONIMUNION BALANCE AND ITS RELATIONSHIP \\ TO SEX ROLE STEREOTYPING \\ BY \\ DOROTHY THOMPSON}

A DISSERTATION SUBMITTED IN PARTIAL FULFILLMENT OF THE REQUIREMENTS FOR THE DEGREE OF

DOCTOR OF PHILOSOPHY

IN

PSYCHOLOGY

UNIVERSITY OF RHODE ISLAND - 


\section{ABSTRACT}

The purpose of this investigation was to examine a model of interacting with life situations which does not carry with it the restrictions implicit in the masculinityfemininity-androgeny concepts. However, the model includes positive aspects of behavior generally imbedded in the masculinity-femininity concepts. This model utilizes David Bakan's (1966) concepts of agency and communion, modifying his description of these modes of interacting and positing a complementary (completing, non-conflicting) relation between them. An agency/communion theoretical model was developed which emphasizes the potential for balance between the modes. Problems with the traditional gender dichotomy were discussed. The transcending of sex roles and agency/ communion balance were then considered in relation to each other.

Existing measures of agency and communion are tied to the assumptions of bipolarity and/or gender (agency as male and communion as female). Therefore, an exploratory instrument, the Ways of Interacting Questionnaire (WIQ), was developed to measure indications of agency and communion which assumes the unity of each construct, the independence of the constructs from each other and their independence 
from gender. Data obtained from 162 undergraduates at the University of Rhode Island were used to analyze the WIQ to determine whether predictions based on those three assumptions were supported. The WIQ consists of 15 situations, for each of which three agentic and three communal behavioral alternatives were given. The participants were asked to rate the likelihood that (s) he would respond in that situation in each of the alternative ways described. Two dominant constructs emerged from a component analysis, but more than one component reflected each mode and in some situational contexts the complementarity of the modes overrode their independence. Agency and communion, as measured, were independent of gender.

It was hypothesized that persons who manifest balance between agency and communion will be less stereotypic in their attribution of characteristics to men and women than persons who manifest lesser balance. From the component analysis of the WIQ one component was selected to best represent agency (A) and one, communion (C). Sex role stereotyping was measured for self, same sex and opposite sex using three administrations of the Bem Sex Role Inventory. Data from 135 of the same participants used in the component analysis were used to test the hypothesis. The hypothesis was not supported, however there were differences between imbalanced groups depending on whether $A>C$ or $C>A$. A $>C$ men and women stereotyped themselves less than $C>A$ persons, but $C>A$ men and women stereotyped the opposite sex 
less than A $>C$ persons. Questions were raised about other facets of the theoretical model that could be explored. 


\section{ACKNOWLEDGEMENTS}

I am poignantly aware at this time of a host of persons to whom I am grateful for their belief in and support of my achieving the goal of completing requirements for a PhD. As a person who has exemplified Matina Horner's description of the bright woman who is in a bind because she is achievement-oriented but very much afraid of success, their encouragement and/or practical help has made a difference in my continuing in spite of that bind.

To Bernice Lott, my mentor guiding this project, whose combination of challenge to me to keep clarifying and tightening the intellectual content combined with unstinting availability of time and emotional support so clearly exemplies actualization of a high degree of integration of agency and communion--

To Al Lott, who repeatedly listened and gave acutely relevant and sensitive comments; to Henry Biller and Dick Travisano, both of whom gave valuable global encouragement; to Wayne Velicer, who not only facilitated my becoming well acquainted with the computer center, but who directly made possible the component analysis--

To other academic colleagues, two professors from my belated and timid undergraduate years, Robert Sprinthall 
and James Brennan; to Al Willoughby for invaluable help during the first years in graduate school; to the others in our close band of fellow students who started the PhD program together--

To my psychotherapists who at crucial times have helped me to utilize my own energy and ability: Eleanor (Ranger) Hamilton, Cynthia Wilcox, and Henry Altenberg--

To my family (biological and otherwise): my parents, Paul and Carolyn Thompson, who loved me through a much delayed adolescence; my adult offspring, Grace, Carter, and Charlotte Boynton, who show delight in my becoming a whole person; my former husband, Bob Boynton, who is glad for me; my commune family with whom I spent a year and a half who: willingly served as trial participants in the research; and my partner in living, Don Leveridge, who would have shared much more from his research background, but understands that it is important to me that the dissertation endeavor be unquestionably mine--

Thank youl 
TABLE OF CONTENTS

LIST OF TABLES. . . . . . . . . . . . . . v v

INTRODUCTION. . . . . . . . . . . . . . I

I. THEORETICAL CONSIDERATIONS. . . . . . . 3

Ways of Interacting

Examples of Two Modes Potentially in

Balance

Bakan's Concepts of Agency and Communion

The Relationship Between Agency and

Communion

Influence of Gender on Evaluations of Personality

Transcending Traditional Sex Roles

Dichotomized Sex Roles Related to Disorders

Transcending Sex Roles Related to Optimal

Development

Balance of Agency and Communion as an

Indication of Transcending Sex Roles

II. OBJECTIVES OF RESEARCH. . . . . . . . 25

Development of Measure of Agency and

Communion

Using the Measure of Agency and Communion

III. MEASURE OF AGENCY AND COMMUNION . . . . . . 35

Development

Preliminary Steps

Establishing Rater Agreement with the

Researcher's Designation of Alternatives

as Reflecting Agency or Communion

Ways of Interacting Questionnaire

Component Analysis

Predictions

Method

Participants

Procedure 


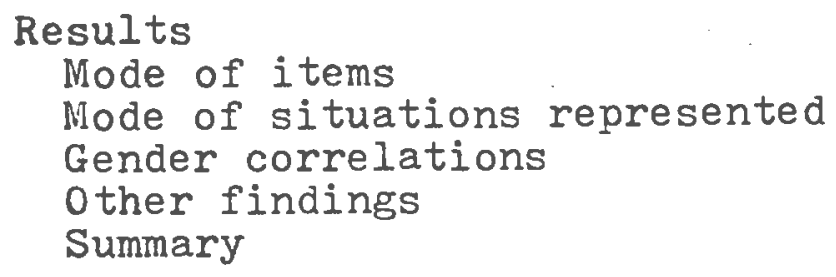

IV. TESTING THE RELATIONSHIP BETWEEN AGENCY/

CONINUNION BALANCE AND SEX ROLE

STEREOTYPING. . . . . . . . . . . 70

Introduction

Predictions

Method

Participants

Procedure

Results

Overall Analysis

A Priori Comparisons

other Findings

V. DISCUSSION. . . . . . . . . . 87

Evaluation of Ways of Interacting Questionnaire

Relationship Between A/C Balance and Sex

Role Stereotyping

Re-examination of Theoretical Model

Further Questions

APPENDIX A. . . . . . . . . . . . . . 100

APPENDIX B.................. 110

APPENDIX C. . . . . . . . . . . . . . 119

REFERENCES. . . . . . . . . . . . 126 


\section{IIST OF TABLES}

1. Eigen Values and Percent of Accounted Variance of Nine Extracted Components. . . . . . . 44

2. Varimax Rotated Component Pattern

Correlations. . . . . . . . . . . 45

3. Positive Emotion (Component I) . . . . . . 49

4. Self-Centeredness (Component II) . . . . . 50

5. Union with Objects or Events

(Component III) . . . . . . . . . 51

6. Union with Friends (Component IV). . . . . 53

7. Pragmatism (Component V) ......... 55

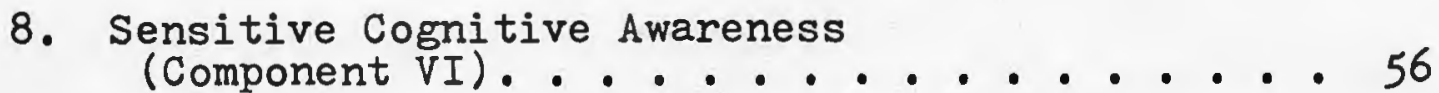

9. Analysis (Component VII) ....... 58

10. Competence (Component VIII). . . . . . . 59

11. Uninterpreted Component (Component IX) . . . . 60

12. Point Biserial Correlations Between Sex and Component Scores.......... 65

13. High Representation of Situations on Components............ 68

14. ANOVA Summary Table for Self Stereotyping Scores. . . . . . . . . . . . 78

15. Self Stereotyping Scores for Groups on Three Levels of Agency and of Communion . . . . 78

16. ANOVA Summary Table for Ideal Woman Stereotyping Scores . . . . . . . . 79

17. Ideal Woman Stereotyping Scores for Groups on Three Levels of Agency and of Communion . . . 
18. ANOVA Summary Table for Ideal Man

Stereotyping Scores . . . . . . . . 80

19. Ideal Man Stereotyping Scores for Groups on

Three Levels of Agency and of Communion . . . 80

20. Sex Differences on the BSRI Stereotyping

Scores.............. 81

21. A Priori Comparison of Balanced versus

Imbalanced Groups on Stereotyping Scores using ANOVA of Agency and Communion . . . . 82

22. A Priori Comparison of $C>A$ versus $A>C$ Groups on Stereotyping Scores using ANOVA of

Agency and Communion. . . . . . . . 85

23. Stereotyping Scores for Groups Imbalanced

on WIQ C and A Factors. ........ 85

24. Self and Same Sex Ideal Differences on

the BSRI Stereotyping Scores. . . . . . 86 


\section{INTRODUCTION}

There is a growing appreciation that optimal human functioning covers a range of behaviors, some of which have been considered masculine and others feminine. Therefore, for a person to show an "opposite sex" attitude or behavior may be an indication of mental health or maturity. The shift to considering aspects of functioning as human rather than masculine or feminine does not come easily, however, and researchers in psychology continue to accept culturally determined untested assumptions about sex-related behavior. A practice which helps to perpetuate the cultural mind-set of associating a given behavior with the person's gender is the continued usage of the terms masculine and feminine as descriptive adjectives for personality. These terms are deplored by some and set off in quotation marks by others but their use continues. The concept of androgeny, reflecting the potential for a person to exhibit characteristics associated with both genders, sets a model for balance or complementarity within an individual. However, this concept carries with it direct implications of gender.

The purpose of this investigation was to examine a model of interacting with life situations which does not carry with it the restrictions implicit in the masculinity-femininity-androgeny concepts but which includes the positive 
aspects of behavior generally imbedded in the masculinityfemininity concepts. This model utilizes David Bakan's (1966) concepts of agency and communion, modifying his description of these two modes of interacting and positing a complementary (completing, non-conflicting) relation between them. An agency/communion theoretical model is developed which emphasizes the potential for balance between the modes. Problems with the traditional gender dichotomy are discussed. The transcending of sex roles and agency/communion balance are then considered in relation to each other. Existing measures of agency and communion are tied to the assumptions of bipolarity and/or gender (agency as male and communion as female). Therefore, an exploratory instrument, the Ways of Interacting Questionnaire, is developed to measure indications of agency and communion which assumes the unity of the two constructs, the independence of the constructs from each other and their independence from gender. This instrument is analyzed to determine whether predictions based on those three assumptions are supported. The instrument is also used to predict sex role stereotyping. It was hypothesized that persons who manifest balance between agency and communion will be less stereotypic in their attribution of characteristics to men and women than persons who manifest lesser balance. 


\section{CHAPTER I}

\section{THEOREPICAL CONSIDERATIONS}

\section{Ways of Interacting}

Examples of Two Modes

Potentially in balance

The idea that there are two fundamentally different basic ways of reacting to persons, things, and situations is a recurring theme in the study of personality. Several theorists, e.g., Bakan (1966) and May (1967), deal with a struggle in the individual between individuation and union; Adler (1964) assumes both an innate striving for superiority and an innate social interest; White (1960) emphasizes the presence of competence motivations that are in both task and interpersonal areas; Piaget (1936/1952) posits alternation between accommodation and assimilation.

The idea of two basic modes is expressed in other areas besides psychology. The most succinct example is from the religious philosopher Martin Buber (1923/1958) who describes in lyrical prose two ways of knowing the world. "To man the world is twofold, in accordance with his twofold attitude.... in accordance with the twofold nature of the primary words which he speaks....The one primary word is the combination I-Thou. The other primary word is the combination I-It ( $p .3) . "$ Buber describes the I-It attitude as one 
of experiencing objects (animate or inanimate), whereas in I-Thou a person takes his/her stand in relation to someone or something with no sense of boundaries or time.

In the arts Aaron Copland (1939) gives examples of composers using different patterns in composing music, all of which I interpret in terms of different degrees of balance of two modes. Copland also describes an integration that is possible for the listener of music which he summarizes by saying, "The ideal listener is both inside and outside the music at the same moment, judging it and enjoying it... (1957. p. 23)." Paolo Friere (1970), Brazilian educator, asserts that constructive change for oppressed people must come from their having a developing awareness and functioning in two modes. One is the individual's affirming his/her being of value and capable of action to change conditions; the other is a loving of humankind and an openness to learning from others, even those who at a given time are the oppressors. Friere then posits a certain kind of dialogue ("praxis") between these two necessary dimensions, reflection and action.

There are common elements across the pairs of ways of interacting given as examples. In each example one mode refers to the person as observer and/or structurer; the other mode refers to the person as subjective and within a process. In each description or conceptualization there are the implicit or explicit assumptions that both modes are not only potential in all individuals, but so necessary that 
there is distortion in living if one is lacking. May (1967) uses himself in giving examples of problems which may arise when persons function too much in one mode or the other (p. 9); Friere (1970) describes the crippling effect of functioning in one dimension without the other (p. 75-76). Descriptions of the contrast between the distortion of a mode (when not balanced by the other) and the realized positive potential when a mode is balanced suggest an advantage which results when the modes complement each other.

\section{Bakan's Concepts of Agency and Communion}

Each of the theoretical approaches mentioned above struck a chord of recognition in me, but all were too general or too specific for me to adopt as a model until I came across David Bakan's (1966) scheme. ${ }^{1}$ Here was a model on a general level of abstraction which was also specific enough to apply to day-to-day instances of behavior. Most of the overall descriptions of the individuation mode and the union mode and the potential for attaining a balance between them fit the conceptual frame of reference for which I had been searching.

The key concept of the mode Bakan calls agency is separation, with emphasis on the person as an individual organism. The key concept of the second mode, communion, is union, where the individual feels part of a larger entity. Bakan describes agency as manifesting itself in self-

I I was led to Bakan's ideas through reading J.H. Block (1973) and then R. Carlson (1972). 
preservation, self-assertion, self-expansion, in the formation and maintenance of separations of things and isolation of the individual, in the urge to master, in repression of thought, feelings and impulse. He describes communion as manifesting itself in the sense of being at one with other organisms, in lack of separation of things and the individual, in non-contractual cooperation, in lack and removal of repressions.

Some of the details of Bakan's descriptions of agency and communion did not fit my emerging concepts and appeared not to follow the otherwise logical scheme he had set up with agency as separation and communion as union. For example, by including expression of feeling and impulse as manifestations of communion, Bakan has apparently taken the approach that repression is agentic and expression is communal without applying his basic scheme to the content of what is being repressed or expressed. Logically there would be two modes of thinking and two modes of feeling if there are two basic ways of approaching any aspect of life. The agentic mode of thinking as a manifestation of separation would include analytic and systematic ways which structure, objectify, and manipulate ideas. The communal mode of thinking as a manifestation of union would include intuitive ideas which come together with the person as a catalyst of the process. Similarly, the agentic mode of feeling would include the distancing ones of anger and the sense of difference from others while the communal mode would include 
caring and empathy which draw people closer to one another.

The Relationship Between Agency

and Communion

My major divergence from Bakan's postition is in regard to the relation of the two modes to each other. He sees them as basically in conflict. The agentic mode is vividly portrayed, especially its destructiveness when it is "unmitigated" by the communal. The communal mode comes across as rather bland and vaguer than the agentic mode (Buber, 1923/ 1958, in contrast, richly described the analogous I-Thou attitude as an active stance). I suggest that Bakan posits the two tendencies in basic conflict with each other because, although he shows he is highly aware of the destructive effects on society and individuals when agency predominates, he seems to stress (perhaps unknowingly) the agentic aspect in his own thinking. He sees the relationship between agency and communion in terms of mastery of one over the other, i.e., in agentic terms. At the same time, other than as a softening effect on agency, Bakan seems to have less grasp of communion and the creative and sustaining role it can have. By the same token, in thinking of communion mainly. as beneficent when mitigating agency, Bakan omits looking at the negative consequences on society or the individual when communion is not mitigated!

Related to Bakan's view that agency and communion are in conflict are two other aspects of his theory; he asserts that the two modes are universal tendencies in all living 
forms but at the same time he assumes that an increase in one tendency must be accompanied by a decrease in the other. Therefore, for one tendency to manifest itself, it must push against, push down the other. If, however, one conceives of the tendencies as on two continua rather than one, it is possible to manifest both at equal or unequal levels. For example, some people who have a strong sense of individuality may also have a strong sense of unity with the universe (Maslow, 1962). Bakan often equates isolation with agency. Since it is possible to be highly separate and also to be interdependent, I see isolation simply as an absence of communion without reference to agency.

My position regarding the relation of agency and communion to each other is that each mode is independent and unipolar; that each can be developed in any person at any age in such a way as to be complementary and in balance with the other. When the modes are in balance, a person's functioning is better than when they are not in balance. If, however, one is developed strongly and the other weakly or the two are temporarily out of balance, the two ways may seem to be in opposition and in conflict with each other. To illustrate, when a person is operating in an efficient, goaloriented manner in a particular situation, it may seem thwarting for someone to introduce a spontaneous digression. Similarly, when a person has been in a state of harmony, being confronted by an imperfection can seem to be jangling. Thus when one is strongly interacting in one mode, the other 
seems to be an intrusion, uncomfortable, and inappropriate.

I have become aware as a psychotherapist of moments when agency and communion are integrated. I move back and forth between being confronting (agentic) and being supportive (communal), trying to maintain an even balance or move toward one or the other mode as each seems appropriate at a particular point in time. At the moments when I find myself being agentic without some degree of communion, something is missing. I am too critical, too distant. On the other hand, in the moments when I find myself being communal without being agentic, again something is missing. I am overidentifying with the client.

The times of being both agentic and communal simultaneously coincide with the moments of feeling that, as a therapist, I am functioning holistically and optimally. They are the times when I seem both objectively clear and subjectively in tune. The emphasis may be agentic as I lay out a different approach for a client to try, but I am doing so with compassion and understanding; or the emphasis may be communal as I enter to some degree into the suffering which the client experiences, but I am doing so knowing that responsibility for reaction to that situation lies within the individual. The main point for me is that these two ways of interacting can operate simultaneously and in harmony.

\section{Influence of Gender on Evaluations of Personality}

Psychologists have put a good deal of effort into measuring masculinity and femininity as part of an overall 
attempt to understand human behavior. Except for rare anomalies, the two sexes are physically distinct. In addition, across cultures one finds that members of each sex are consistently socialized to behave differently from members of the other sex (Barry, Bacon \& Child, 1957); within cultures there are stereotypes of what is masculine and what is feminine (Block, 1973; Broverman, I., Vogel, Broverman, D., Clarkson, \& Rosenkrantz, 1972); and there are measurable modal differences in behavior between the sexes (Broverman, D., Klaiber, Kobayashi \& Vogel, 1968). An approach that has validity in describing sex-related personality differences in a population has limits, however, when interpretation of differences is then applied to different sub-cultures. Masculinity (i.e., behaviors deemed appropriate for men) and femininity (i.e., behaviors appropriate for women) are in large measure culture-bound so that what is masculine in one cultural situation may be feminine in another, and vice versa (Mead, 1933/1963).

A more serious difficulty arises when we apply norms for male behavior and norms for female behavior to individual males and females. When one group of characteristics is labeled masculine and another feminine, what follows is an assumption of the appropriateness of the different behaviors for males and females, respectively. This assumption comes both from those who emphasize a biological basis for the behavior differences (Deutsch, 1944; Erikson, 1963; Freud, 1933/1969) and those who emphasize the social utility 
of a division of labor in adult sex roles (Barry, Bacon \& Child, 1957; Parsons, 1955).

The main drawback of the assumption of appropriateness of sex-related behavior is that the converse is also assumed, i.e., expression of "masculine" characteristics by a female is considered unnatural, inappropriate and deviant and similarly of "feminine" characteristics by a male (Constantinople, 1973). Since American society, especially, tends to value being male more highly than being female (Hacker, 1951; Myrdal, 1944/1969), a male is viewed as weak and inferior if displaying "feminine" behaviors and a female is in some ways chastized when aspiring to behavior associated with the more dominant male. If labeling affected only a rare individual it might be overlooked. However, since there is considerable overlap even within our culture in the distribution among males and among females of both "masculine" and "feminine" labeled characteristics, many people are perceived by others as deviant. Diagnoses of emotional disorder are made from test results without validation (Constantinople, 1973) and from "deviant" behavior without regard to whether it is appropriate and/or adaptive for the individual (Chesler, 1972).

The pejorative connotations of identifying a woman as "masculine" or a man as "feminine" come from internal evaluations as well as external ones (Horner, 1972). Over and over in feminist writings are examples of women describing their experiences of having established cognitively the 
appropriateness of exhibiting a full range of human characteristics, but who have had difficulty expressing those that are labeled "masculine." Woman after woman has described what a gradual process it is to feel "I'm O.K." to the extent that she is "masculine," regardless of how "feminine" she is also.

Female bodies are different from male bodies, so probably there are some experiential differences related to living inside a female body as compared to living inside a male one. But some of the meanings which theorists have assumed must stem from the physical difference may be exaggerated, distorted or incorrect. It is one thing to describe a penis as a projectile and a vagina as a receptacle; it is another to say that every thing or action that is intrusive is masculine and that every thing or action that is inclusive is feminine, or to posit, as Erikson (1963) does, that the dominant mode for a person with a penis is intrusion because the mode is a biologically "preformed function" and that the dominant mode for a person with a vagina is inclusion because the mode is a biologically "preformed function."

Freud's position, as expressed in "Anatomy is Destiny" (1933/1969), is that the boy child feels that he has something special he might lose, whereas the girl child feels that she has already lost something important, and that very different personality strengths and weaknesses develop because of this difference. Freud points out three avenues 
that he considers a girl may follow because of her supposed "castration", sexual inhibition, a masculinity complex, or normal femininity. Note that as he describes them even the best of the three patterns that a woman may develop is inferior to what he describes as possible for a man and therefore to be a feminine woman (best adjustment) is inferior to being man and to be a masculine woman is decidedly worse.

The extremeness of Freud's views has been noted by those concerned with cultural influence (e.g.. Horney, 1967). ${ }^{2}$ However, the assumption that women view themselves as genitally inferior continues to crop up and perpetuates the mythology that woman is both different from and inferior to man. Kohlberg (1966), for example, assumes that as a child actively structures his/her concept of gender identity, individuals of both sexes perceive the male anatomy as more basic and therefore the female body as negative. Apparently neither Freud nor Kohlberg knew any delightfully happy little girl who considered her own body as basic and perceived boys as having those strange extra things.

Even when differential socialization for males and females is recognized, the relationship between what is generally appropriate for a woman (and therefore feminine) and appropriate for a man (and therefore masculine) and what

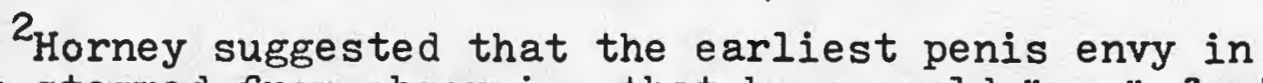
girls stemmed from observing that boys could "pee" farther and that boys may also feel inferior to girls because they cannot grow up to have babies. 
has influenced these expectations in a given cultural milieu becomes blurred. Gutmann (1965), for example, says that it is not fair to evaluate a woman's ego strength by the same criteria as for a man because women have different adaptive styles than men. The different ego style is attributed to the fact that women live in an autocentric milieu whereas men live in an allocentric milieu. Somehow even though Gutmann acknowledges in a footnote that men in a primitive autocentric milieu react as women (in western research) do, the overall impact is that he is describing how women (or men) are. Similarly, Barry, Bacon and Child (1957), having shown that societies in which greater physical strength is required (e.g., those which hunt large animals) socialize their boys and girls to be more divergent from one another than societies requiring less physical strength (e.g., those with fishing economies), and having acknowledged the ever decreasing need for brute strength in the current mechanized culture, still affirm the social need for distinct adult sex roles.

We know that in our society male and female children are reacted to differently from early infancy (Goldberg \& Lewis, 1969) and we know that there are prenatal and postnatal hormonal modal differences that apparently affect brain pathways (Money \& Ehrhardt, 1972). However, the crucial experiment of raising a group of young humans without differential treatment according to sex has not been done, so we do not know what modal physical differences would 
still remain and whether these differences are at all relevant to personality (Weisstein, 1969). Recognition of the possibility of similarities between individuals of both sexes across the full spectrum of attitudes and behavior helps to avoid overgeneralizing on the basis of gender; recognition that modal differences between the sexes are, at the least, heightened by cultural norms leads to a search for the ways socialization as a female may be different from socialization as a male. Lack of recognition of similarities between individuals of both sexes across the full spectrum of attitudes and behavior promotes internal and exter- nal pressure to restrict an individual within a sex role.

\section{Transcending Traditional Sex Roles}

Dichotomized Sex Roles Related to Disorders

One-sided adoption of sex roles gets both men and women into trouble. Sherman (1972) has summarized research findings on inadequacies in women as related to traditional sex role characteristics in areas of mental health, childbearing and rearing, and intellectual development. Similarly, Mussen (1962) has pointed out occupational and interpersonal difficulties for adult males who, as adolescents, had been high in stereotypic masculine interests, Jourard (1964) has associated physical illness and shorter life span for males with strong adherence to the male role, and chessler (1972) suggests that the much higher incidence of jail incarceration for men than for women is related to the sex 
role expectation that men be more aggressive.

Although psychotherapy has probably predominantly emphasized developing the "appropriate" sex role characteristics, (e.g., Rheingold, J., 1964), there are also those who advocate developing patterns that are associated with masculinity and femininity for both men and women. Cumming and Cumming (1970) consider that the hospital program they have developed has been effective when a patient (male or female) has (re)developed both work (instrumental) role competence and socio-emotional role competence. Carkhuff and Berenson (1969) suggest that an effective counselor should display both a masculine (action-oriented) function and a feminine (nurturant) function and that both functions serve as needed models for the counselee.

Transcending Sex Roles Related to Optimal Development

Some researchers have pointed out that the presence in a person of characteristics identified with the opposite sex can exist along with those of the same sex and that this is associated with higher intellectual ability (Maccoby, 1966). higher level of ego development (Loevinger, 1966. 1970), higher level of moral development (Kohlberg, 1964), and a greater degree of self-actualization (Biller, 1972). Pleck (1975) suggests that the dichotomized sex roles which are the goals of the traditional masculine-feminine paradigm be considered an intermediate phase. The paradigm he proposes has three phases which parallel Kohlberg's (1964) 
levels of moral development: 1) amorphous, 2) conforming to rules (sex roles), and 3) transcending (psychological androgeny according to individual needs and temperaments). The conforming-to-rules phase fits, at the beginning, with the concrete conceptual structuring stage as Piaget (1952) has described it. It may be, however, that the concrete thinking child or adult (who has not moved beyond that level of conceptualization) thinks in terms of dichotomized sex roles because somewhere (if not at home, then in his/ her broader cultural milieu) that model is given. If, however, both at home and abroad a child were exposed to the idea that it was "right" for all persons to exhibit a range of behaviors and "wrong" for a person to have a limited repertoire, the "rule" level of thinking would have a different content than it tends to now.

Perhaps as the result of a growing awareness of the positive aspects of "cross-sex" characteristics and/or eventual transcending of sex roles, there has been an increase in research with young children that suggests that behavior that has been considered appropriate to one sex is highly in evidence in both sexes. A recent summary of the literature by Maccoby and Jacklin (1971) reveals a comparable amount of exploratory and active behavior away from mothers by both pre-school boys and girls, Rheingold (1973) has demonstrated that both boys and girls aged eighteen months shared with their mothers things they found in a laboratory by showing them, giving them, or playing with them. 
In addition, there have always been individuals who were exceptions to the cultural norm. I suggest that it is the unusually bright, determined, and/or emotionally secure child or young adult who is currently able to transcend the traditional sex roles but that as less rigid models become more generally available, transcendance will not be so unusual.

Most studies of adult sex differences compare persons scoring at opposite ends of a single masculinity-femininity continuum based on two untested assumptions--unidimensionality and bipolarity (Constantinople, 1973). S. Bem (1972) has pointed out that in these studies those participants who show a mixture of the variables measured fall in the middle and are left out of the analyses. Her countertechnique has been the development of two separate scales and the use of a score for the difference between them as representing androgeny, defined as a nonsignificant difference between scores on masculine/assertive/instrumental characteristics and on feminine/yielding/éxpressive characteristics (Bem, 1974). Similarly Berzins and Welling (Welling, 1975) have developed an androgeny measure in which the category androgeny represents scoring above the median on both their masculinity scale and their femininity scale. One advantage of continuing to use the terms masculine and feminine and then attempting to expand people's awareness by suggesting that both patterns of behavior can be present in one person, as the term androgeny suggests 
(Bem, 1975), is that of starting from a base of familiarity and common usage. However, a corresponding disadvantage is that the terms are so diffuse and complex that masculine and feminine have to be defined by each researcher relative to the population (s)he is dealing with, the situations looked at, and his/her own approach. "The terms masculinity and femininity have a long history in psychological discourse, but both theoretically and empirically they seem to be among the muddiest concepts in the psychologist's vocabulary" (Constantinople, 1973, p. 390).

Another disadvantage is that even when we try to consider masculinity or femininity simply on the basis of defined core commonalities, there remains the tendency to evaluate in terms of sex-appropriateness or inappropriateness, i.e., surplus meaning. This disadvantage would extend to the term androgeny so that one is likely to think of an androgenous person as one who has characteristics common to men and characteristics common to women (with perhaps bisexual connotations) rather than as displaying some range of human characteristics. The women staff members of a feminist magazine, Women $(1974)$, gave reactions to the term androgeny in an issue devoted to the concept. Most were uncomfortable with the term. They objected to the implications of gender identity and/or combining gender roles. Those who were comfortable with the term were also unperturbed about thinking of themselves as in some way both male and female. 
Why not utilize the concepts expressive and instrumental adopted by Parsons and used extensively (Bem, 1974; A. Heilbrun, 1965; Johnson, 1963; Parsons, 1955) and describe persons in terms of a balance of these ways of interacting? Even though these terms have sex-role associations, they probably have less excess meaning than the terms mascùlinity and femininity. Instrumental relates principally to tasks and expressive relates principally to affect between persons. These concepts, therefore, while clearer than masculinity and femininity have a limited behavioral breadth, hence it was decided not to use them.

Balance of Agency and Communion as an Indication of Transcending Sex Roles

The concept of agency has much in common with the general concept of masculinity in western civilization and communion with the general concept of femininity. Block (1973). in investigating attributes considered self-ideal by men in Norway, Sweden, Denmark, Finland, England and the United States, found that psychologists judged 10 of the attributes to be agentic (e.g., practical, assertive, dominating, rational), and judged none as communal, while six were not specifiable as either. In contrast, of the attributes considered self-ideal by women in the same countries seven were judged to be communal (e.g., loving, sympathetic, sensitive, artistic), one was judged agentic, and nine could not be classified. Does use of the terms agency and communion come so close to the terms masculine and feminine 
that the overall effect would simply be a relabeling? While that could happen, it seems to me that there is a clear enough distinction between the sets of concepts that agency and communion can be used to advantage independently. Agency and communion have basic independent meanings not tied to time and place although the relative value of each could be interpreted differently depending on the context. A specific way of interacting that is agentic in one culture may be valued in one culture and not in another.

Bakan (1966) assumes the usefulness of a male "principle," and a female "principle," and that "what we have been referring to as agency is more characteristically masculine, and what we have been referring to as communion is more characteristically feminine (p. 110)." He takes this position while acknowledging both the presence of individual differences and the influence of culture and also the belief that agency and communion characterize both sexes. Bakan supports his position with the kind of generalizations from modal differences between the sexes and from genital differences that were discussed earlier. My position is that agency and communion need not be tied to different populations of persons, as the "masculinity/femininity" concepts are, i.e., agency and communion are not necessarily sex role stereotype related.

A major drawback to adopting the concepts of agency and communion in describing people is the lack of familiarity with the terms so that it takes time to have a clear grasp 
of them. Agency, as an objective mode, is easier to describe in operational terms while communion is more elusive. Because its expression tends to be more overt, agency is apt to be thought of as active while the more covert processes of communion are thought of as passive. But I believe that each has an inherent vitality which is incomplete when not in juxtaposition to the other. More than that, as previously stated, there is a heightened quality of production and experience as the modes complement one another, when each mode is developed and accessible in the repertory of an individual.

To think in terms of agency and communion it is necessary to stand back and be willing to try to shift perspective, to move out of the traditional male-female role mind set, to look at human beings as persons about whom gender is an integral, but not necessarily definitive, attribute. Some friends and strangers have immediately grasped the agency/communion balance scheme because they apparently had already been applying the underlying concepts. Susan Roecher, a visual artist, is such an individual. She and I met on a long distance bus ride. Even before I shared with her my research interest, she described to me, in effect, her own integration of the agentic and the communal in her life. She has learned that the mechanics of work she is doing have to fit into where she is in her own process of being and she is also able to utilize her practical skills to then provide time and support for more creative ventures. There 
was no reference to masculinity or femininity, explicitly or implicitly, in her discussion.

Traditionally the agentic male is supposed to be complemented by the communal female in a love or marriage relationship. The traditional pattern creates a communication problem because when males are being reared to be highly agentic and to suppress communal tendencies and females are reared to be highly communal and to suppress agentic tendencies, there is produced an appreciable gap between the two groups in how they think and act. The wider the gap, the less the understanding. The wider the gap, the -greater the sense of polarity, of inherent conflict, and of the battle of the sexes. Within this pattern neither male nor female is a whole person without a mate.

When males and females possess within themselves both agentic and communal characteristics, in balance, then they are whole persons individually. They can understand one another and draw close to each other, not out of struggle and necessity, but from choice. C. Heilbrun (1973) has described such people in her discussion of the famous Bloomsbury group, of which Virginia Woolf, Iytton Strachey, and Maynard Keynes were members.

It is my hope that using the concept of an agency/communion balance may be helpful in moving out of the restrictive masculinity/femininity mind set. It may help reduce our tendency to stereotype other individuals on the basis of their sex; and it may also provide a frame of reference for 
an individual to reduce the amount of self-stereotyping (s) he does. 
CHAPTER II

\section{OBJECTIVES OF RESEARCH}

Development of Measure of Agency and Communion

A first step toward using the concepts of agency and communion in describing individuals and relating the balance between agency and communion to individuals' lives is to see if it is possible to identify these modes in people. Several possible ways of measuring agency/communion balance were considered, selecting an existing paper and pencil measure of agency and communion, selecting subscales and items of an existing personality measure to represent agency and communion, devising situational experiences to represent agency and communion, and devising a new paper and pencil measure of agency and communion. The key criteria used in making this decision were that the measure reflect positive expressions of agency and communion as the researcher is defining them, that expression of each mode be affected by sex role as little as possible (i.e., maximum likelihood for both modes to be expressed irrespective of gender), and that the research endeavor itself reflect an integration of agency and communion, in procedure.

A search of the literature revealed that the only published research thus far on agency and communion either 
emphasizes the identification of agency with "masculinity" and communion with "femininity" (Carlson, 1971) or places agency and communion at opposite ends of a bipolar continuum (Brown \& Marks, 1969). The measure which Carlson (1971) uses to detect agency and/or communion in affective experience was developed within the Bakan framework. The projective techniques she uses allow for a fairly clear assessment of presence or absence of $A$ and $C$, but makes assessment of relative.strength of each difficult. The technique therefore lends itself to the simple conclusion that one group (men) is more agentic and another (women) more communal. - This interpretation is aided by the elimination from the study of those respondents with tied scores on responses rated agentic and those rated communal.

Brown and Marks (1969) have used an Inventory of 124 statements developed by Bakan. The statements are designed so that the presence of one mode precludes the presence of the other both in content and in scoring. In a footnote Brown and Marks acknowledge that "the assumption of bipolarity is critical to this scoring and admittedly wanting empirical verification (p. 473)." Perhaps as a result of the questionable assumption of bipolarity, Brown and Marks include as indices of agency, feelings of isolation and aiienation along with the sense of oneself as an individual. (If agency and communion are viewed as two continua, isolation and alienation would indicate the low end of the communion scale and not appear on the agency scale at all). 
It is not surprising, then, that they have found a high amount of agency often to be equated with pathology.

As previously pointed out, published measures of masculinity-femininity reflect aspects of agency for males and communion for females which are culturally emphasized in Western countries and those might be used to measure agency and communion. However, because these measures are designed to detect differences between women and men, they tend to minimize the possibility of similarities. Thus, they are less likely to discern that a successful competitive male business executive might be gentle with his children or that a male scientist might utilize "hunches" in his research, that a female professor might systematically prepare a year's coursework or that a mother might effectively manipulate the environment in the interests of her child. Even the Bem Sex Role Inventory (Bem, 1974), which was developed to provide a measure of androgeny, builds upon the same cultural biases as have previous measures. The adjectives on the $M$ and $F$ scales from which the androgeny score is derived were chosen by Bem to be those which are more socially desirable for males and females, respectively. A glance at the scales shows the masculine one to be almost entirely composed of attributes that could be said to be agentic ones and the feminine one to be largely composed of attributes that could be said to be communal ones. Support for the use of agentic descriptive adjectives as indications of masculinity, and communal ones as indications of 
femininity can be found in J. H. Block's (1973) cross-cultural study. In fact, several of the descriptive adjectives judged to be agentic and chosen more often by men in the Block study are items on the masculinity scale in the Bem instrument, as are several items judged communal in the Block study to be found on the Bem femininity scale. It was decided not to use any masculinity-femininity measure in order to reduce the likelihood of gender expectations and to leave more open the possibility of both gender similarities and differences regarding agency and communion to emerge. Other established personality measures were also eliminated. Shostrom's Personal Orientation Inventory (POI) (1964) was considered because Maslow's (1962) description of self-actualizing persons suggests an integration of agency and communion, and the POI, as a measure of self-actualization, would be likely to tap both modes. It does, but many items also tap emotional maladjustment, a variable the researcher chose intentionally not to include.

The possibility of trying to directly measure agency and communion by having participants perform in one or more primarily agentic situations and one or more primarily communal situations had appeal as probably having better predictive validity than a paper and pencil measure. The problem presented by such an approach is that almost any overt behavior (whether in a situation that might be primarily agentic, primarily communal, or neutral) could be enacted either agentically or communally. 
The decision was made to develop a paper and pencil measure of agency and communion for this project. To be comprehensive, however, a measure of agency should do more than reflect individualism; it should reflect efficient organizing of symbols, materials, and people, the intent of which need not be exploitative. To be comprehensive, a measure of communion should do more than reflect maintaining emotional closeness to people (which may be constructive or destructive in effect); it should also reflect awareness of inherent potentialities in symbols, materials and persons. A person might be predominantly agentic (or communal) in one or more areas of his/her life and manifest the other tendency more in other areas. Or both tendencies may be present equally in the same area. A good measure must be able to reflect these possibilities. When studied in depth a complex pattern of areas of $\mathrm{A} / \mathrm{C}$ balance and imbalance would probably emerge that would be unique in its content for that individual although there might be similar patterns across individuals.

Carlson (1972) has pointed out the predominance of the agentic-objective approach in most psychological research and has presented a case for the addition of communal approaches, especially in research on women (sic). In the present effort to develop a scale of agency and communion, utilization of both modes in the research process-procedure itself was attempted. My basic assumption has been that the two hypothesized modes may complement one another in 
all aspects of life--including research. ${ }^{3}$ Participants in the research process have been thought of as persons and not as subject-objects. (Kastenbaum, 1973, has recently ar- . gued for the elimination of the appellations $\underline{E}$ and $\underline{S}$ and their one-up, one-down connotations from professional journals.) In preliminary steps, the people who were asked to participate were encouraged to contribute to the measure of agency and communion through input regarding both content and process. The instrument that was developed was a straightforward one intended to have people identify with many of the examples. It related to the lives of two participants so much that it resulted in the loss of their data. A man and a woman started filling out the questionnaire with the intent of learning about themselves and each other and then asked to take their responses homel At all stages the project was explained to participants and they had an opportunity to ask questions.

The measure of agency and communion developed was intended to be an exploratory effort to operationalize

${ }^{3}$ During the research process, therefore, I have tried to identify the primarily communal stages, for example, when new possibilities suddenly emerged, and the primarily agentic stages, as in a concerted push to meet a deadline, and the times that reflected $\mathrm{A} / \mathrm{C}$ complementarity, for example, when systematically presenting my ideas to someone in a way that facilitates understanding and a constructive flow of ideas between us. For me, at least, it appears necessary to maintain an $\mathrm{A} / \mathrm{C}$ balance over time. Predominantly communal flights by myself or with others have been transiently satisfying, but leave only. fragments of content. Similarly, my agentic persisting in setting up and going through certain steps has suffered from too much determination to obtain measurable results and not enough staying in tune with the basic core of what it was I was trying to do. 
two complex concepts. In addition, while the two modes of interacting with life are being conceived of as independent, they are also being thought of as complementary. That is, the two modes are different but one mode serves to fill out or complete the other in the way a person interacts with life. If the modes are complementary, and possibly both present concurrently or sequentially, separating them for measurement may be difficult.

Three predictions about the measure were implicit in its development. One, although complex, the unity of each mode would be demonstrated; two, although complementary, the two modes would be shown to be independent; and three, both modes would be equally shown by both sexes.

\section{Using the Measure of Agency and Communion}

With a measure for estimating people's preferences for agentic or communal modes of response, it would then be possible to test predictions regarding the relationship between general $\mathrm{A} / \mathrm{C}$ balance or imbalance and certain specific behaviors or attitudes. The broad proposition underlying this research, as developed in Chapter $I$, is as follows: If a person interacts with life situations with the separate agentic and communal modes in balance, (s) he will experience them as complementary, i.e., not in conflict. Both modes would be appreciated as being of value and contributing to the individual's wholeness as a person and therefore to more constructive functioning.

There are many aspects of living to which this proposi- 
tion could be related, ranging from specific contexts, e.g., employment situations or emotionally significant relationships to personality development, e.g., level of ego or identity development, self-actualization, etc. Sex-role stereotyping was chosen as a specific aspect of personality to which $\mathrm{A} / \mathrm{C}$ balance might be expected to be significantly related. A person who experiences in her/himself the complementarity of agency and communion in balance would be likely to see in her/himself--and to look for in others-a range of characteristics that are both "masculine" and "feminine", in contrast, a person who experiences in her/ himself a gap and probably a conflict between agency and communion would be likely to see in her/himself--and to look for in others--more of those characteristics traditionally considered gender-appropriate and fewer of those considered inappropriate. Therefore, it was hypothesized that persons who manifest balance between agency and communion will be less stereotypic in their attribution of characteristics to men and women in general and to themselves than persons who manifest lesser balance.

Sex-role stereotyping is operationalized in this study as follows: a) by the nature of adjectives chosen to describe one's self on a standard measure of masculinityfemininity and b) by adjective descriptions (using the same scale) of "ideal man," and of "ideal woman." Sex-role stereotyping is here defined as a self-description in either the "masculine" (for men) or "feminine" (for women) direction 
and by the description of either sex in the socially approved or prescribed manner.

Spence, Helmreich, and Stapp (1974) have developed a measure which will provide the desired range of information. They developed the Personal Attributes Questionnaire (PAQ) based on the much-used Rosenkrantz, et al, Sex-Role Stereotype Questionnaire (SRSQ) (Rosenkrantz, Vogel, Bee, Broverman, I., \& Broverman D., 1968). The PAQ has several advantages over the SRSQ; a) it is shorter and machine scoreable, b) the items are all stereotypic across several populations and conditions, and $c$ ) with three subscales in addition to a stereotypic score, one can obtain separate scores for masculinity and femininity. However, even with the improvements over the SRSQ, the $P A Q$ seems more complex and analysis of data more tedious than necessary.

The Bem Sex Role Inventory (BSRI) (Bem, 1974) was chosen to provide the necessary measures of sex-role stereotyping for this study. This instrument was developed to yield separate scores of masculinity and femininity and also one of androgeny, defined by a statistically nonsignificant difference between a masculine (assertive/instrumental) score and a feminine (yielding/expressive) score. It consists of 20 personality characteristics (adjectives) previously rated as more desirable in American society for men than women (Nasculinity, Scale), 20 rated as more desirable for women than men (Femininity Scale) and 20 rated as neutral with regard to gender, 10 of which weré rated by Bem 
as positive and 10 negative (Social Desirability Scale). An Androgeny Score is derived either as a simple difference score $(F-M)$ or as a $\underline{t}$ score. Respondents rate each adjective on a seven-point scale from 1 (Never or almost never true) to 7 (Always or almost always true). Scores on the $F$ or $M$ scales, therefore, can range between 20 and 140 and Androgeny raw scores from 0 to \pm 120 .

The respondent to the BSRI is asked to describe him or herself. For this study the instructions were adapted to obtain "ideal man" and "ideal woman" ratings, as well as self ratings. In each case an Androgeny Score ( $F-M)$ was used as the indicator of stereotyping, a low score (i.e., close to zero) indicating non-stereotypic responses and a high positive score when describing women or a high negative score when describing men indicating stereotyped ones.

In addition to testing the hypothesis about $\mathrm{A} / \mathrm{C}$ balance, the BSRI self stereotyping measure was used as a validity check for the $\mathrm{A} / \mathrm{C}$ measure. This was made possible by the fact that some items on the Bem $M$ and $F$ scales had been judged $A$ or $C$ in the Block (1973) cross-cultural study cited previously. The Block items are as follows: indicating Communion-Loving, Sympathetic, and Sensitive; indicating Agency-Assertive, Dominating, and Competitive. It was predicted that $A$ and $C$ scores on the $A / C$ measure developed in this study would relate to scores on the $A$ and $C$ Block items in BSRI. 
CHAPTER III

MEASURE OF AGENCY AND COMMUNION

Development

\section{Preliminary Steps}

The concepts of agency and communion were described to a group of seven members of a self-awareness group (in which the present author was a participant) with examples of how each might be manifested in interaction with other people, with nature, with ideas, in performing a task, and in expression of feeling. Each person was asked to try to think of and write down situations in which ( $s$ ) he had been agentic, communal, and both in each of the situations given as examples. Many individuals were able to take the abstract ideas and think of relevant specific examples from their own experience; one person was not.

The goals of this preliminary step in the research process were: a) to move beyond the researcher's own frame of reference in defining agency and communion; b) to learn how to effectively communicate the concepts; and c) to increase the pool of life situations which people identify as ones in which both agency and communion may be manifested.

From these first participants came further examples of situations in which one could function agentically, 
communally, and both, and the idea of setting up a range of situations for each of which a set of alternative ways of responding could be formulated. Fifteen situations were subsequently described, each with six behavioral alternatives, three of which were agentic and three communal. The total number of items, therefore, was 90 with 45 agentic and 45 communal.

The situations were judged by the researcher to be ones to which most people, regardless of gender, could readily relate. Within the range of situations were included some which seemed primarily agentic, some primarily communal, and some not necessarily either, but in all of these situations both modes of response were possible. Across the situations there was opportunity in the alternatives presented to exhibit both agency and communion in regard to other people, thought, art forms, physical nature or tasks. Each alternative, however, was intended to represent either agency or communion. An illustrative situation, with accompanying behavioral alternatives is as follows:

One is listening to some music and is:

a) Aware of separate aspects, like melody, rhythm, harmony, instruments.

b) Feeling sheer pleasure from the sound itself.

c) Experiencing a particular mood or range of moods expressed in the music or associated with hearing it.

d) Sensing a rapport between oneself as listener and/ or the performer and composer.

e) Acknowledging the ability of the composer in terms of his/her use of musical materials.

f) Comparing the quality of execution by the performer(s) to others previously heard playing the same piece. 
Despite the communal nature of the situation, both agentic and communal behavior is possible within it. Alternatives $b, c$, and $d$ were formulated as communal ways of interacting; alternatives $a, e$, and $f$ were formulated as agentic ones.

Establishing Rater Agreement with the Researcher's Designation of Alternatives as Reflecting Agency or Communion

The initial instrument items were formulated by the researcher on a theoretical basis. A content analysis was done for two reasons. First, support for validity of the meaning of the items was sought through rater agreement on the agentic or communal connotation of the behavioral alternatives presented. Secondly, though complex, if the concepts of agency and communion are to be useful to a broader range of persons than psychologists and other mental health professionals or social scientists, the concepts must be grasped fairly easily and have a face validity. To include the latter purpose, it was decided to use naive raters.

Definitions of the concepts of agency and communion were formalized. The 90 item instrument, previously described, was adapted for administration to raters. To counter bias from the order in which the situations were formulated, their order was randomized. Two steps were taken to counter guessing on the part of raters a) the order of the agency and communion alternatives within each situation was randomized and b) one item was randomly selected and dropped from each situation (in case raters might try 
to identify an equal number of agentic and communal behaviors for each situation) leaving three representing one mode and two the other. This instrument, called Test $I$, which consisted of definitions of agency and communion and 75 items, 37 agentic and 38 communal, can be found in Appendix $A$.

Test. I was given to 17 participants, 14 of whom were students in a summer college course (Toward Self Understanding), and the remainder acquaintances of the researcher (one a secretarial school graduate and two college graduates). Their ages ranged from 17 to 46 . The raters were given an introduction to the project, definitions of agency and communion, and then the questionnaire. Their task was to designate each behavior alternative as illustrating an agentic or communal response and whether it did so "clearly," "possibly," or "don't know." After the questionnaire was completed some of the raters contributed comments and suggestions. Fourteen questionnaires were scoreable and analyzed.

The most useful information provided by this first administration of the questionnaire was on how to improve the administration procedure. Consequently, the definitions of agency and communion were elaborated so that each is presented on two levels, the first global and the second more specific; a practice situation was added for discussion in advance to better familiarize raters with the two modes; and items were modified to counter the tendency 
shown by raters to see communion more often than agency in the behavioral alternatives. Patterns of ratings and comments of participants strongly suggested that it would be an exceptional individual who would try to equalize the number of agency and communion items, therefore the sixth item in each situation was returned.

The revised questionnaire, Test II, was given to ten acquaintances of the researcher, nine of whom were able to give detailed feedback. These participants were aged 26-56, all but one are college graduates in professions ranging from engineering and business administration to teaching and counselling. The range of agreement by raters with the researcher on designation of all items as agentic or communal was from 62 to 99\%. From this administration it was learned that raters could follow the logic of the questionnaire and additional suggestions were obtained regarding how to clarify wording of some items. The definitions, in their revised form, were judged to be relatively unambiguous. The designation of items as clearly or possibly agentic or communal did not yield useful information and so were dropped. In both administrations the "Don't know" option was used rarely, and it was therefore decided that subsequent raters would not be unduly pressured by being forced to choose between agentic and communal on each item.

For the final ratings, naive participants were sought. Seventy undergraduates at the University of Rhode Island, members of two sections of a Theories of Personality course 
agreed to participate. Test III (Appendix B) was administered to these students. This version includes revised definitions of agency and communion, and a total of 15 situations (including the practice one), each followed by six alternatives (three agentic and three communal), to be rated. The situations themselves were also rated as being primarily agentic, primarily communal, or neutral. After the students responded to the questionnaire, the researcher described the development of the theory and the instrument and solicited comments.

Sixty-seven questionnaires were complete. These came from 45 women, 19 men, and 3 persons of unknown gender. The mean number of items per rater in agreement with the researcher was 79.33 (or $87 \%$ ) with fewer than $9 \%$ of the participants showing less than $80 \%$ agreement. The item-byitem agreement ranged from 69 to 100\% for women, 58 to $100 \%$ for men, and 72 to $99 \%$ all raters. Only one item was rated more often in the other mode than intended by the researcher. Ratings of situations as agentic, communal, or neutral yielded an acceptable range. More than 50\% of the students rated four situations as more agentic than communal and six as more communal than agentic; the remaining five situations were judged as being agentic, communal, or neither by less than 50\%. On the basis of these results and the high overall level of rater agreement, it was decided to keep all of the items in Test II unchanged and to await the results of a component analysis for further refinement 
at a later time. This final agency/communion instrument became the Ways of Interacting Questionnaire (WIQ).

\section{Ways of Interacting Questionnaire}

The Ways of Interacting Questionnaire was constructed on a theoretical basis with the intent that it principally reflect two relatively independent modes, agency and communion. Through content analysis items of alternative ways of interacting were rated agentic or communal. In addition these items were placed within the context of situations which themselves were rated as primarily agentic, communal, or neither. Built into the instrument were examples, for each mode, of instances when it could be manifested by a person in relation to other people, to tasks, to ideas, to art forms, to nature and physical exercise. Each behavioral alternative was formulated as a positive manifestation of agency or communion. Situations and alternative items included in the questionnaire were considered by the researcher to be as likely to be experienced by one gender as the other.

This questionnaire (Appendix C) consists of 15 situations, for each of which three agentic and three communal behavioral alternatives are given. The participant is asked to rate the likelihood that $(s)$ he would respond in that situation in each of the alternative ways described, on a scale from 7 (definitely or always) to 1 (definitely not or never). With 45 agency items and 45 communion items, the potential range of both total A scores and total C scores 
is $45-315$.

For a particular situation, one respondent might rate all agentic behaviors as highly likely and all the communal ones as highly unlikely; on another situation the same individual might do the opposite or might score low, medium, or high on both agentic and communal items. Because individual behavioral alternatives represent either agency or communion, indications of a person's A/C balance or complementarity must come from the sums of the $C$ and $A$ item scores relative to one another. An indication of $\mathrm{A} / \mathrm{C}$ balance is provided by a small difference between total $A$ and total $C$ scores whereas an indication of imbalance is a large difference between the two scores, in either direction.

\section{Component Analysis}

\section{Predictions}

The predictions that the WIQ would reflect two unitary modes and that these would be relatively independent were tested by a component analysis. The prediction that the two modes are independent of gender was tested by the correlations of the total $A$ and $C$ scores, the components, and the separate items to sex.

Method

Participants. Those taking part in the study were 171 University of Rhode Island students in two undergraduate sections of a class entitiled Toward Self-Understanding. They were non-psychology majors from a wide range of fields, 
aged 18 to 36, but primarily within the 18-23 category. The participants were almost equally divided between the sexes, with 83 men and 85 women, and three of unknown gender. The questionnaires fully completed by 162 of the undergraduate students ( 80 women, and 79 men and three of unknown gender) were used in the analysis.

Procedure. A principle component analysis was used, the number of components extracted being determined by the Velicer (197.4) method of average partial correlations. To assist in interpretation, the pattern was rotated orthogonally by a varimax method (Kaiser, 1959). Items that cor-related with a component more than .30 were retained for further examination.

\section{Results}

Mode of items. The component analysis yielded nine components. These nine components accounted for only $41.7 \%$ of the total variance, but any subsequent components would each account for $2 \%$ or less of the variance. See Table 1 for the unrotated and rotated order, eigen values, and percent of variance accounted for. See Table 2 for varimax rotated component pattern. The items loading on each component more than .30 were arranged in descending order. Tables 3 through 11 show the composition of the nine components in the order in which they were extracted after rotation. Instead of two main components, one consisting of communal items and the other of agentic items, nine components were found. Two components were composed predominantly 


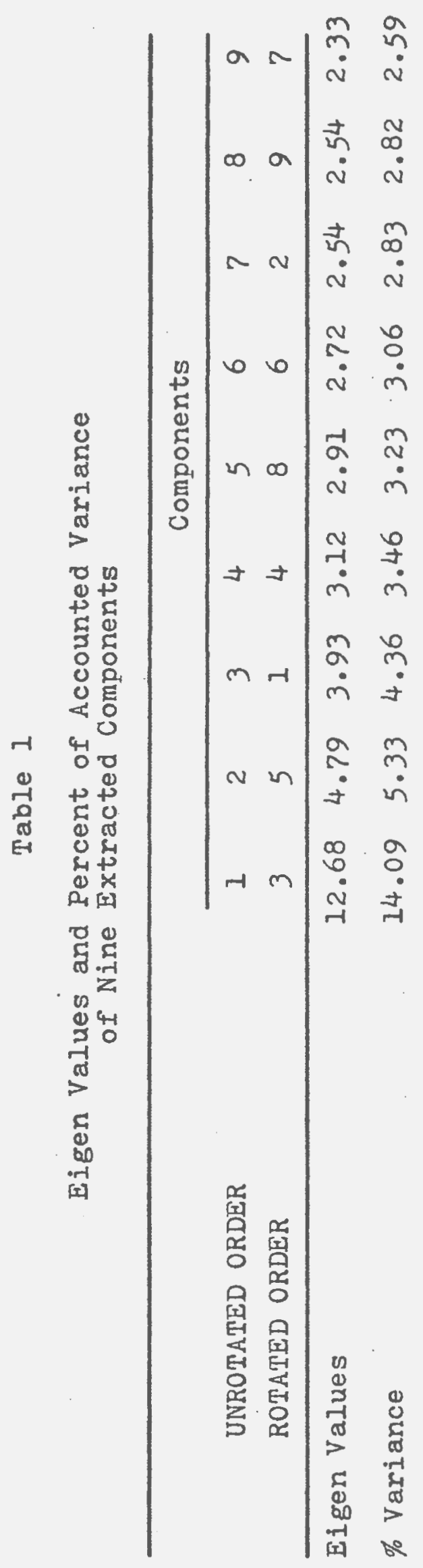




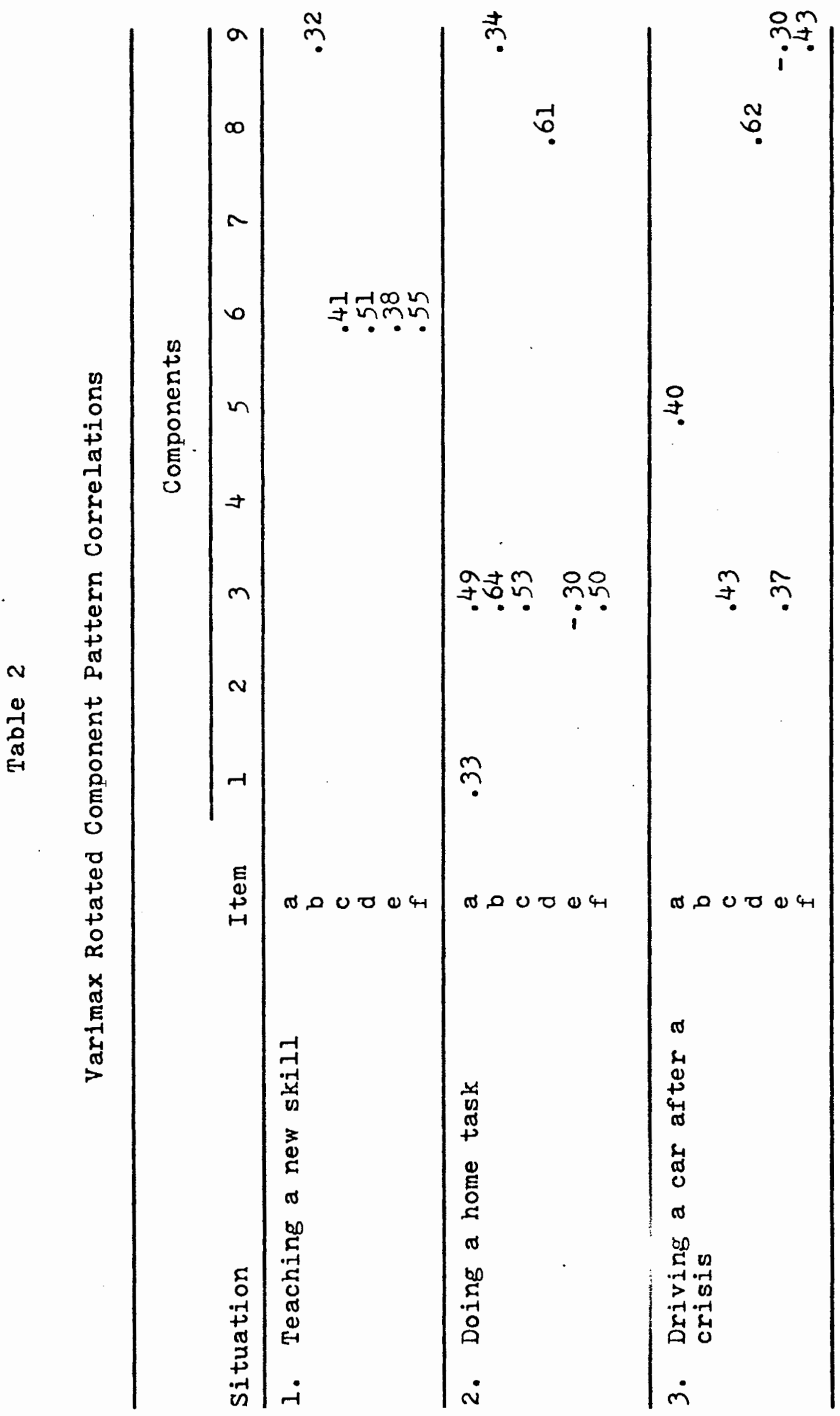




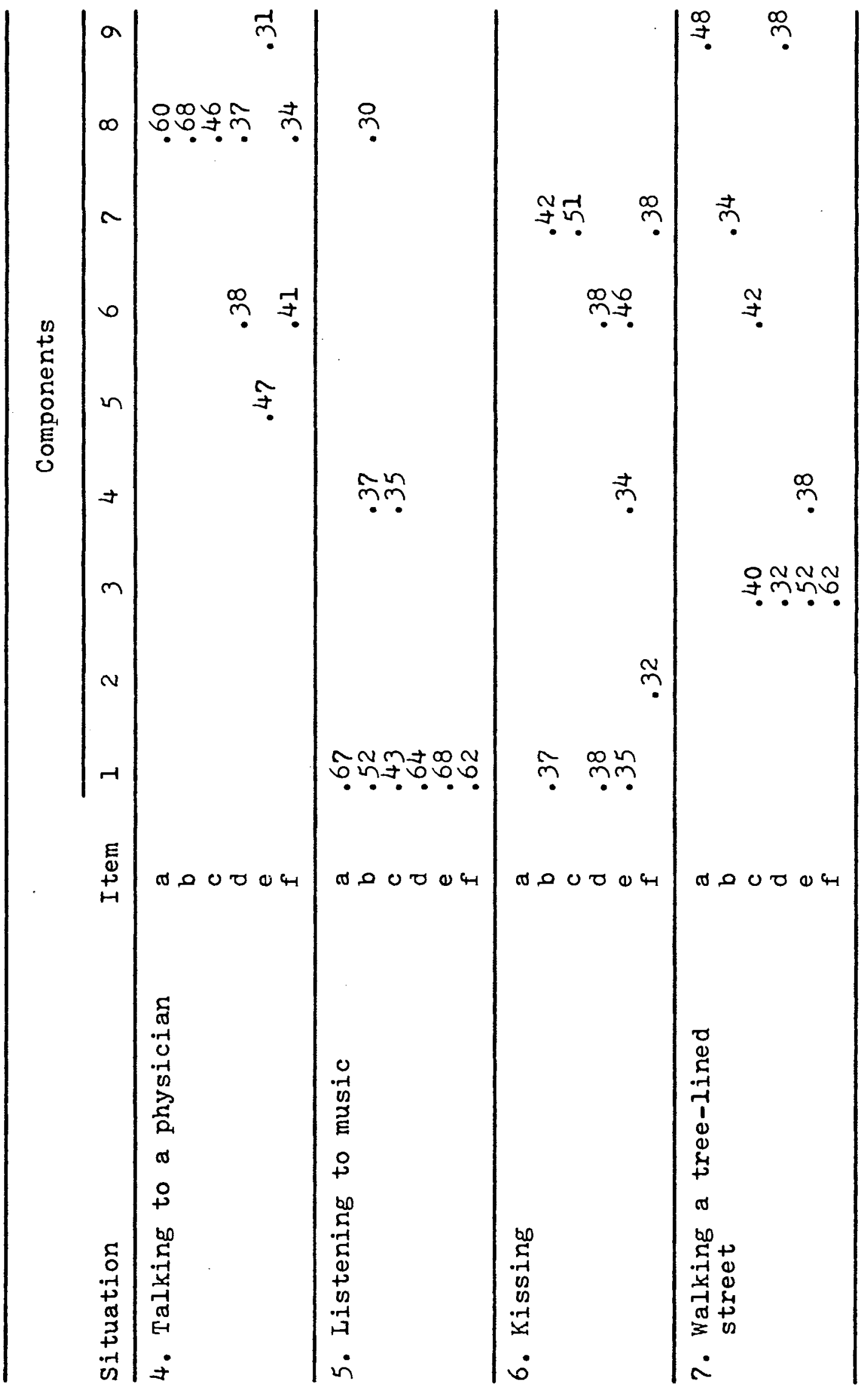




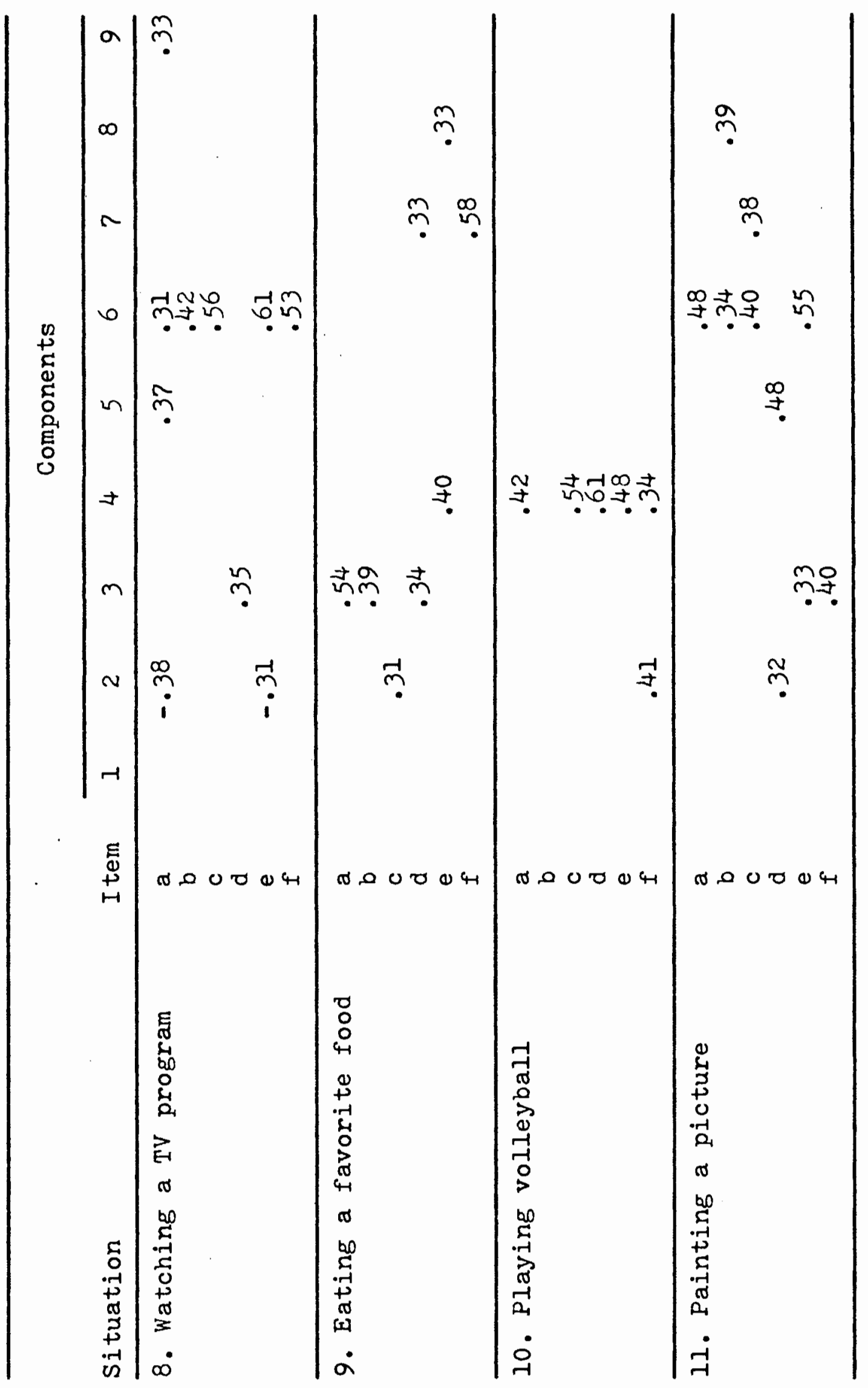




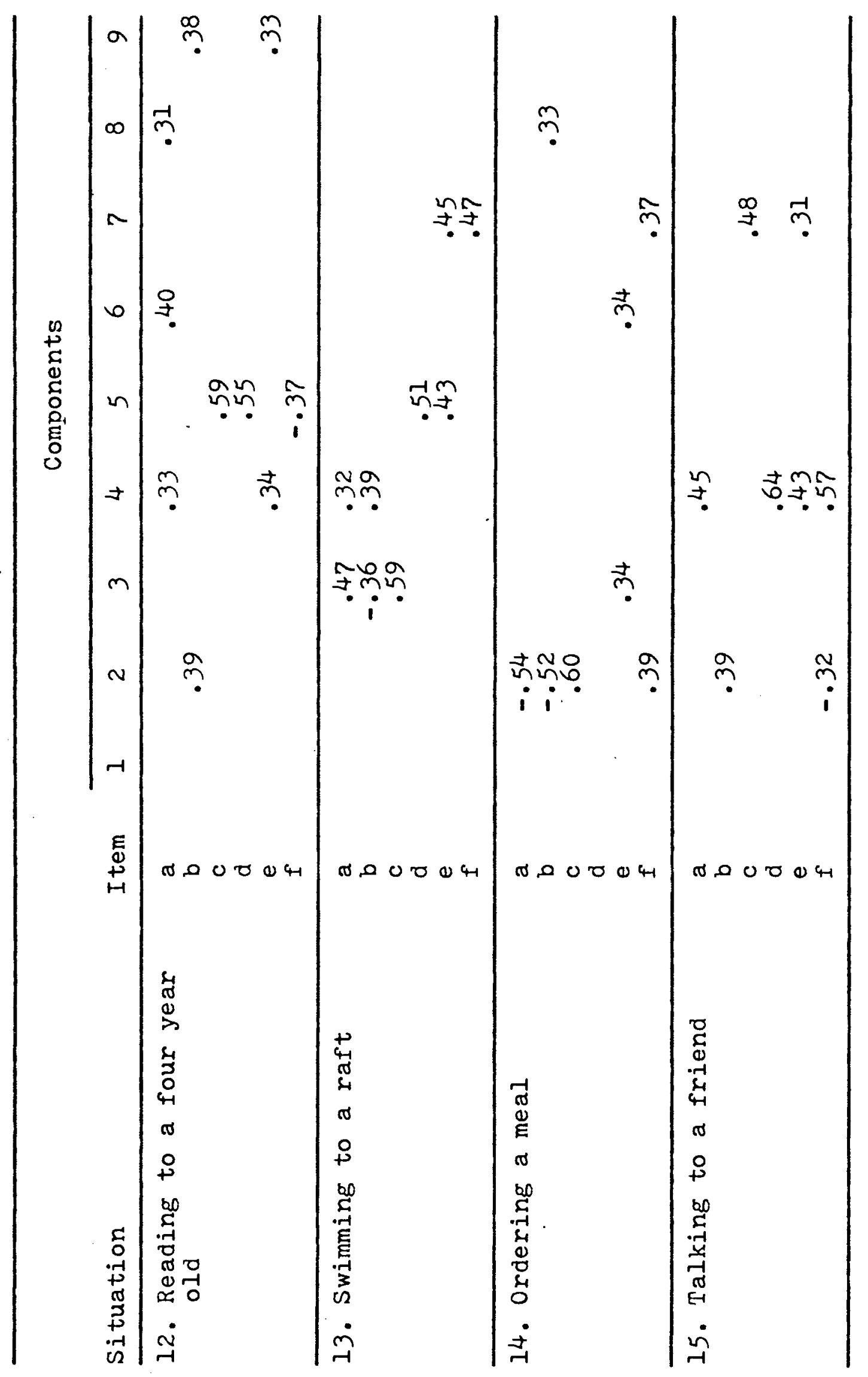




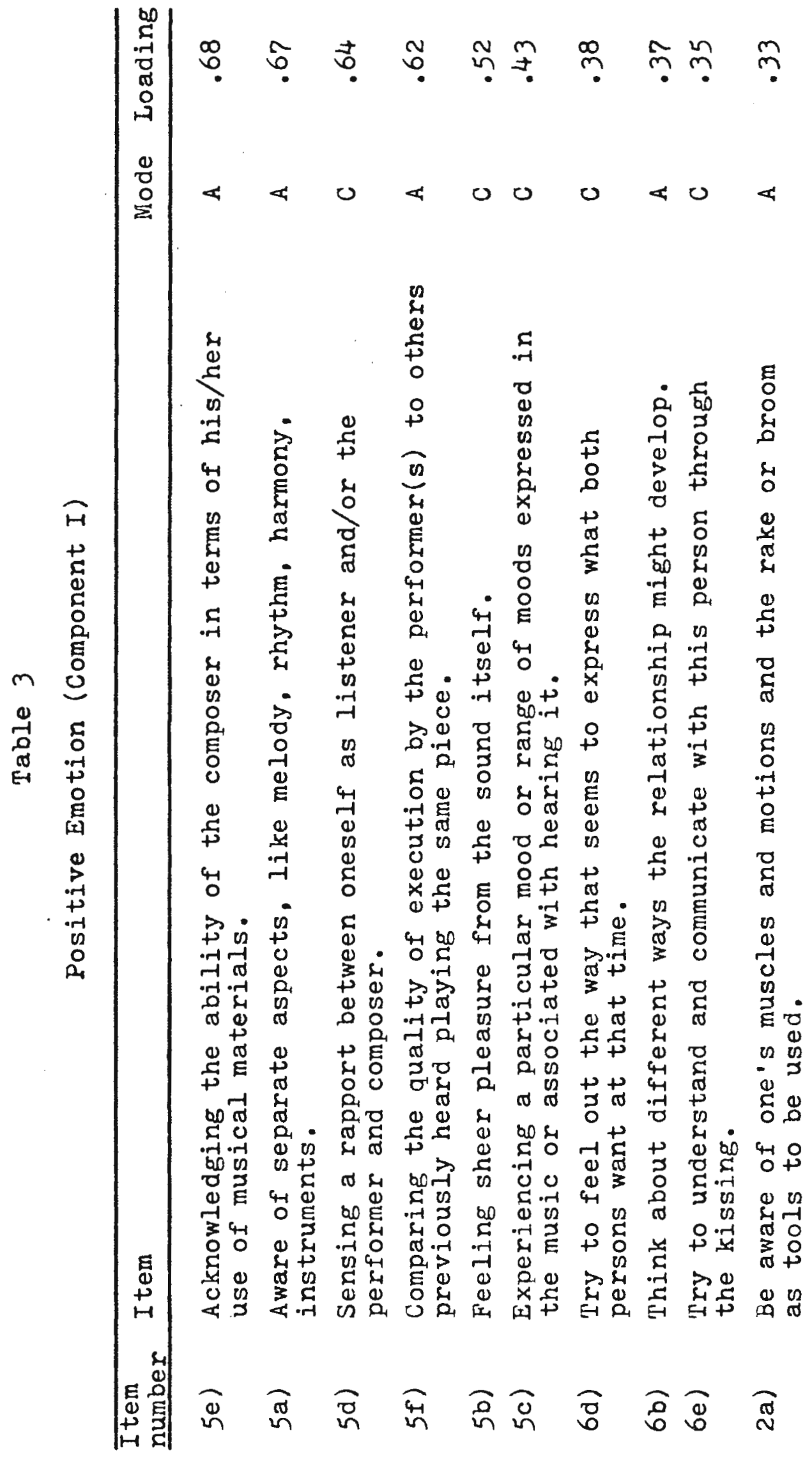




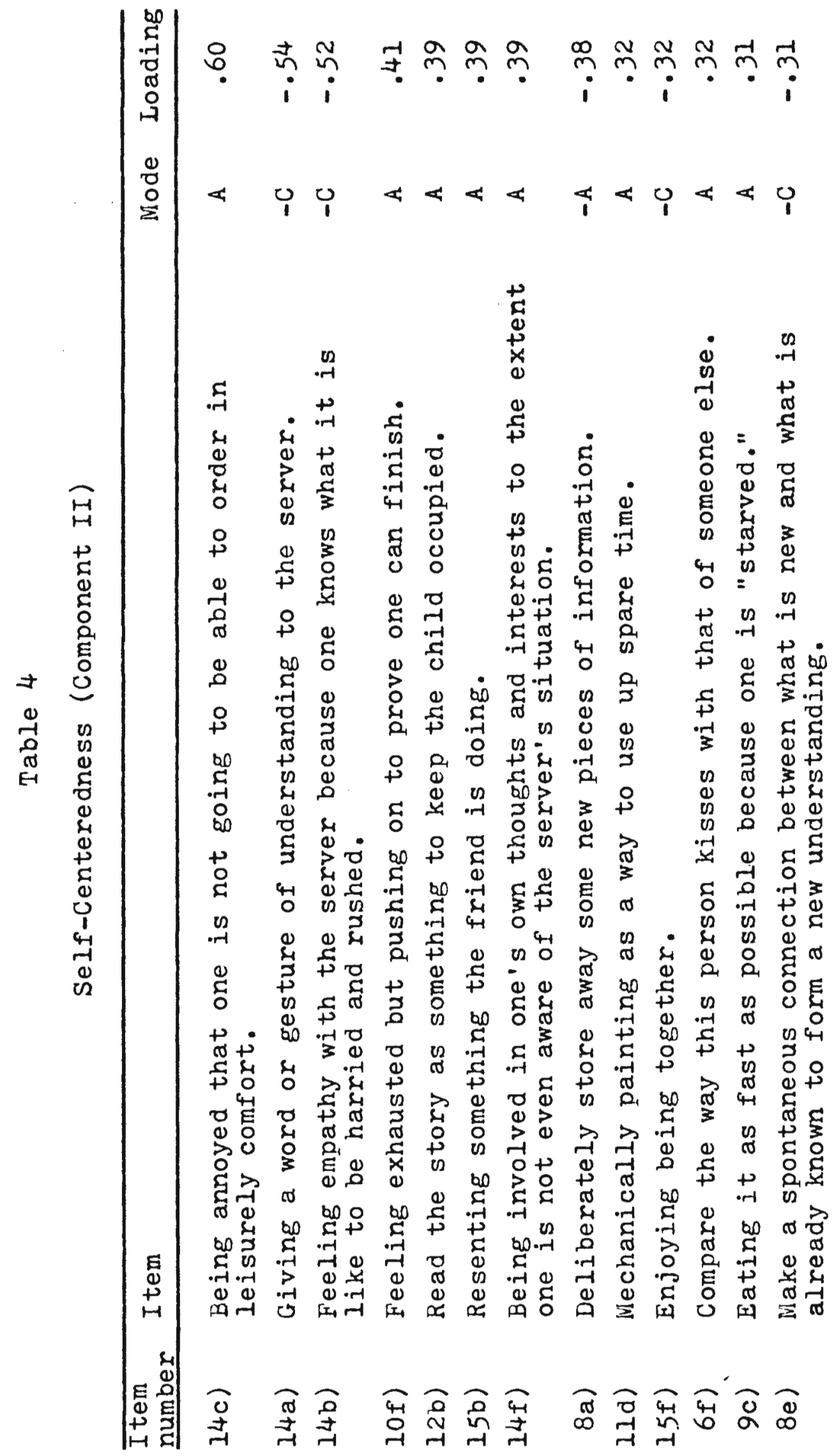




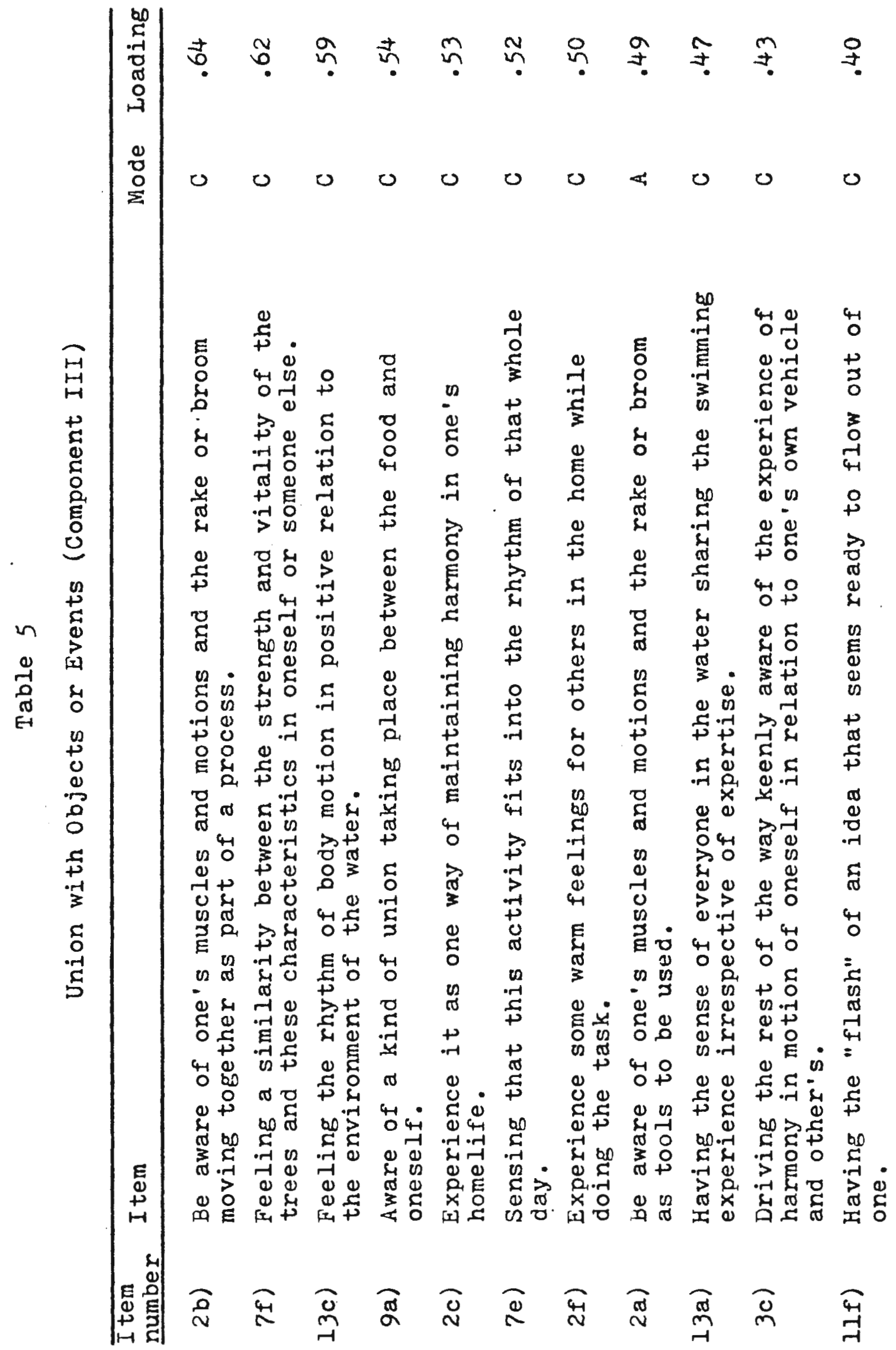




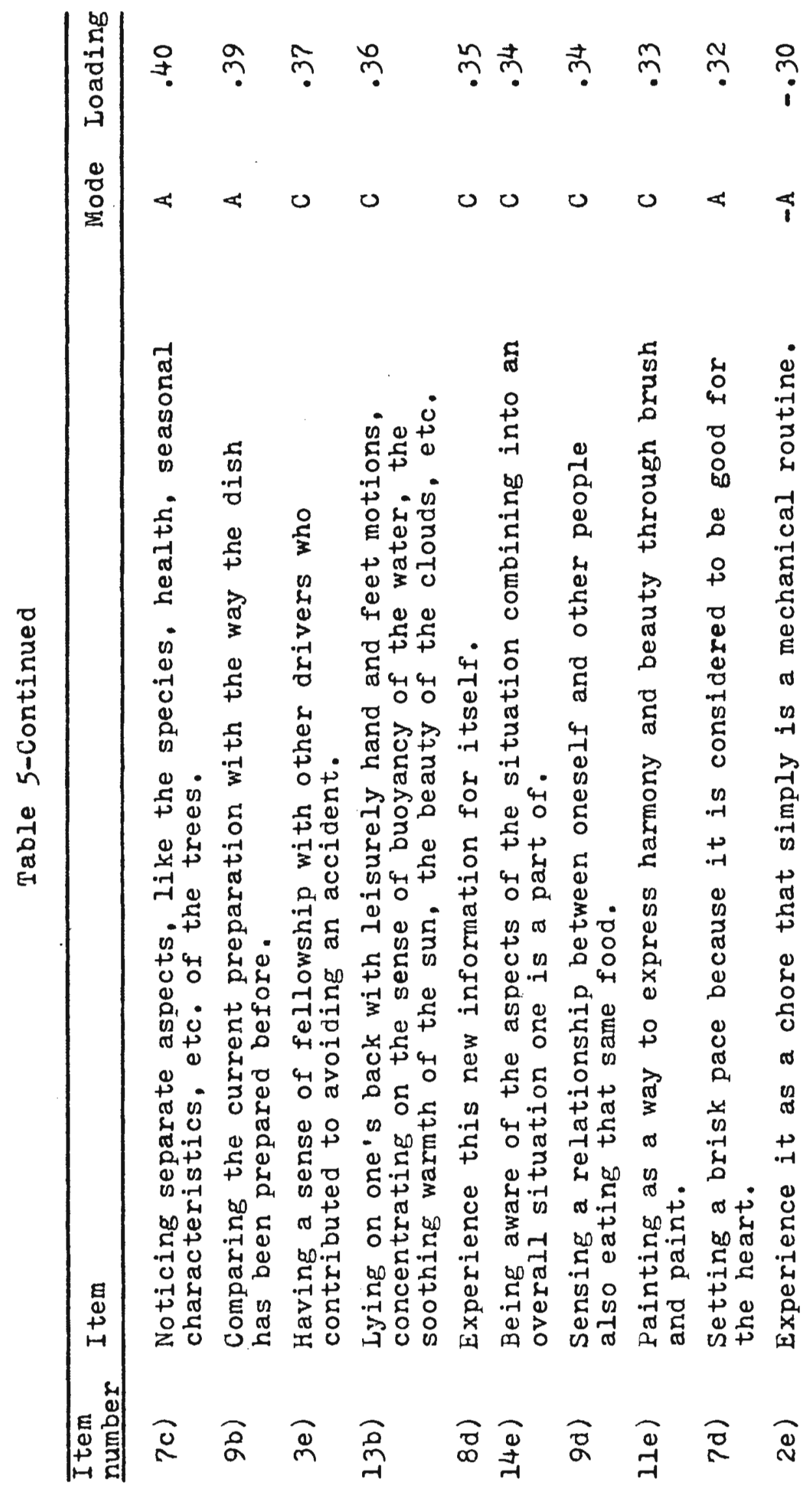




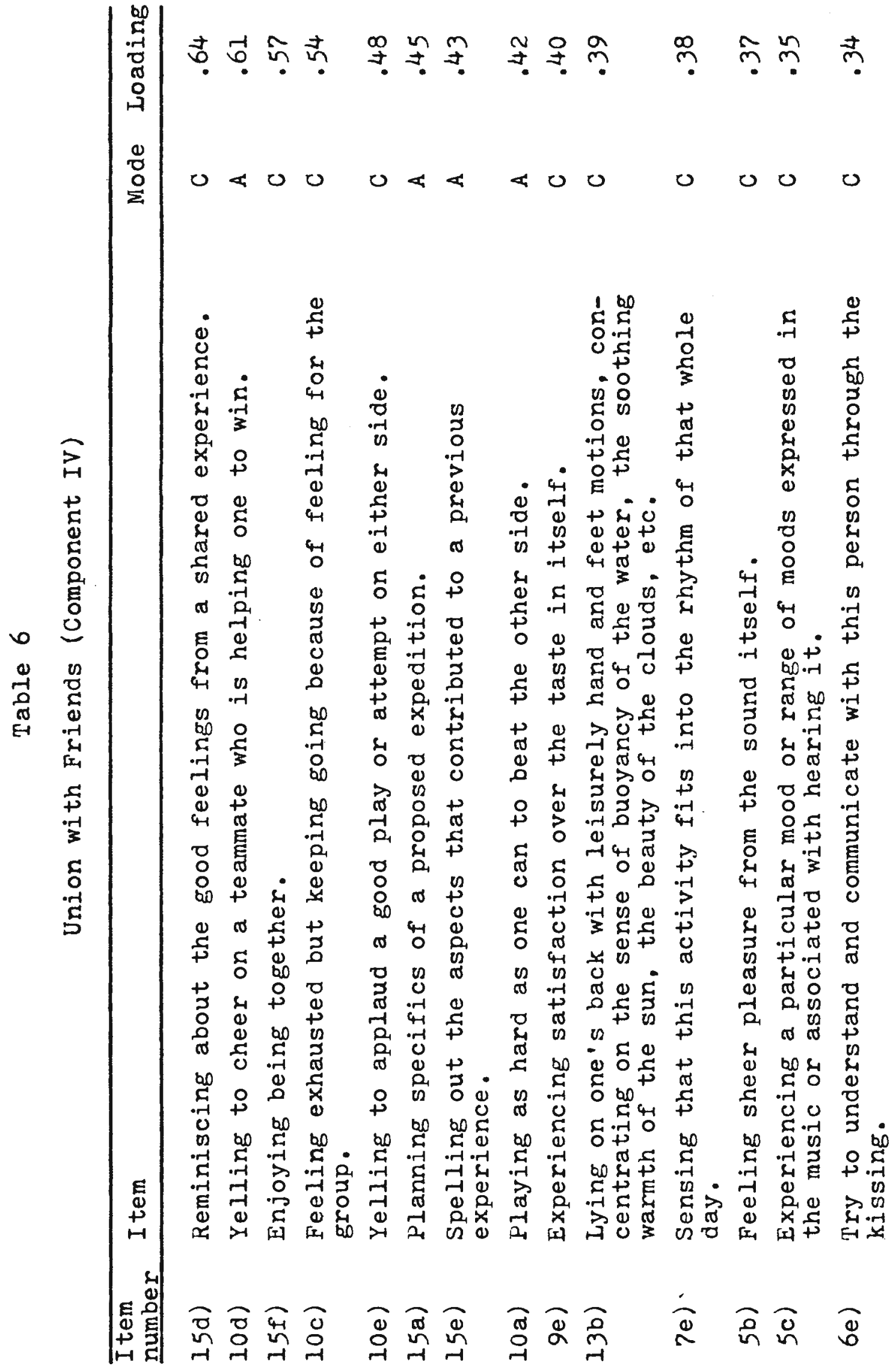




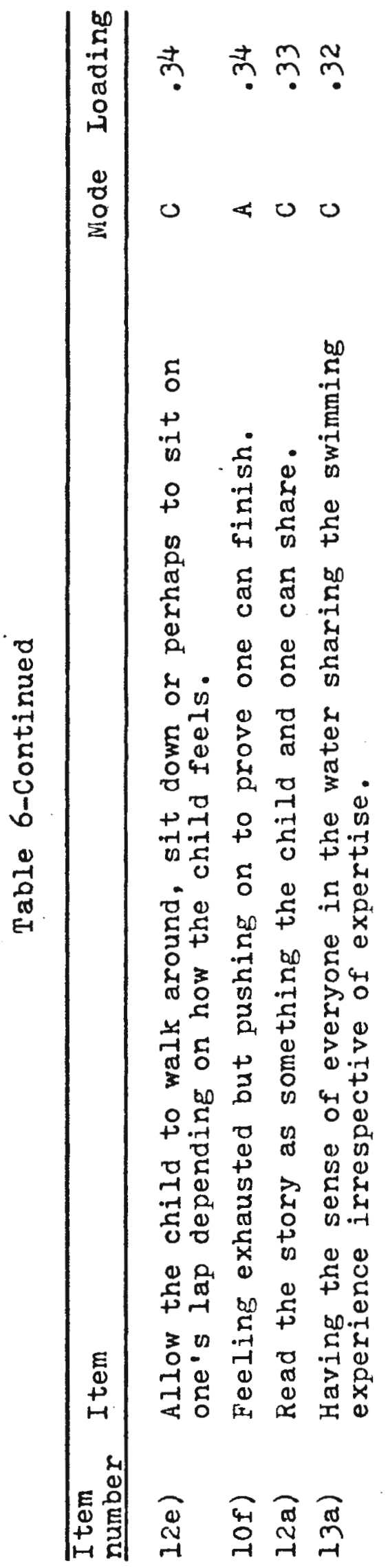




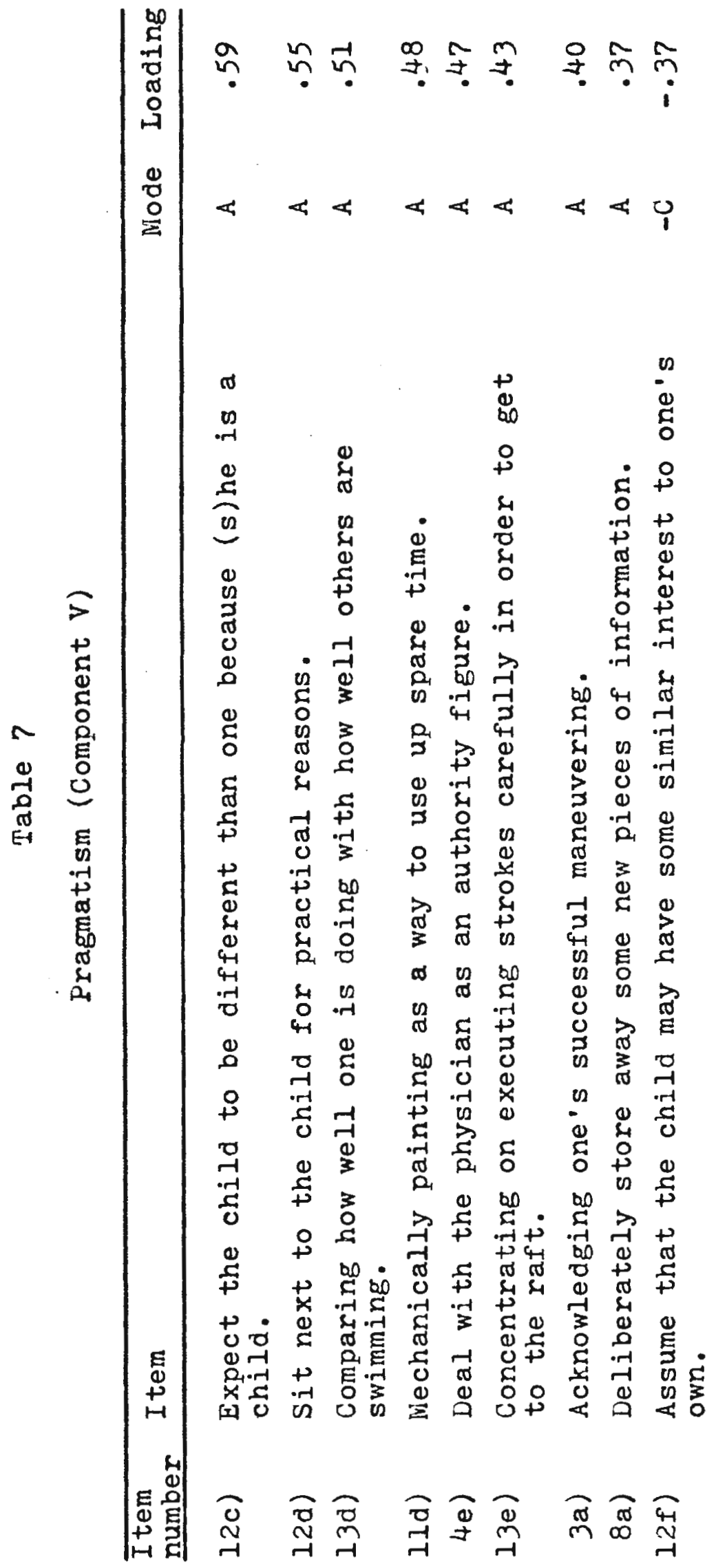




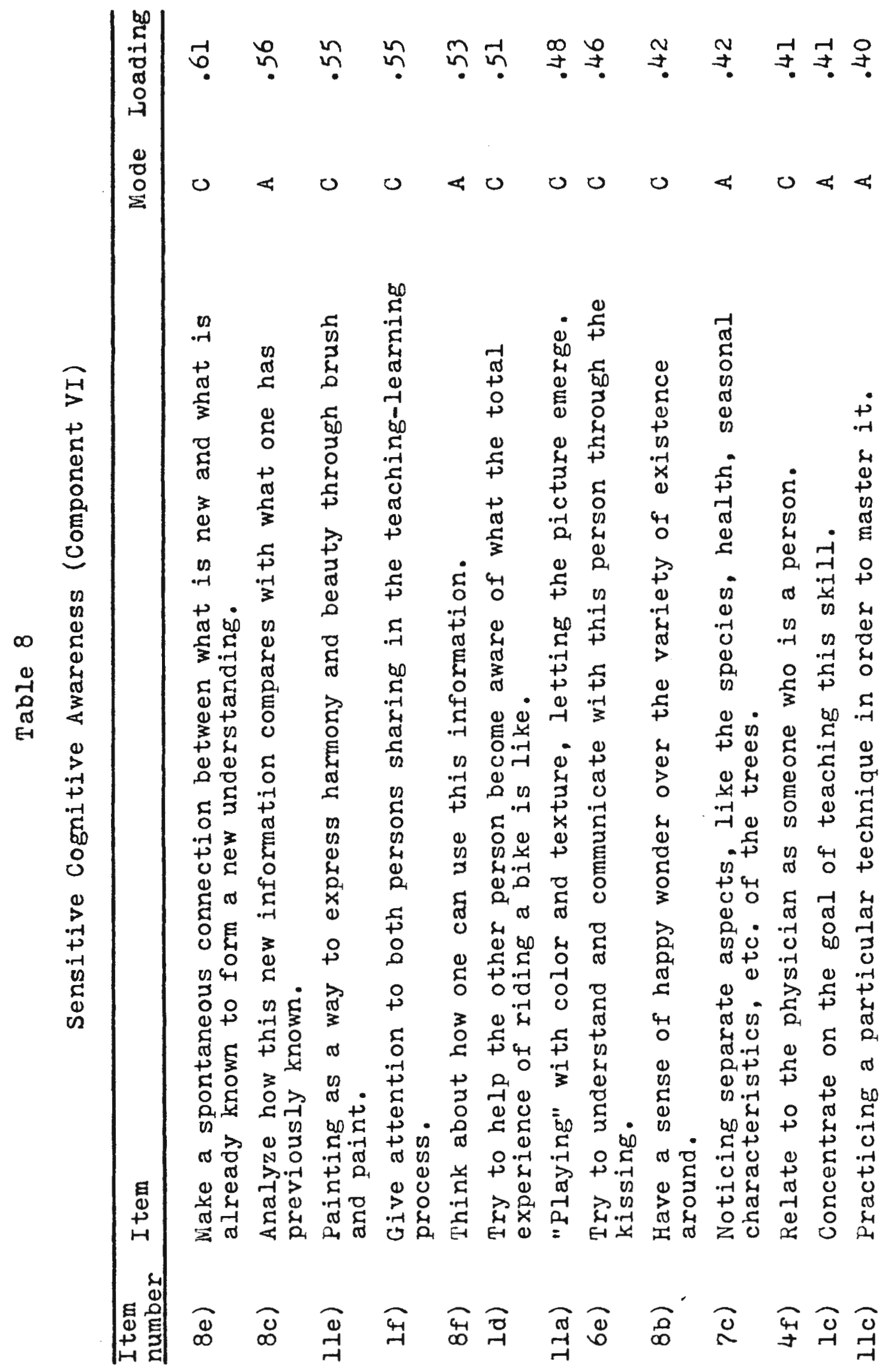




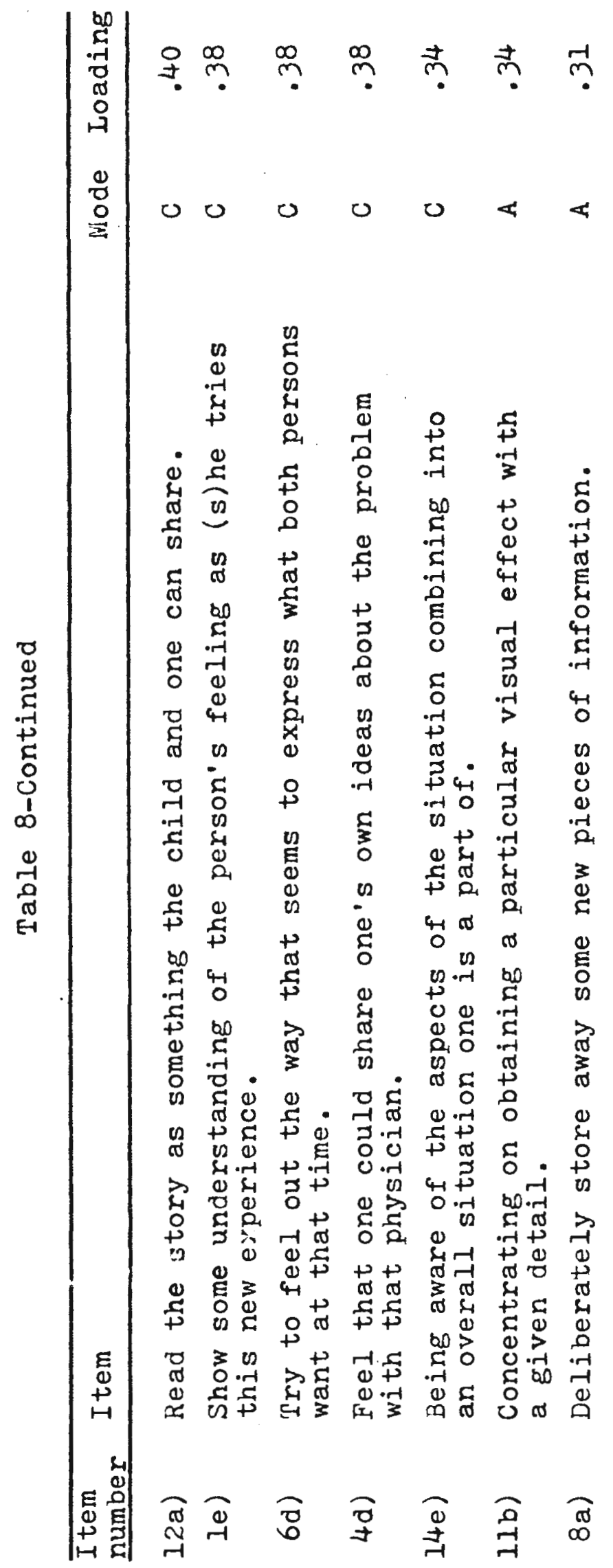




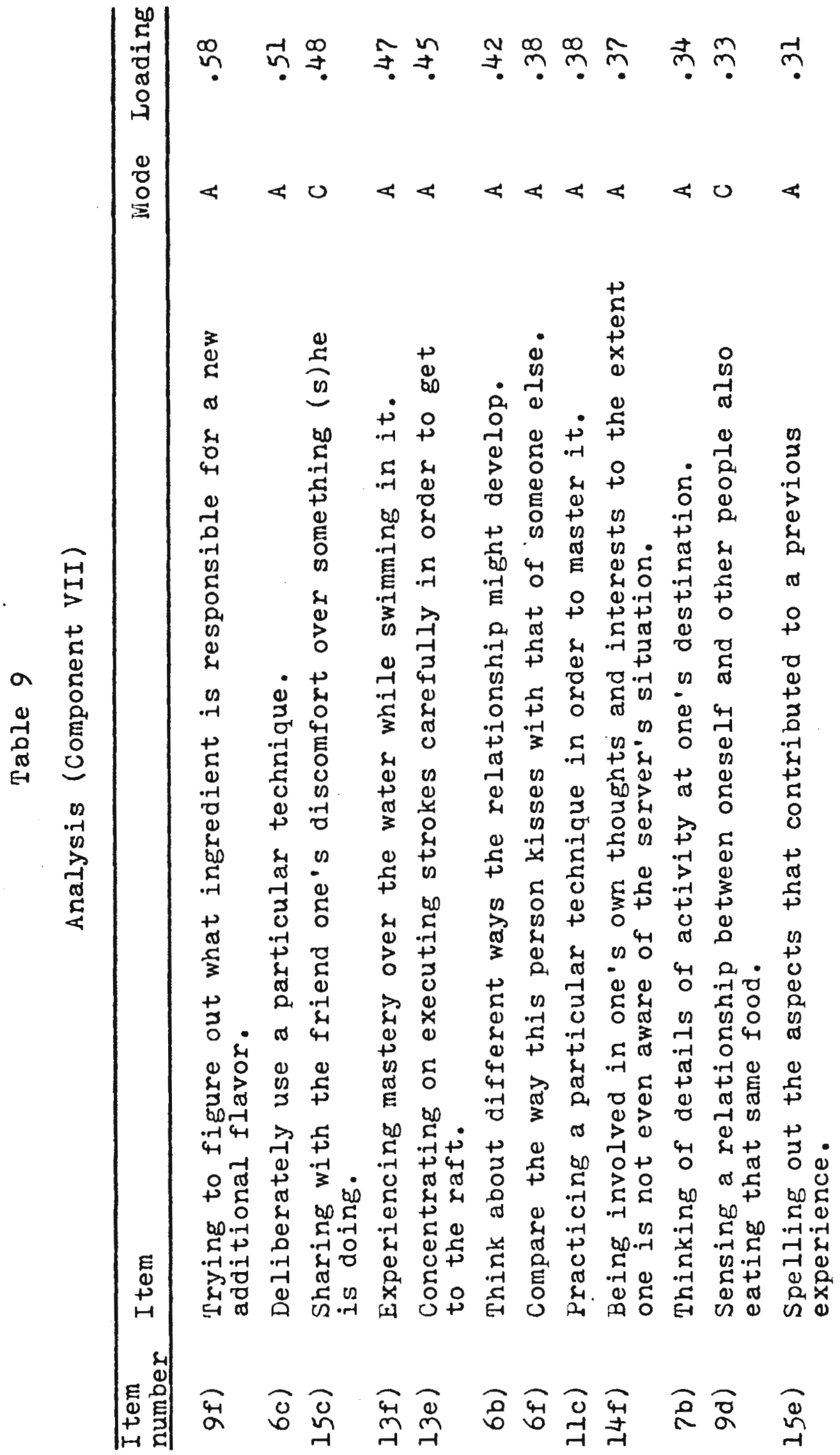




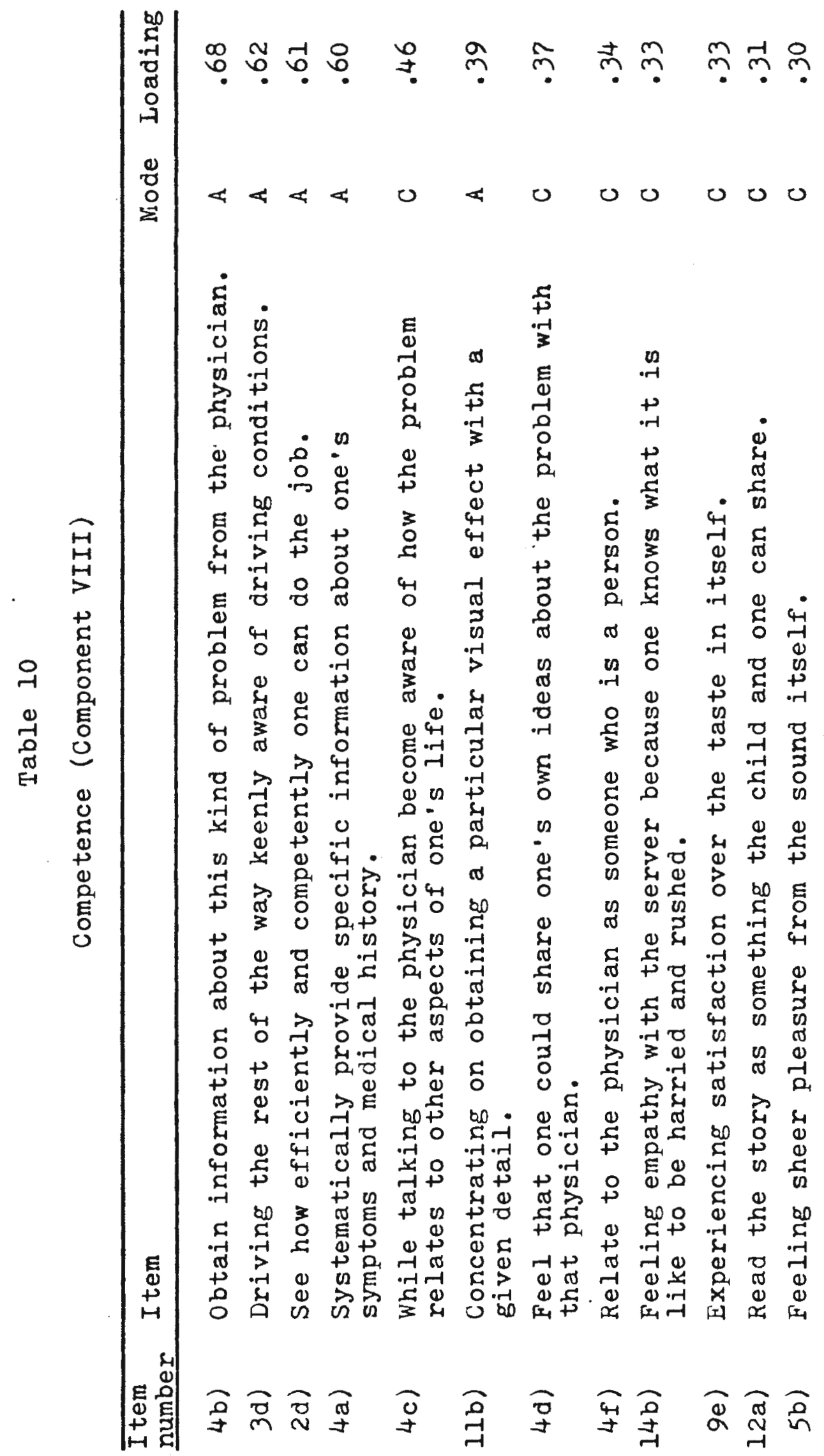




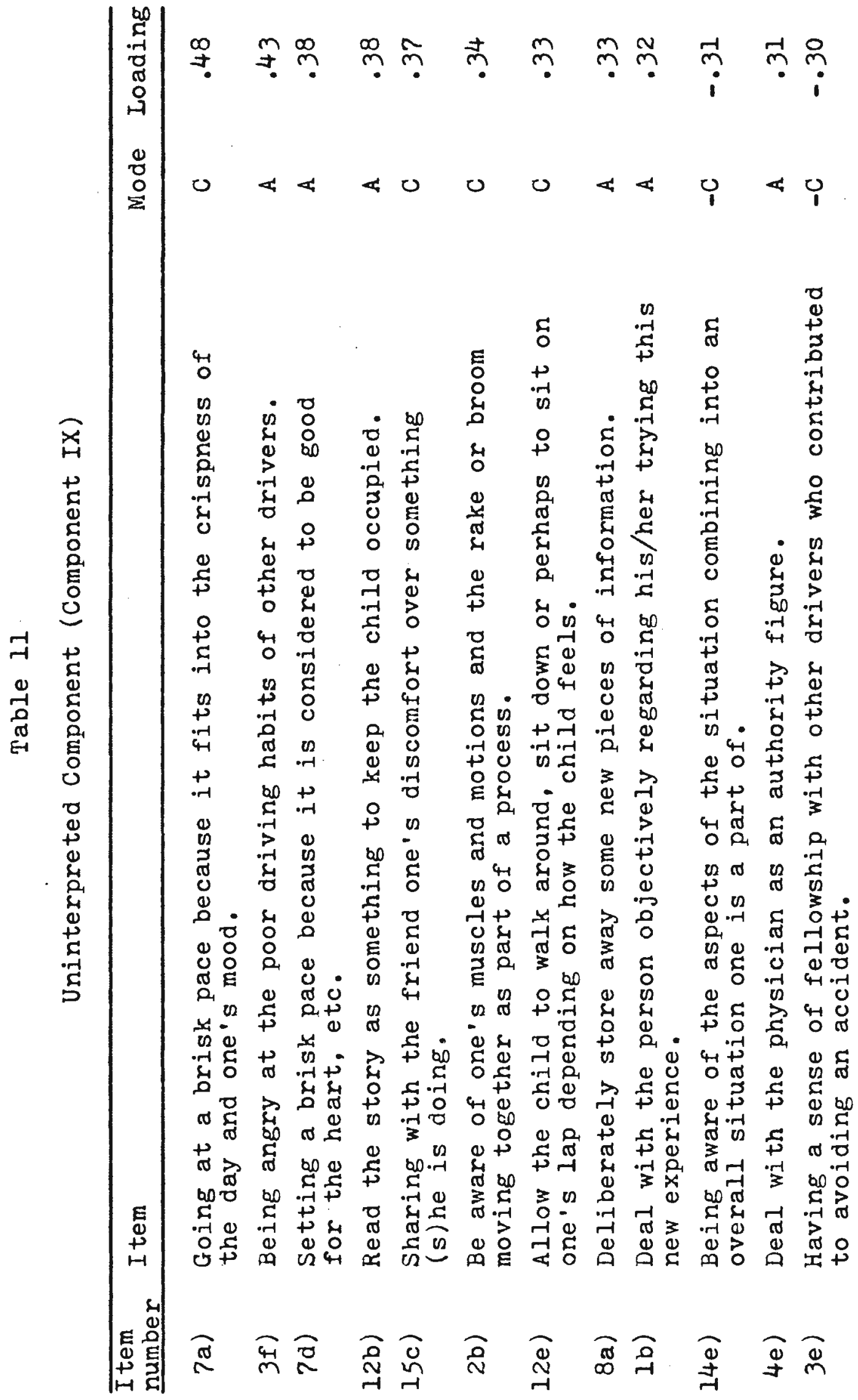


of communion items, three components were composed predominantly of agentic items and four were part agentic items and part communal items (predominantly being defined here as two-thirds or more items of one mode). Five items did not load on any factor more than .30 .

Half of the items in Component I, identified as Positive Emotion, are agentic ones and half communal ones (Table 3). Component II, identified as Self-Centeredness, is predominantly agentic $(92 \%)$ if one adds the four communal items negatively correlated to the eight positively correlated agentic items (Table 4). Component III is identified as Union with Objects or Events (Table 5). The items in this component are predominantly ones conceptualized as communal, i.e., 16 out of $21(76 \%)$. Component IV also consists predominantly of communal items, i.e., 13 out of 18 (72\%) and is identified as Union with Friends (Table 6). Component V, Pragmatism, is composed predominantly of agentic items (i.e., eight out of nine or $89 \%$; Table 7 ). Component VI is a mixed one, consisting $65 \%$ (13 out of 20 ) of communal items and is identified as Sensitive Cognitive Awareness (Table 8). Component VII, Analysis, is composed predominantly of agentic items; i.e.. 10 out of 12 or $83 \%$ (Table 9). Component VIII is a mixed one, consisting 58\% (seven out of twelve) of communal items and is identified as Competence on the basis of the clear marker items, i.e., those loading above .50 (Table 10). Component IX is also mixed. However, this component has no clear marker items 
and study of the items did not yield a discernable pattern; therefore, it was not interpreted (Table 11).

Mode of situations represented. It is of interest to note that the majority of the items in some components are from situations tending to reflect one mode while others are from a mixture of mode category for the situations. Competence (Component VIII), while a mixture of agentic and communal items, seems to reflect the situations represented. Seven out of the eight items with the highest loadings on the component are from three of the four situations previously rated as agentic. More.strikingly, 10 of the 11 .items on Positive Emotion (Component I) are from two of the six situations previously rated as communal, the listening to music and kissing situations.

In contrast the situations which are represented in the three components consisting primarily of agentic items (Self-Centeredness-II, Pragmatism-V, and Analysis-III) are mainly communal or neutral. The reverse is true of the situations represented in one of the components (Union with objects or Events-III) consisting primarily of communal items and which has no items from a communal situation. This suggests that it is something about the behavioral alternative and not the situation in which persons behave which is the dominant unifying thread within these components .

Union with Friends (Component IV) is the only component that predominantly reflects one mode (communion) both in 
terms of percentage of items and in terms of the situations represented. More than half of the items $(76 \%$ or 14 out of 18) are from situations previously rated primarily communal (and the rest are ambiguous) and out of 18 items the eight with the highest loadings on the component (plus one with a lesser loading) are from two communal situations which involve interaction with friends. These items also include the only agentic items in the component.

In contrast, Sensitive Cognitive Awareness (Component VI) is the only component which is mixed with regard to both the predominant mode of the items and of the situations represented. Items on this component appear to reflect more sensitive and more balanced functioning than the other components. While nearly two-thirds of the items were formulated as communal ones, there is a common strand going through them of cognitive awareness. At the same time the agentic items reflect the service of agency toward communal goals. This component fits the concept of a qualitative "plus" from integration of the two ways of interacting. Combining dominant mode of the items with dominant mode of the situations represented, the following patterns are apparent, (a) four components consist of items predominantly of one mode with the situations represented being mixed, one communal (Union with objects or Events) and three agentic (Self-Centeredness, Fragmatism, and Analysis); (b) two components consist of a mixture of items representing the two modes while the situations represented are 
predominantly one mode, one communal (Positive Emotion) and one agentic (Competence); (c) one component consists of both items and situations that predominantly represent one mode, communion (Union with Friends); (d) and then one component consists of both the items and the situations representing a mixture of the two modes (Sensitive Cognitive Awareness).

Each component in which the mode of the situations dominates can be thought of as reflecting an aspect of the mode, but in such a way that the type of situation colors the cluster of specific behaviors. In contrast, each component in which the mode of the items dominates, can be thought of as reflecting an aspect of the mode across situations. The component in which neither dominates could reflect an integration of the two modes.

Gender correlations. The goal of constructing a measure of agency and communion on which it would be possible for gender similarities to emerge was achieved. Out of the nine components all were, for practical purposes, similarly responded to by both sexes. Two showed a significant difference in scores between the men and the women $(\underline{2}<.05)$. in both instances the women scoring higher than the men. These were two of the components that appeared influenced by the situations in which the items appeared, Union with Friends and Competence. However, while statistically significant, the correlations have little practical importance because gender accounted for only $4 \%$ and $5 \%$ of the variance even on these two. See Table 12 for these correlations. 
Table 12

Point Biserial Correlations Between Sex and Component Scores

\begin{tabular}{|c|c|c|c|c|c|c|c|c|c|}
\hline \multirow[b]{3}{*}{$\underline{r}$} & \multicolumn{9}{|c|}{ Component } \\
\hline & 1 & 2 & 3 & 4 & 5 & 6 & 7 & 8 & 9 \\
\hline & -.09 & -.10 & .08 & $.19^{*}$ & -.13 & .07 & .02 & $.23^{* *}$ & .07 \\
\hline & $\begin{array}{r}.05 \\
<.01\end{array}$ & & & & & & & & \\
\hline
\end{tabular}

While the results of the component analysis contraindicate using rotal $C$ and Total $A$ scores as unambiguous representations of agency and communion, the total scores do not need to be disregarded entirely. It is interesting to note that there was no significant relationship between the variable of gender on Total A scores (point biserial $\underline{r}=.02$ ), on Total $C$ scores (point biserial $\underline{r}=.12$ ), or on a balance measure, Total C minus Total A, (point biserial $\underline{r}=.10$ ). The women had a mean Total. A score of 212.50 and the men, 211.27; the women had a mean Total C score of 215.50 and the men, 209.24; the women had a mean balance score of 2.80 and the men, -2.04 . Out of 90 items on the WIQ, 68 (76\%) showed no significant difference in response $(\mathrm{g}<.05)$ between men and women. However, of the 19 in which women scored significantly higher than men more had been conceptualized as communal (13) than agentic (four), whereas of the five on which the men scored significantly higher than the women, four were agentic and one communal. 
other findings. Looking at the components in terms of the amount of the total variance represented, accounting for the most variance was a component composed predominantly of communion items; then a component consisting entirely of agentic items (except a communal item correlated negatively with the component) which accounted for much less variance; then a component consisting of a mixture of agentic and communal items, and so on. The two components accounting for the most variance are ones which are composed primarily of items representing one mode (Union with Object or Eventscommunion and Pragmatism-agency) and at the same time are not influenced by a dominant mode of the situations represented.

Looking at the components in terms of whether agency and communion can be considered bipolar or two dimensions, only Self-Centeredness appears to be measuring a bipolar variable. Out of 85 items loading . 30 or more on one or more of the nine components, nine or $11 \%$ are correlated negatively and load negatively once each. of the nine, two are on the interpreted component, one each on two components and the remaining five on one component, Self-Centeredness. On this component, the four negatively correlated communal items fit with the eight positively correlated agentic items for an overall tone of feeling negative about or separation from others. (Representative of this component are the four items on it from Ordering a Meal, $2 \mathrm{~A}$ and $2 \mathrm{C}$.$) of the$ nine components generally and also of the five components 
composed of items predominantly designated as representing one mode or the other, two communal and three agentic, SelfCenteredness, then, is the only one on which the agentic and communal items are to some extent in opposition to one another.

It is apparent that items from many of the situations clustered together on the components. Out of 15 situations, 10 were heavily represented (four or more items) on a total of six components. This occured across components whether they consisted predominantly of one mode or the other in terms of items and/or situations: (See Table 13 for this representation). Three of these components would have been given the same identifying labels just on the basis of the items from the highly represented situations alone: Union with Friends. Sensitive Cognitive Awareness and Self-Centeredness. For the other three components. Positive Emotion, Union with Objects or Events, and Competence, it was the combination of items from the highly represented situations plus others that led to an overall identifying label. When participants responded to alternatives in these situations, they must have done so, high or low, across the range of agentic and communal alternatives because the alternatives in some way go together.

Summary. Based on the component analysis of the WIQ, two predictions were upheld and one was not. It was predicted that two dominant constructs, agency and communion, would emerge. This occured, but the component analysis 
Table 13

High Representation of Situations on Components

\begin{tabular}{|c|c|c|}
\hline Component & Situations & Items \\
\hline I Positive Emotion & Listening to music & $3 \mathrm{~A}, 3 \mathrm{C}$ \\
\hline II Self-Centeredness & ordering a meal & $2 A, 2-C$ \\
\hline $\begin{array}{l}\text { III Union with Objects } \\
\text { or Events }\end{array}$ & $\begin{array}{l}\text { Doing a home task } \\
\text { Walking a tree-lined } \\
\text { street }\end{array}$ & $\begin{array}{l}1 A, 1-A, 3 C \\
2 A, 2 C\end{array}$ \\
\hline IV Union with Friends & $\begin{array}{l}\text { Playing volleyball } \\
\text { Talking to a friend }\end{array}$ & $\begin{array}{l}3 A, 2 C \\
2 A, 2 C\end{array}$ \\
\hline $\begin{array}{l}\text { VI Sensitive Cognitive } \\
\text { Awareness }\end{array}$ & $\begin{array}{l}\text { Teaching a new skill } \\
\text { Watching a TV program } \\
\text { Painting a picture }\end{array}$ & $\begin{array}{ll}1 A, & 3 C \\
3 A, & 2 C \\
2 A, & 2 C\end{array}$ \\
\hline VIII Competence & Talking to a physician & $2 \mathrm{~A}, 3 \mathrm{C}$ \\
\hline
\end{tabular}


led to more than one component reflecting each mode. It was predicted that agency and communion are independent, but the component analysis suggests that in some situations they are not. It was predicted that agency and communion are independent of gender and this prediction was supported. 


\section{CHAPTER IV}

TESTING THE RELATIONSHIP BETWEEN AGENCY/CONMUNION

BALANCE AND SEX ROLE STEREOTYPING

\section{Introduction}

This study tests the hypothesis that persons who manifest balance between agency and communion in their ways of reacting to situations will be less stereotypic in their attribution of characteristics to men and women than persons who manifest lesser balance. It was therefore predicted that persons with a small difference between $C$ score and $A$ score on the WIQ will stereotype less than persons with a high difference between $\mathrm{C}$ score and A score.

Since the component analysis of the WIQ did not reveal that two components, one agency and one communion, accounted for a high proportion of the variance, it was decided not to use the Total A and Total C scores to test the hypothesis. It was deemed more appropriate to single out, on the basis of content examination and loadings, one component to represent agency and another component to represent communion. For agency and for communion, there was (a) one component each which accounted for the highest amount of variance of the components reflecting that mode; (b) the items were predominantly ones rated in that mode; (c) the 
dominant mode of the situations represented was not the same as that of the items; and (d) each represented a basic aspect of that mode.

The single component selected to represent agency was Pragmatism (Component V), consisting of nine items. Of the three components comprised predominately of agentic items, this was the clearest. It accounted for the largest variance of the three and two-thirds of the items did not load above .30 on any other component (compared to $31 \%$ of the items for Self-Centeredness and $25 \%$ for Analysis loading above .30 on other components).. In addition, the Pragmatism component contained the highest proportion ( $89 \%$ ) of items conceptualized as agentic which also correlated positively with the component. On a purely conceptual basis, either Pragmatism or Analysis could have been chosen as representing the most basic aspect of agency. The SelfCenteredness component, on the other hand, seemed to represent a negative kind of separateness, i.e., $31 \%$ of the items are ones that were conceptualized as representing communion (union) but correlated negatively with this factor and therefore is partly bipolar. As in the case of Analysis and Self-Centeredness, Pragmatism was not confounded by the situational contexts of the items.

The component selected to represent communion was Union with objects or Events (Component III), consisting of 21 items. This component accounted for the largest amount of variance of any component. It was the only highly 
communal component that was not confounded by the situational contexts of the items. In this component $76 \%$ of the items had been conceptualized as communal and $48 \%$ do not load above .30 on any other component. Conceptually, Union with Objects or Events represents a basic aspect of communion.

Scores on the component associated with integration, Sensitive Cognitive Awareness (Component VI), might have been used as a direct measure of agency/communion balance. The decision not to use it was made for two reasons: an integration component per se was not expected; and balance was defined in terms of an equal tendency to behave agentically and communally, measured separately.

The two components selected to represent agency and communion happen to represent aspects of those modes that are generally less associated with masculinity-femininity than are other aspects. The assertive aspect of agency which consistently forms an important feature of measures of masculinity was not included in the pool of items; the expressive aspect of communion which consistently forms an important feature of measures of femininity emerged on the two components affected by communal situational context. Empirically neither component as a whole showed a significant difference between men and women and both are relatively free of sex differences on individual items. On $78 \%$ or seven of the Pragmatism items there are no significant differences between the scores for men and women; on l item 
(11\%) women scored higher than the men and on another men scored higher than the women $(p<.05)$. On 18 items $(86 \%)$ of the Union with Objects or Events show no statistical difference between the scores for men and women, while women scored higher than the men on 3 items $(14 \%)(2<.05)$ and men scored higher than the women on none.

Total scores on the selected WIQ communion component (Union with Objects or Events) were used to measure Communion and total scores on the selected WIQ agency component (Pragmatism) were used to measure Agency. Participants were categorized as high, middle, or low on each of these dimensions on the basis of where they fell after the distributions were divided into equal thirds. Participants who were high on both $A$ and $C$, low on both $A$ and $C$, or in the middle on both $A$ and $C$ (and for whom, therefore, there would be small difference scores) were labeled Balanced. All other participants, who were high on one measure and either low or middle on the other (six possibilities) were considered Imbalanced.

Stereotyping measures were derived from scores on the BSRI, i.e., total score on the feminine scale minus the total score on the masculine scale $(F-M)$ on each of the administrations of the scale for Self, Ideal Woman, and Ideal Man. Scores around 0 indicate androgeny and were, therefore, defined as not stereotypic; the farther from 0 , the more stereotypic, the direction depending upon whether the attributed traits are more "masculine" or more "feminine" 
as defined by the BSRI items.

\section{Predictions}

The prediction that $\mathrm{A} / \mathrm{C}$ balanced persons would have lower BSRI scores (less stereotypic) than Imbalanced persons was tested separately for traits attributed to Self, Ideal Man and Ideal Woman by means of $2 \times 3 \times 3$ factorial ANOVAs (SeX X Agency X. Communion). In each case it was predicted that there would be no significant Agency or Communion main effect but a significant Interaction representing the variable of Balance. A Sex main effect was predicted for self (the women's mean score away from zero on the plus side, the men's away from zero on the negative side) but not for Ideal Man or Ideal Woman.

Separate 3-way Analyses of Variance were performed on the stereotyping scores for Self, Ideal Woman, and Ideal Man. Next, a priori comparisons were made to test the predicted relationship between $A / C$ balance and sex-role stereotyping for men and women separately by comparing all $\mathrm{A} / \mathrm{C}$ balanced persons with all imbalanced persons.

In addition, a priori comparisons were made to see if there was a relationship between the kind of $\mathrm{A} / \mathrm{C}$ imbalance $(C>A$ versus $A>C)$ and sex-role stereotyping for men and women separately by comparing $C>A$ imbalanced persons with A $>$ C imbalanced persons. This study had been designed simply to compare persons who were deemed balanced regarding agency and communion with those who were deemed imbalanced. The question emerged, however, whether persons who 
were imbalanced because they were more communal than agentic might relate to stereotyping differently than persons for whom agency was stronger than communion. That is, which mode was stronger might affect the results. Or it might be that agency-stronger-than-communion in women would have a different effect than agency-stronger-than-communion in men, and vice versa. Whether one's $\mathrm{A} / \mathrm{C}$ imbalance was in the direction of the traditional expectation for men and women could be related to one's tendency to attribute differential and stereotyped characteristics to oneself and to other men and women. It was decided to compare the two types of imbalance after the primary analysis was done. The validity check on the WIQ was obtained by using total A and $C$ scores. A positive correlation was predicted between the $\mathrm{C}-\mathrm{A}$ scores obtained on the WIQ and the C-A scores obtained from the Block items (previously described) on the BSRI self description.

\section{Method}

Participants

Those taking part in the study were the same 171 University of Rhode Island students in two undergraduate sections of a class entitled Toward Self-Understanding described in the component analysis. Complete data on both questionnaires were obtained from 135 participants (68 women and 67 men).

Procedure

The students were asked to take part in the study and 
promised a later description of the research and an opportunity for discussion. They were then given two booklets: one consisted of the Ways of Interacting Questionnaire (described previously); the other was an answer booklet containing an answer sheet for the WIQ (with spaces for age, sex, and major), as well as question-and-answer sheets for three different adminstrations of the Bem Sex Role Inventory. The BSRI was first presented with the standard instructions "Describe youself," next with the instructions "Describe your ideal woman," and last with the instructions "Describe your ideal man."

\section{Results}

\section{Overall Analysis}

Before proceeding with the analyses of variance, Hartley's $F \max$ test for homogeneity of variance was done for each of the three variables, Self, Ideal Woman, and Ideal Man stereotyping. No significant violation was found for Self stereotyping $(\underline{F} \max =18.61, \underline{p}>.05)$ or for Ideal Wo$\operatorname{man}$ stereotyping $(\underline{F} \max =7.32, \underline{p}>.05)$. Violation of homogeneity of variance was found for Ideal Man stereotyping $(\underline{F} \max =200, \mathrm{p}<.01)$. However, an examination of the cell standard deviations showed that this extremely high value for the $F \max$ test was primarily due to the extremely low standard deviation for the Low Agency, High Communion male group. Since this is based on only two observations, it is likely to be unstable. If this group is excluded from the Analysis of Homogeneity of variance, the resulting test 
is not significant $(E \max =5.82, \underline{p}>.05)$. In view of this and the general robustness of the ANOVA with respect to violations of this assumption, the ANOVA was also performed for Ideal ilan stereotyping.

The 3-way factorial analysis of variance (Sex X Agency $\mathrm{X}$ Communion) of Self stereotyping scores showed the expected significant main effect for $\operatorname{Sex}(\underline{F}=58.95, \underline{p}<.001)$ and one interaction effect, Sex with Agency $(\underline{F}=3.66, \underline{p}<.05)$. Table 14 summarizes this ANOVA and the means and standard deviations of the cells are shown in Table 15.

The interaction effect can be seen by looking at Table 15 and noting that while the means of all the women's scores are positive and all but one of the men's is negative, the women's scores indicate greater stereotyping as one moves from high to low agency, a trend observable in the men's scores, but not as clearly.

The 3-way analysis of variance of Ideal Woman stereotyping (Sex $X$ Agency $X$ Communion) showed one main effect, Sex $(\underline{F}=38.37, \underline{p}<.001)$. The summary table for this ANOVA is shown in Table 16 and the means and standard deviations of these cells are shown in Table 17. The sex main effect can be seen by looking at Table 17 and noting that the least stereotypic of the men's scores is more stereotypic than the most stereotypic of the women's. Likewise, the analysis of variance of Ideal Man stereotyping, showed the same one main effect, Sex $(F=5.40, p<.05)$. The summary table for this ANOVA is shown in Table 18 and means and 
Table 14

ANOVA Summary Table for Self Stereotyping Scores

\begin{tabular}{|c|c|c|c|c|}
\hline Source & $\begin{array}{l}\text { Sum of } \\
\text { Squares }\end{array}$ & $\begin{array}{l}\text { Degrees of } \\
\text { Freedom }\end{array}$ & $\begin{array}{l}\text { Mean } \\
\text { Square }\end{array}$ & $\underline{F}$ \\
\hline Sex & 13068.51 & 1 & 13068.51 & $58.95^{* *}$ \\
\hline Agency & 209.92 & 2 & 104.96 & 0.47 \\
\hline Communion & 70.81 & 2 & 35.40 & $0.16 *$ \\
\hline$S \mathrm{X} A$ & 1624.91 & 2 & 812.46 & $3.66^{x}$ \\
\hline$S \mathrm{X} C$ & 560.65 & 2 & $280 \cdot 32$ & 1.26 \\
\hline $\mathrm{A} X \mathrm{C}$ & 553.82 & 4 & 138.46 & 0.62 \\
\hline$S \quad X A X C$ & 796.66 & 4 & 199.16 & 0.89 \\
\hline Error & 25938.65 & 117 & 221.70 & \\
\hline
\end{tabular}

Table 15

Self Stereotyping Scores for

Groups on Three Levels of

Agency and of Communion

\begin{tabular}{|c|c|c|c|c|c|}
\hline \multicolumn{6}{|c|}{ Female } \\
\hline & & & \multicolumn{3}{|c|}{ Agency } \\
\hline & & & High & Middle & Low \\
\hline & High & $\begin{array}{l}\text { Mean } \\
\text { SD }\end{array}$ & $\begin{array}{r}6.38 \quad n=8 \\
10.01\end{array}$ & $\begin{array}{l}13.10 \\
24.42\end{array} \mathrm{n}=10$ & $\begin{array}{l}18.20 \\
14.77 \quad n=5\end{array}$ \\
\hline \multirow[t]{2}{*}{ Communion } & Middle & $\begin{array}{l}\text { Mean } \\
\text { SD }\end{array}$ & $\begin{array}{l}10.57 \\
14.00 \quad n=7\end{array}$ & $\begin{array}{l}17.00 \\
13.19\end{array} \mathrm{n}=6$ & $\begin{array}{l}19.70 \\
12.88\end{array} \quad n=10$ \\
\hline & Low & $\begin{array}{l}\text { Mean } \\
\text { SD }\end{array}$ & $\begin{array}{r}5 \cdot 30 \\
21.40\end{array}$ & $\begin{array}{r}8.33 \\
21.63\end{array}$ & $\begin{array}{r}17.33 \\
8.85\end{array}$ \\
\hline \multicolumn{6}{|c|}{ Male } \\
\hline \multirow{3}{*}{ Communion } & High & $\begin{array}{l}\text { Mean } \\
\text { SD }\end{array}$ & $\begin{array}{r}-5.36 \\
8.45\end{array} \quad n=11$ & $\begin{array}{r}-13.00 \\
10.45\end{array} \quad n=9$ & $-13.00 \quad n=2$ \\
\hline & Middle & $\begin{array}{l}\text { Mean } \\
\text { SD }\end{array}$ & $\begin{array}{r}1.83 \\
10.78\end{array}$ & $\begin{array}{r}-19.63 n=8 \\
16.52 n=8\end{array}$ & $\begin{array}{r}-11.75 \quad n=8 \\
20.58 \quad n=8\end{array}$ \\
\hline & Low & $\begin{array}{l}\text { Mean } \\
\text { SD }\end{array}$ & $\begin{array}{l}-8.00 \\
10.53\end{array} \quad n=6$ & $\begin{array}{r}-1.80 \\
7.33\end{array} \quad n=5$ & $\begin{array}{r}-5.92 \\
8.31\end{array}$ \\
\hline
\end{tabular}


Table 16

ANOVA Summary Table for Ideal Woman

Stereotyping Scores

\begin{tabular}{lrcrc}
\hline Source & $\begin{array}{c}\text { Sum of } \\
\text { Squares }\end{array}$ & $\begin{array}{c}\text { Degrees of } \\
\text { Freedom }\end{array}$ & $\begin{array}{c}\text { Mean } \\
\text { Square }\end{array}$ & \multicolumn{1}{c}{ F } \\
Sex & 7106.80 & 1 & 7106.80 & $38.37^{*}$ \\
Agency & 153.02 & 2 & 76.51 & 0.41 \\
Communion & 804.36 & 2 & 402.18 & 2.17 \\
S X A & 558.59 & 2 & 279.29 & 1.50 \\
SXC & 432.22 & 2 & 216.11 & 1.17 \\
AXC & 959.27 & 4 & 239.82 & 1.29 \\
SX A X C & 187.71 & 4 & 46.93 & 0.25 \\
Error & 21671.81 & 117 & 185.23 & \\
& & & &
\end{tabular}

Table 17

Ideal Woman Stereotyping Scores for Groups on Three Levels of Agency and of Communion

\begin{tabular}{|c|c|c|c|c|c|}
\hline \multicolumn{6}{|c|}{ Female } \\
\hline & & & \multicolumn{3}{|c|}{ Agency } \\
\hline & & & High & Middle & Low \\
\hline & High & $\begin{array}{l}\text { Mean } \\
\text { SD }\end{array}$ & $\begin{array}{r}5.13 n=8 \\
10.20 \quad n=8\end{array}$ & $\begin{array}{l}-0.10 \\
15.67\end{array}$ & $\begin{array}{r}7.40 \quad n=5 \\
18.24 \quad n=5\end{array}$ \\
\hline \multirow[t]{2}{*}{ Communion } & Middle & $\begin{array}{l}\text { Mean } \\
\text { SD }\end{array}$ & $\begin{array}{l}-1.71 \\
10.05\end{array} \quad n=7$ & $\begin{array}{r}-6.67 n=6 \\
9.69 n=6\end{array}$ & $\begin{array}{r}4.40 \\
13.20 \quad n=10\end{array}$ \\
\hline & Low & $\begin{array}{l}\text { Mean } \\
\text { SD }\end{array}$ & $\begin{array}{l}-2.60 \\
14.75\end{array}$ & $\begin{array}{r}5.83 \\
15.78 \mathrm{n}=6\end{array}$ & $\begin{array}{l}8.00 \\
8.65\end{array} n=6$ \\
\hline \multicolumn{6}{|c|}{ Male } \\
\hline \multirow{3}{*}{ Communion } & High & $\begin{array}{l}\text { Mean } \\
\text { SD }\end{array}$ & $\begin{array}{l}14.82 \\
12.07\end{array}$ & $\begin{array}{r}12.00 \\
7.11 \quad n=9\end{array}$ & $\begin{array}{r}16.00 \mathrm{n}=2 \\
8.49\end{array}$ \\
\hline & Middle & $\begin{array}{l}\text { Mean } \\
\text { SD }\end{array}$ & $\begin{array}{l}18.50 \\
15.73 n=6\end{array}$ & $\begin{array}{l}19.13 \mathrm{n}=8 \\
18.71 \mathrm{n}\end{array}$ & $\begin{array}{r}11.25 \mathrm{n}=8 \\
9.57 \mathrm{n}\end{array}$ \\
\hline & Low & $\begin{array}{l}\text { Mean } \\
\text { SD }\end{array}$ & $\begin{array}{l}17.50 \\
19.23\end{array} \mathrm{n}=6$ & $\begin{array}{l}30.80 \\
12.85\end{array} \quad n=5$ & $\begin{array}{l}21.67 \\
14.80\end{array}$ \\
\hline
\end{tabular}


Table 1.8

ANOVA Summary Table for Ideal Man

Stereotyping Scores

\begin{tabular}{lrccc}
\hline Source & $\begin{array}{c}\text { Sum of } \\
\text { Squares }\end{array}$ & $\begin{array}{c}\text { Degrees of } \\
\text { Freedom }\end{array}$ & $\begin{array}{c}\text { Mean } \\
\text { Square }\end{array}$ & $\underline{F}$ \\
Sex & 785.28 & 1 & 785.28 & $5.40^{*}$ \\
Agency & 568.20 & 2 & 284.10 & 1.95 \\
Communion & 61.54 & 2 & 30.77 & 0.21 \\
SX A & 551.79 & 2 & 275.90 & 1.90 \\
SXC & 285.71 & 2 & 142.85 & 0.98 \\
A X C & 142.80 & 4 & 35.70 & 0.25 \\
SX A X C & 299.19 & 4 & 74.80 & 0.51 \\
Error & 17006.34 & 117 & 145.35 & \\
* & & & &
\end{tabular}

Table 19

Ideal Man Stereotyping Scores for

Groups on Three Levels of Agency and of Communion

Female

\begin{tabular}{|c|c|c|c|c|c|}
\hline & & & \multicolumn{3}{|c|}{ Agency } \\
\hline & & & High & Middle & Low \\
\hline & High & $\begin{array}{l}\text { Mean } \\
\text { SD }\end{array}$ & $\begin{array}{r}-17.13 n=8 \\
8.28 \quad n=8\end{array}$ & $\begin{array}{r}-11.30 \quad n=10 \\
14.03 \quad n=10\end{array}$ & $\begin{array}{l}-5.40 \\
19.95\end{array} \quad n=5$ \\
\hline \multirow[t]{2}{*}{ Communion } & Middle & $\begin{array}{l}\text { Mean } \\
\text { SD }\end{array}$ & $\begin{array}{r}-15.86 \quad n=7 \\
7.31\end{array}$ & $\begin{array}{r}-18.50 \\
9.59\end{array}$ & $\begin{array}{r}-12.00 \quad n=10 \\
8.96 \quad n=10\end{array}$ \\
\hline & Low & $\begin{array}{l}\text { Mean } \\
\text { SD }\end{array}$ & $\begin{array}{r}-20.00 \\
13.73 n=10\end{array}$ & $\begin{array}{r}-23.17 \\
11.89\end{array}$ & $\begin{array}{l}-7.83 \mathrm{n}=6 \\
12.01\end{array}$ \\
\hline \multicolumn{6}{|c|}{ Male } \\
\hline \multirow{3}{*}{ Communion } & High & $\begin{array}{l}\text { Mean } \\
\text { SD }\end{array}$ & $\begin{array}{r}-18.18 \\
12.42\end{array}$ & $\begin{array}{r}-22.89 n=9 \\
8.27\end{array}$ & $\begin{array}{r}-22.00 \\
1.41 \mathrm{n}=2\end{array}$ \\
\hline & Middle & $\begin{array}{l}\text { Mean } \\
\text { SD }\end{array}$ & $\begin{array}{r}-19.67 \quad n=6 \\
11.64 \quad n=6\end{array}$ & $\begin{array}{r}-20.75 n=8 \\
8.71 \quad n=8\end{array}$ & $\begin{array}{r}-18.13 \\
13.66 \quad n=8\end{array}$ \\
\hline & Low & $\begin{array}{l}\text { Mean } \\
\text { SD }\end{array}$ & $\begin{array}{r}-16.17 \\
11.84\end{array} \quad n=6$ & $\begin{array}{r}-20.60 \mathrm{n}=5 \\
10.09\end{array}$ & $\begin{array}{r}-19.00 \\
16.01 \quad n=12\end{array}$ \\
\hline
\end{tabular}


standard deviations of these cells are shown in Table 19. Examination of the stereotyping scores on the different adminstrations of the BSRI indicate some striking differences between men and women and probably led to the Sex main effects shown in each ANOVA. On a scale designed to have the women's mean score positive and the men's mean score negative, the difference on Self stereotyping was to be expected. Of greater interest is the finding that men described both their Ideal Man and their Ideal Woman more stereotypically than did the women. In both cases the difference is statistically different. Table 20 presents the group means and standard deviations for all men and all women.

Table 20

Sex Differences on the BSRI Stereotyping Scores

\begin{tabular}{ccc}
$\begin{array}{c}\text { Stereotyping } \\
\text { Score }\end{array}$ & $\begin{array}{c}\text { Males } \\
\mathrm{n}=67\end{array}$ & $\begin{array}{c}\text { Females } \\
\mathrm{n}=68\end{array}$ \\
\hline Self Description & & \\
M & -8.51 & 12.10 \\
SD & 12.88 & 16.71 \\
Ideal Woman & & \\
M & 17.55 & 1.97 \\
SD & 14.02 & 13.31 \\
Ideal Man & & \\
M & -19.58 & -14.81 \\
SD & 11.54 & 12.36 \\
\hline
\end{tabular}

\section{A Priori Comparisons}

The general prediction that persons with balanced $\mathrm{A} / \mathrm{C}$ 
factor scores would stereotype themselves, the same sex, and the opposite sex less than persons with imbalanced $\mathrm{A} / \mathrm{C}$ factor scores was not supported. Table 21 presents the sums of squares for the a priori comparisons between the balanced and imbalanced groups. The table indicates that there was no difference for either men or women on Self, Ideal Woman, and Ideal Man stereotyping between the three balanced and the six imbalanced groups.

\section{Table 21}

A Priori Comparison of Balanced versus Imbalanced Groups on Stereotyping.Scores using ANOVA of Agency and Communion

Stereotyping Score
Sex

$$
\text { F }
$$

Ideal Woman

Ideal Man

Self
The other balanced groups: rection of traditional expectation, and scores were in the opposite direction. A separate comparison was calculated for males and females for each of the three dependent variables. For women the traditional lack of balance was indicated by higher communion than agency scores, while for men the traditional lack of balance was
.13

.00

.06

.00
.06
Comparison $\quad \underline{F}$

27.84
$105 \cdot 37$

8.60 
indicated by higher agency than communion scores. Conversely, for women lack of balance in the direction opposite to tradition was indicated by higher agency than communion scores, while for men lack of balance in the direction opposite to tradition was indicated by higher communion than agency scores.

Since the $C$ and $A$ factor scores were each divided into thirds, the imbalanced groups with $C$ greater than $A$ consisted of persons who scored in three categories: High $\mathrm{C} /$ Middle $\mathrm{A}$, High $\mathrm{C} /$ Low $\mathrm{A}$, and Middle $\mathrm{C} /$ Low $\mathrm{A}$. The imbalanced groups with A greater than C also consisted of persons who scored in three categories, High A/Middle $C$, High $A /$ Low $C$, and Middle $A /$ Low $C$.

Four comparisons were significant. Nen with $A>C$ scores (imbalanced in the traditional direction) were more stereotypic in describing their Ideal Women than men with C > A scores (imbalanced in the direction opposite to tradition) $(\underline{F}=3.20, \underline{p}<.01)$. Similarly, women with $A>C$ scores (imbalanced in the direction opposite to tradition) were more stereotypic in describing their Ideal Man than women with C>A scores (imbalanced in the traditional direction) $(\underline{F}=7.81, \underline{p}<.01)$. Men with $C>A$ scores (imbalanced in the direction opposite to tradition) were more stereotypic in describing themselves than men with $A>C$ scores (imbalanced in the traditional direction) $(\underline{F}=3.13, \underline{p}<.01)$. Again women with C>A scores (imbalanced in the traditional direction) were more stereotypic in describing themselves than 
women with $\mathrm{A}>\mathrm{C}$ scores (imbalanced in the direction opposite to tradition) $(\underline{F}=4.00, \underline{p} \angle .01)$. Table 22 presents the sums of squares for the a priori comparison between the two imbalanced groups and Table 23 presents the means and standard deviations of these groups.

\section{Other Findings}

The prediction that the $\mathrm{C}-\mathrm{A}$ scores derived from the Block items on the BSRI would correlate with the C-A scores on the total. WIQ was supported for total group of participants $(\underline{r}=.33, \underline{\mathrm{p}}<.001)$, and separately for the women $(\underline{r}=.34, \underline{p}<.002)$; and for the $\operatorname{men}(\underline{r}=.29, \underline{p}<.009)$, supporting the validity of the WIQ total scores.

Not only did the men stereotype significantly more than the women in describing their Ideal Man and Woman, as indicated by Table 20 and mentioned previously, but men and women behaved differently in attributing characteristics to their own sex Ideal, relative to themselves. Table 24 presents the Mean BSRI scores for men and women on Self and Same Sex Ideal. It can be seen that the latter was viewed by men as significantly more in the masculine direction than they viewed themselves $(t=12.39, p<.001)$, whereas women saw their Ideal Woman as significantly less feminine and more androgynous (hence less stereotyped) than they saw themselves $(\underline{t}=9.28, \mathrm{p}<.001)$. 
Table 22

A Priori Comparison of $C>A$ versus $A>C$ Groups on Stereotyping Scores using ANOVA of Agency and Communion

Stereotyping Score

Sex
Comparison

Sums of Squares
$\underline{F}$ $4.00^{*}$ 886.72 692.85 3.69 * $7.81^{*}$ .17

*

p<.01

Table 23

Stereotyping Scores for Groups Imbalanced on WIQ $C$ and $A$ Factors

\begin{tabular}{|c|c|c|c|c|}
\hline \multirow{2}{*}{$\begin{array}{c}\text { Stereotyping } \\
\text { Scores } \\
F \rightarrow M\end{array}$} & \multicolumn{2}{|c|}{ Male } & \multicolumn{2}{|c|}{ Female } \\
\hline & $\begin{array}{c}\text { Traditional } \\
A>C\end{array}$ & $\begin{array}{l}\text { Opposite } \\
\text { C }>A\end{array}$ & $\begin{array}{c}\text { Traditional } \\
\text { C }>\mathrm{A} .\end{array}$ & $\begin{array}{c}\text { Opposite } \\
\text { A }>\text { C }\end{array}$ \\
\hline \multicolumn{5}{|l|}{ Self } \\
\hline $\begin{array}{l}M \\
S D\end{array}$ & $\begin{array}{l}-2.66 \\
11.14\end{array}$ & $\begin{array}{r}-12.58 \\
14.19\end{array}$ & $\begin{array}{l}17.00 \\
17.62\end{array}$ & $\begin{array}{r}8.07 \\
18.20\end{array}$ \\
\hline \multicolumn{5}{|l|}{ Ideal Woman } \\
\hline $\begin{array}{l}M I \\
S D\end{array}$ & $\begin{array}{l}22.27 \\
15.24\end{array}$ & $\begin{array}{r}13.08 \\
6.09\end{array}$ & $\begin{array}{r}3.90 \\
14.42\end{array}$ & 13.514 \\
\hline \multicolumn{5}{|l|}{ Ideal Man } \\
\hline $\begin{array}{l}M \\
S D\end{array}$ & $\begin{array}{r}-19.15 \\
9.68\end{array}$ & $\begin{array}{r}-21.01 \\
9.68\end{array}$ & $\begin{array}{l}-9.57 \\
13.65\end{array}$ & $\begin{array}{r}-19.68 \\
10.50\end{array}$ \\
\hline
\end{tabular}


Table 24

Self and Same Sex Ideal Differences on the BSRI Stereotyping Scores

\begin{tabular}{llrl}
\hline $\begin{array}{c}\text { Stereotyping } \\
\text { Score }\end{array}$ & Self & $\begin{array}{c}\text { Same Sex } \\
\text { Ideal }\end{array}$ & $\underline{t}$ \\
\hline $\begin{array}{c}\text { Males } n=67 \\
\text { M }\end{array}$ & -8.51 & -19.58 & $12.39^{*}$ \\
SD & 12.58 & 11.54 & \\
Females $n=68$ & 12.10 & 1.97 & $9.28^{*}$ \\
M & 16.71 & 13.31 & \\
SD & & & \\
* & & &
\end{tabular}


CHAPTER V

\section{DISCUSSION}

Evaluation of Ways of

Interacting Questionnaire

One goal of this research was to develop a measure of agency and communion, each conceptualized as an independent mode of reacting across a variety of situations and not determined by gender. Previous measures of agency and communion have assumed their bipolarity and/or expression of male and female principles. In this study it was assumed that each mode could be manifested in different ways, e.g., agentic behavior in relation to ideas will differ from agentic behavior in relation to physical nature, while both behaviors will still meet the common definition of agency. The measurement problem, therefore, involves two levels of assumptions: in this case, the assumption of an underlying unitary process for each mode and also the assumption of differing manifested forms which that process takes within each kind of situation. In addition, there is the problem of how the assumption of the two modes as complementary would effect measurement of them.

The component analysis supports the position that the WIQ represents agency and communion to some degree, but indicates that in its present form it does not provide a 
simple measure of the two modes. From the component analysis it can be seen that while two clear orthogonal components, agency and communion, did not emerge, eight out of nine components extracted do relate to the constructs. Perhaps separate concepts were being subsumed under umbrella constructs of agency and communion, but the possibility that the modes are unitary in the abstract, but multiple when manifested could account for the separate aspects of agency and communion in the extracted components. Besides there being several components extracted, the fact that these components accounted for less than half the total variance indicates that other concepts or aspects of concepts were included on the instrument. It may be that the researcher was so zealous in trying to provide a wide range of experiences in which each mode could be manifested that the uniqueness of the alternatives interfered with the cohesion of the concepts.

Another variable that is related to a clear component pattern not emerging was that a "halo effect" from some of the situations to which behavioral alternatives were provided seems to have influenced the responses to individual alternatives, producing situational components. Wost striking were two positive kinds of situations. One was fairly strong positive emotional experiences and the other was involvement with other people. This tendency had been noted in the preliminary steps of having raters label items as $A$ or $C$. More items were rated $C$ that had been designated 
as $A$ than $A$ items as $C$. The ones the researcher had designated as agentic which tended to be rated communal were ones in which a positive feeling was associated with behavior conceived as agentic or in which an agentic behavior took place in a situation close to other persons. Much of the revising of items centered around trying to reduce the influence of this tendency. Even so, the feeling-good-withfriends led to the cluster of eight items with highest loadings on Union with Friends and two positive emotional experiences (Kissing and Listening to music) accounted for nine out of the ten items on Positive Emotion. Competence although having a less clear pattern, had its heaviest loadings not only from items out of agentic situations, but five of these marker items were from a situation generally considered unpleasant, i.e., discussing a medical problem with one's physician. It would appear that there is a relationship between positive emotional experiences and communion and between negative or neutral experiences and agency.

Agency and communion have been presented as potentially in balance and complementary. Whether total scores or scores on a single representative component for each mode are considered, in each instance there is an appreciable number of participants whose $A$ and $C$ scores are in the same range. Therefore this study supports the possibility of balance between the two modes. The ten situations from which both agentic and communal items went together on components raises the question of whether the modes may not be 
independent, i.e., distinct ways of interacting. An alternative explanation may be that the intention of proposing situations in which persons would affirm both agentic and communal ways of interacting succeeded. That is, in those situations a range of behavior is natural and the potential for agency and communion not only to balance, but to complement each other is shown.

Support for convergent validity of the WIQ as a measure of these two modes of interacting comes from the ratings of individual items by naive raters, from informal interviews during the preliminary stages, from the findings of a positive correlation between total WIQ scores and self-descriptions of sex attributes previously judged as agentic and communal (the Block items on the BSRI), results from the component analysis, and some secondary findings from the hypothesis testing (discussed in the next section). It is interesting to note the positive correlation between the WIQ and the Block items on the BSRI in view of the fact that the Block agentic items (Assertive, Dominating, and Competitive) represent the aspect of "masculinity" that did not appear in the agency items on the WIQ and that the Block communal items (Loving, Sympathetic, and Sensitive) represent an aspect of "femininity" toned down on the WIQ. Support for divergent validity of the WIQ comes from the fact that women and men scored so similarly on the WIQ, but very differently on the BSRI. The WIQ was intentionally designed to provide examples of life situations in which 
males and females could respond without clear cultural cues with respect to appropriately feminine and masculine behavior. In contrast, the BSRI was designed to maximize differ- . ential cultural expectations for men and women on the personality attributes used. One can be reasonably confident, then, that the relationships that did emerge between $\mathrm{A} / \mathrm{C}$ balance and stereotyping were not due to the fact that the two instruments measure the same constructs.

The WIQ in its present form might be used as a sensitizer to the two modes. A recurring phenomenon observed during the initial stages of developing the instrument was that person after person seemed to become aware of her/his patterns of dealing with life situations as (s)he examined the range of alternative behaviors presented. In a therapeutic setting the WIQ might be a vehicle for persons to explore the possibilities for expanding their repertoire of interaction patterns.

Relationship Between A/C Balance and Sex Role Stereotyping

The prediction that persons with balanced A/C scores on the WIQ would stereotype less than those with less balanced scores was not supported. Was this lack of support due to the question that was being asked or to deficiencies in one or both of the measuring instruments?

Part of the problem may stem from the question. In choosing an aspect of personality to which $\mathrm{A} / \mathrm{C}$ balance might be related, attention was given to the apparent similarities 
between $\mathrm{A} / \mathrm{C}$ imbalance and masculinity-femininity extremes and between $\mathrm{A} / \mathrm{C}$ balance and androgeny. It seemed likely that some of the same variables would be involved in transcending either dichotomy and therefore that persons who were balanced in one area would more likely be balanced in the other. The underlying assumption behind the prediction, therefore, was that persons who had achieved balance between the two ways of interacting with life would also have achieved balance between the sets of attributes considered appropriate for men and those considered appropriate for women. It may be that $\mathrm{A} / \mathrm{C}$ balance is simply not related to sex role stereotyping.

Problems connected with the WIQ have already been discussed. The Bem Sex Role Inventory, on the other hand, appeared to be a very satisfactory measure for the measurement of sex role stereotyping. It is an ins,trument to which participants were able to respond easily, even with three consecutive administrations. It yields two clear sex role scales, masculinity and femininity, now well validated by Gaudreau (1975). One limitation of the BSRI is its inclusion of several items on the femininity scale (Childlike, Gullible, Flatterable) which do not connote positive sex role attributes. Gaudreau (1975) suggests eliminating all of these deprecating items (and making a few other adjustments) based on clear negative loadings found in her factor analysis.

Although the prediction that persons with balanced $\mathrm{A} / \mathrm{C}$ 
scores on the WIQ would stereotype less than those with less balanced scores was not supported, when the persons whose A scores exceeded C scores were compared with those whose C scores exceeded A scores, a consistent pattern of differences did appear. It would seem that in some instances the two kinds of imbalance cancelled each other out leaving no difference between balanced $\mathrm{A} / \mathrm{C}$ and combined imbalanced $\mathrm{A} / \mathrm{C}$ groups. In addition, none of the balanced $\mathrm{A} / \mathrm{C}$ subgroups stereotyped, the least for all of the three measures.

Since the persons with balanced $\mathrm{A} / \mathrm{C}$ scores were not the least stereotypic, who were; and why? There is a pattern in the significant findings which suggests that it is the nature of the dominant mode which relates both to self stereotyping and to opposite sex.stereotyping more than simple imbalance between modes. Both women and men who. scored higher on agency than communion stereotyped themselves significantly less than those who scored the opposite. The person who is more agentic, and hence individually-oriented, and less communal might tend to view her/himself as having a greater range of personality attributes, whereas, in contrast, the person who is more communal than agentic might tend to stereotype him/herself more in the interest of social acceptability.

In contrast to the findings on Self, both men and women who scored higher on communion than on agency stereotyped the opposite sex less than those who scored the opposite. The explanation for this finding may be that 
communally oriented persons of either sex prefer, in those of the opposite sex, persons more like themselves, or persons who are not sharply masculine or feminine, as culturally defined. The C>A women stereotype themselves highly, but do not stereotype Ideal Man in order perhaps to have the men closer to themselves with more potential for communion. C $>\mathrm{A}$ men seem to be behaving in the same way. The $A>C$ women do not stereotype themselves highly and in contrast to the $C>A$ women, appear to have shifted away from the traditional female role, but they stereotype the Ideal Man more (at the level that men stereotype themselves), thus also, perhaps, looking for a partner more like themselves. The $A>C$ men, on the other hand, see their Ideal women in highly stereotyped terms and hence quite differently than they see themselves, thus, apparently preferring a complementary rather than similar partner.

As measured in this study, sex role stereotyping is related to the direction of $\mathrm{A} / \mathrm{C}$ imbalance, not to the simple balance or imbalance variable. The degree of stereotyping is related to a combination of which mode predominates and whether one is describing self or the opposite sex ideal. Thus, $A>C$ men and women stereotyped themselves less than $C>A$ persons, but $C>A$ men and women stereotyped the opposite sex less than $A>C$ persons.

The stereotyping patterns on the different administrations of the BSRI provided interesting incidental serendiptous findings. The male participants stereotyped their 
Ideal Man more than themselves whereas, in contrast, the women stereotyped their Ideal Woman less than themselves and stereotyped both sexes less than the men did. These findings suggest that the average man in this sample would like to fit the traditonal masculine sex-role more than he thinks he does; in contrast, the average woman in this sample would like to have more of a balance of "masculinefeminine" attributes than she thinks she has. It would appear that these men and these women (as groups) are not well matched in sex-role expectations.

Re-examination of Theoretical Model

The objectives of this investigation were to explore the possibility that persons may interact with life situations in accordance with two basic modes (communion and agency) which are independent of masculinity-femininity. The theoretical model pointed to the possibility for balance between two modes of interacting. It was postulated that when these tendencies are balanced or complementary in a person, that person will function more constructively than when one mode is highly predominant.

The investigation gives adequate support to some parts of the model, but not for others. Indications that the idea of two modes of interacting is a valid one came from participants' responses to the WIQ when rating items and commenting as well as from the component analysis and from secondary analysis of the relationship to stereotyping. There 
was also support for the possibility of balance between the two modes. Likewise, there was support and no contraindications in the study of the position that agency and communion are constructs independent of masculinity and femininity.

The study did not adequately test the relation between $A / C$ balance and constructive functioning. The problem here may have been that this question was not addressed by itself, but a tendency not to sex-role stereotype was used as a prototype of constructive functioning. A more adequate test might have been to relate $\mathrm{A} / \mathrm{C}$ balance to functioning in situations in which both modes are particularly needed, such as, in egalitarian primary relationships, psychotherapist effectiveness, or in leadership positions.

From the component analysis the question is raised of whether two independent unitary concepts were being measured. It looks as if the concepts are not unitary, there are several components which, either by item composition or situation representation, or both, are predominantly communal and there are several components which, either by item composition or situation representation, are predominantly agentic. By these criteria, there are three communal components (Union with Objects of Events, Union with Friends, and Positive Emotion) and four agentic components (Self-Centeredness, Pragmatism, Analysis and Competence). In addition, while some of the components support the independence of the two concepts others reflect an interaction 
between agentic and communal behaviors within situations and one component (Self-Centeredness) is bipolar.

Based on this data a revised theoretical model could be as follows: In the abstract there may be two unitary concepts; however, when each is manifested, the uniqueness of aspects of each concept overrides the communality. The aspect is determined by the context or situation in which the behavior occurs, or, alternatively, by the common feature of the specific behaviors. An aspect may be a bipolar or unipolar manifestation of the two concepts depending on the aspect and the complementarity of the two modes will be shown more in some contexts than others.

It should be kept in mind that data results reflect the content of the instruments. In this study, the content of the WIQ came out of an attempt to show the different ways that agency and communion can be manifested. If one aspect of each had been selected in the formation of the instrument without the added dimension of situations, then it would have been more likely for a unitary description of each mode to have emerged. If aspects culturally related to masculinity and femininity had been included, a relationship of agency and communion with gender would probably have emerged.

It is interesting to note that the one component that is bipolar, Self-Centeredness, is closest to the negative connotations of agency that Bakan (1966) points out. The composition of the component suggests not just the individual 
functioning autonomously, but also shutting out other persons.

\section{Further Questions}

This study focused on one facet of the theoretical models positive expression of each mode in adults. Many questions about other facets are waiting to be answered.

There are developmental questions: How does the development of the two modes relate to other lines of development; do manifestations of agency and communion change with age; is balance possible at any age, but complementarity only at a later age?

There are questions related to quality of expression: Does balance equal complementarity or does complementarity add a qualitatively different dimension to the expression of each; is there a relationship between the level of development of the modes and balance?

There are questions related to problems-in-living (psychopathology and sociopathology)s Are there minimum amounts of functioning in each mode necessary for constructive living; does restriction of expression in one or the other mode lead to pathology; what variables in society and/or in individual history lead to destructive agency (e.g., predominantly self- and power-centered) or destructive communion (e.g., dependent on a "delusion of fusion," Kaiser, 1965); what variables lead to therapeutic change in the agentic mode, in the communal mode? 
The most generally relevant question is the one that has appeared in various forms throughout this papers Is the concept of an agency/communion balance an accessible and meaningful one? 


\section{APPENDIX A \\ Agency and Communion}

Suppose there are two major ways people interact with life and situations in it. Each of us may use one way more frequently and easily than the other; may use one sometimes and the other sometimes depending on the situation; or may weave the two together so smoothly that unless one stops to consider what is going on, it seems like one way.

One way can be called Agency. The key idea of Agency is that there is some kind of separation between a person and the rest of the world in his/her interaction at that moment. (S)he is an agent acting upon something, some idea, someone. There is a sense of differences and distance; of being one up (or down); of structuring to fit an immediate or future time-related goal.

The other way can be called Communion. The key idea of Communion is that there is some kind of union between a person and the rest of the world in his/her interaction at that moment. (S) he is being in relation to or acting "with" something, some idea, someone. There is a sense of nearness and lack of firm boundaries; of being on a par with someone or something; of being a party to ideas, things, people coming together (for example, in intuition or empathy) as a process that is immediate and without objective time.

On the questionnaire are some situations most people have experienced. I am asking you to cooperate with me in analyzing the following situations. 


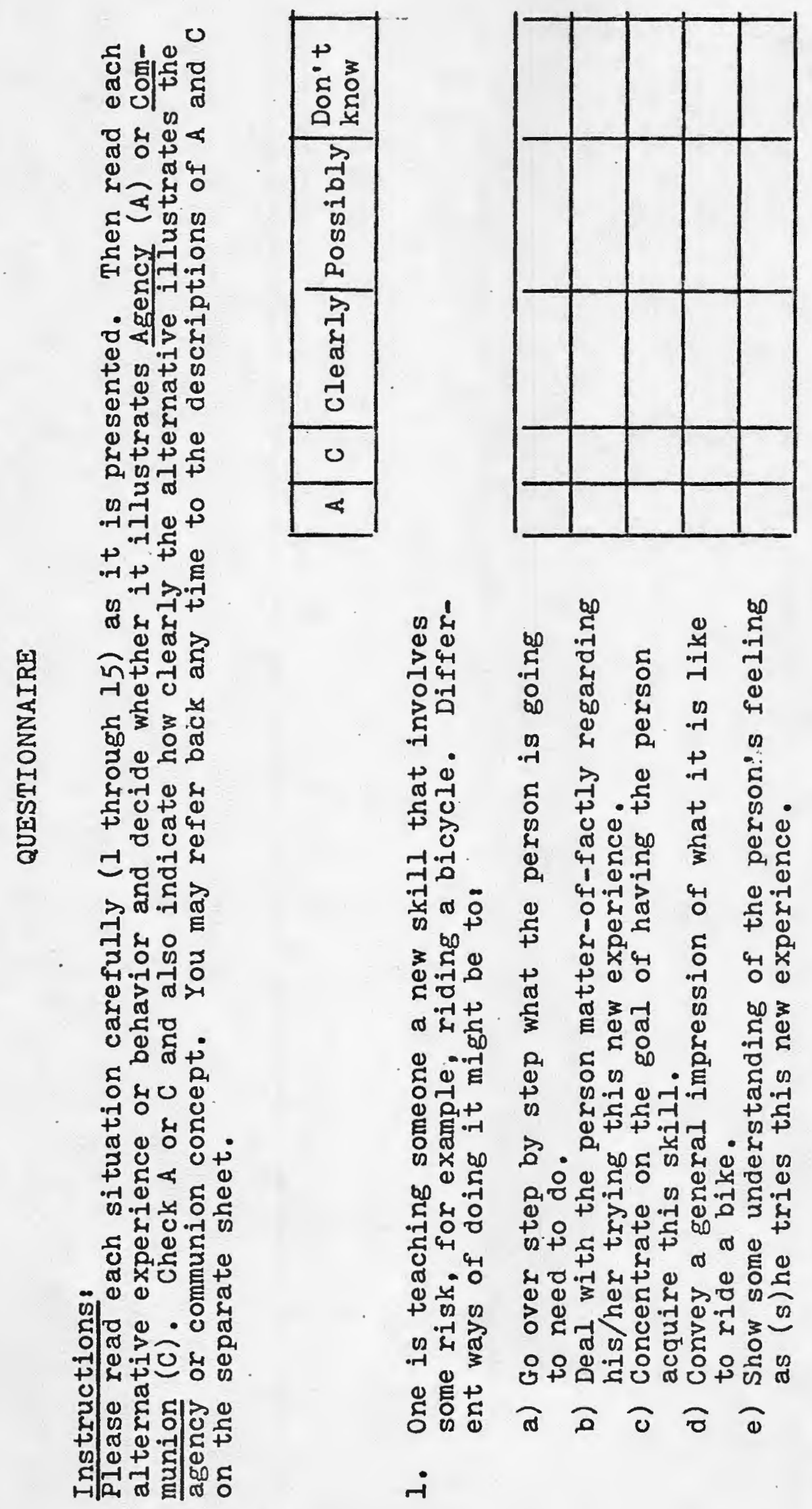




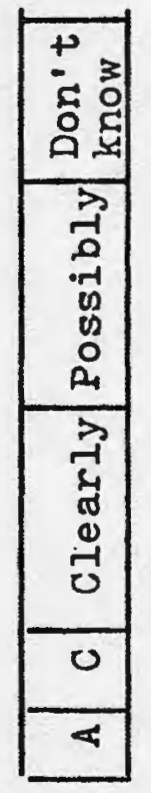

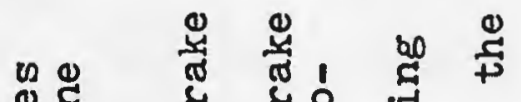

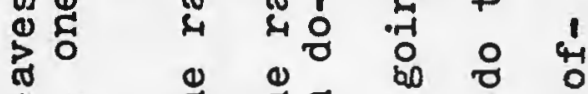

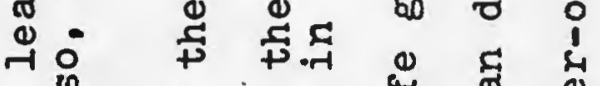

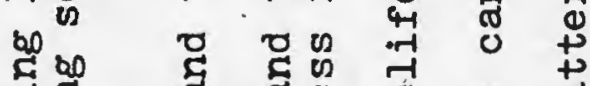

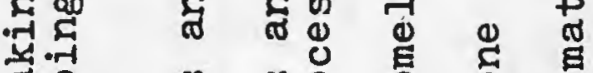

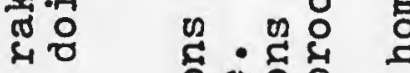

n)

†

टी

3

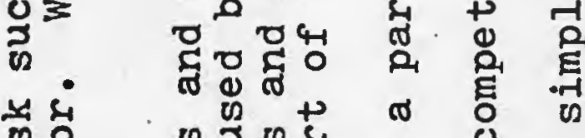

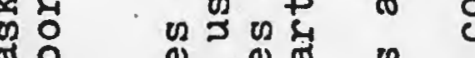

†े

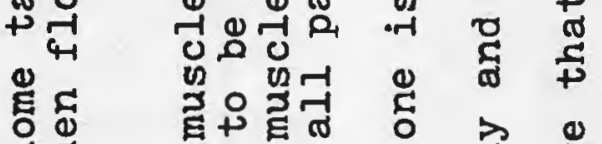

도

d

000

c.

है

O

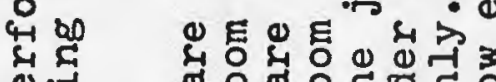

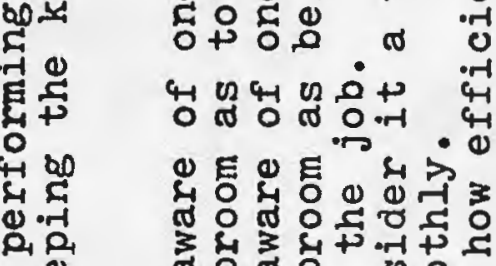

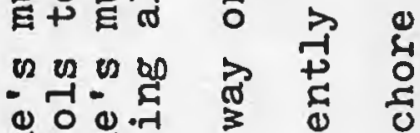

엉

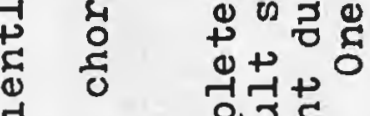

पू @ि

०त

.

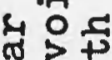

0 ช

o -

00

मी

낸

$\rightarrow 0 \rightarrow>$

8

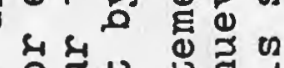

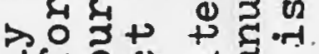

가을 0

ᄀु

4 द्र

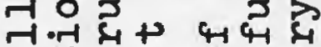

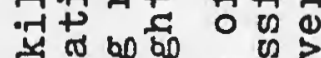

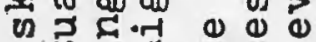

म.ने है

c 0

ט 0 है

000

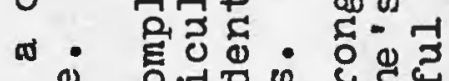

, ¿ \& 00

t)

(1) है

$+$

(1) 3

$\checkmark 8$

ग + का

म

- 02

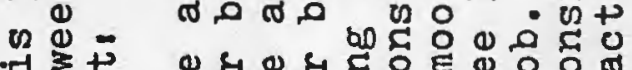

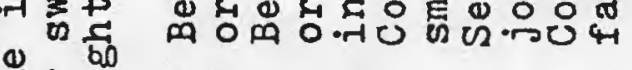

峞舟.

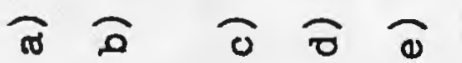

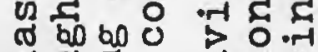
द उ द

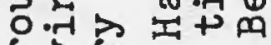
ब) द 5

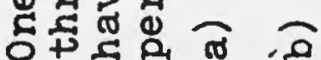

$v 2$ ते है

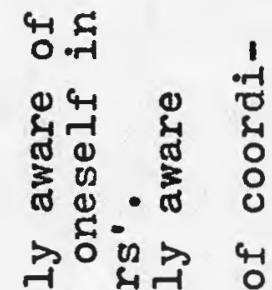

म4 4

त्षै

도이

०० 0

.

$++\mathrm{E}+$

40 तो

ค \& $\Omega_{1}$

Lम

क्नेण के

$3>$ 工

(1)

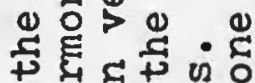

तु

4 ट⿺辶千

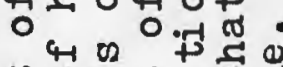

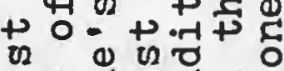

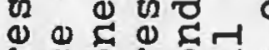

4 仓 ठ

(1) 워

मै

क द्व

c $x .4$ क

. $\rightarrow$ os $>$ वृ. - 0 ब

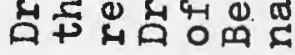
(0) 

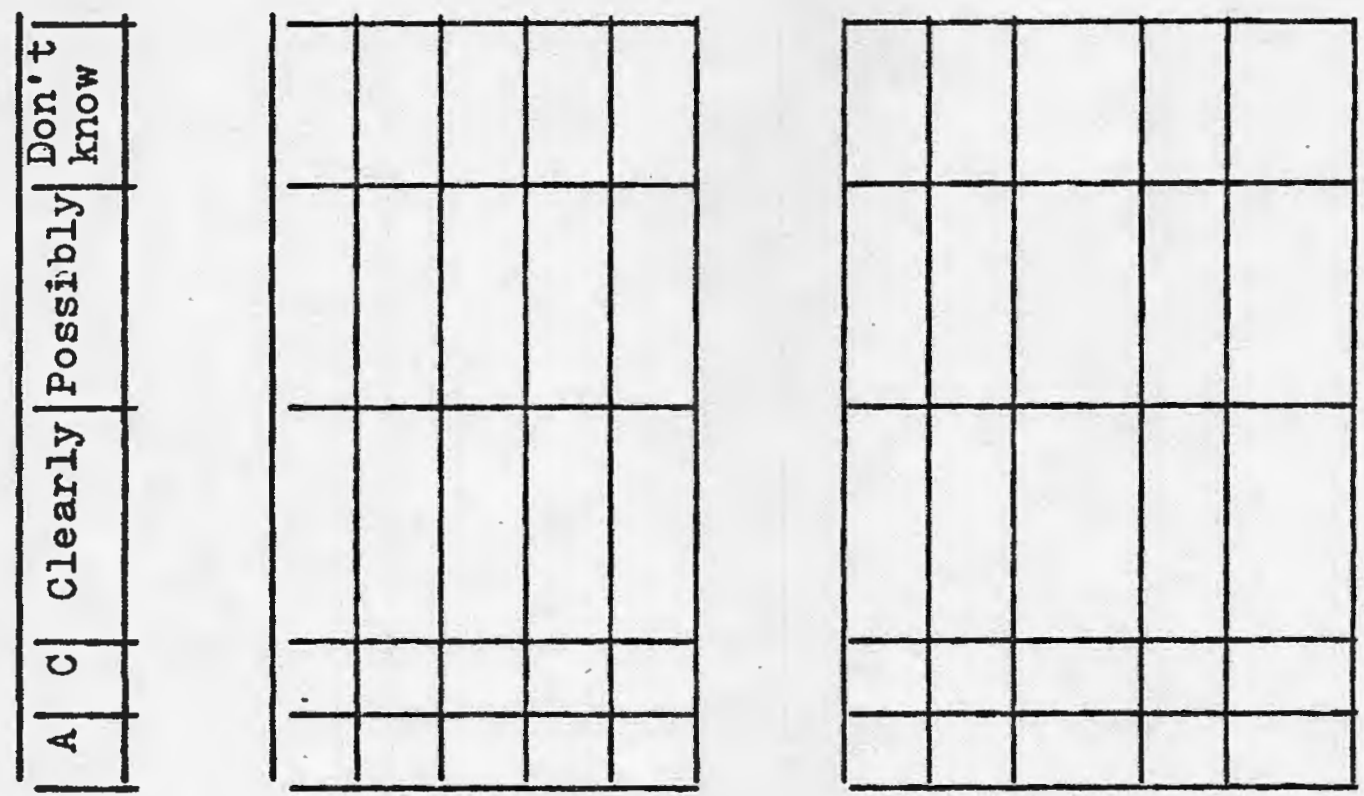

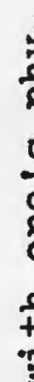

㝘哭

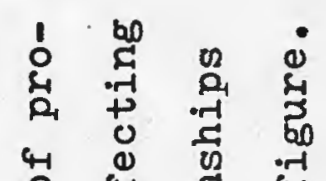

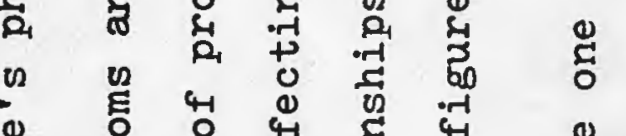

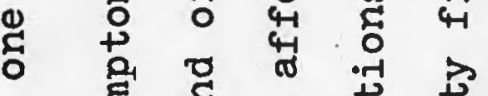

म

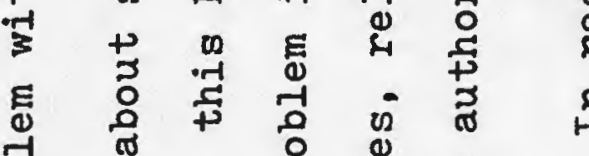

年 ब

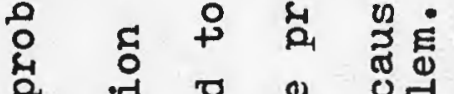

म स व

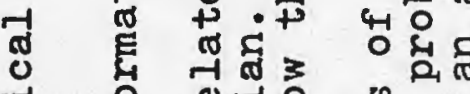

$\because$ ० 0.70 क न

४ स म

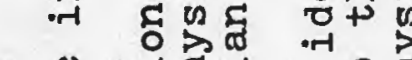

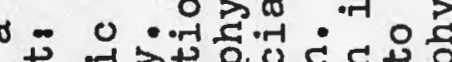

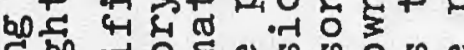

न

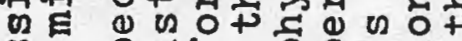

o

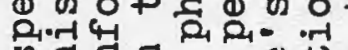

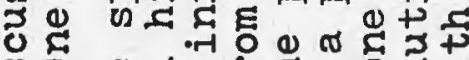

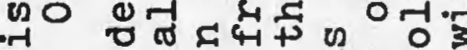

वृ 0.4 की 4 हो

थ द ठ

-

00

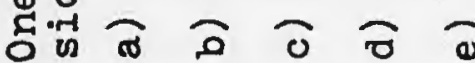

$\dot{0}$

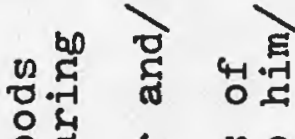

-4 -

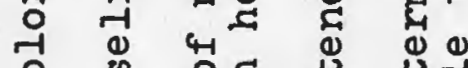

0 8 ⿰讠

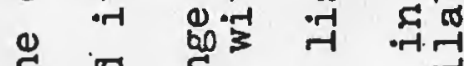

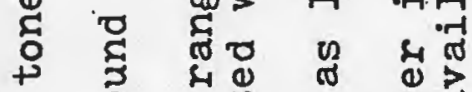

4 क म का

द $>$ थ मून भा

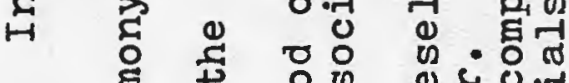

O थ 0 \& 0.4

ข

ह त 0 ขึ

4 द व क्षा

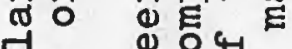

วิำ

ఘू

\&

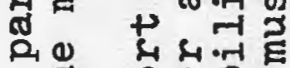

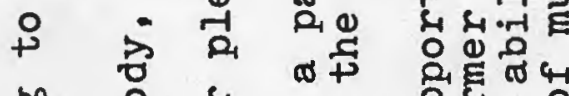

bo $\circ$ म

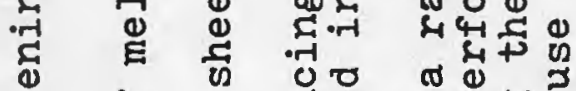

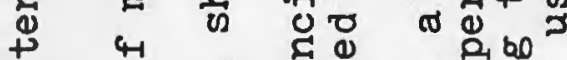

थ 0 bo का की है 4

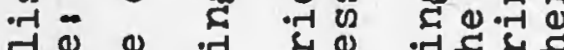

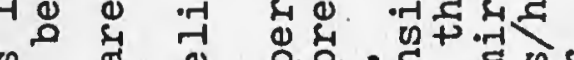

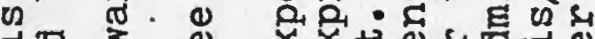

开 द ध

¿

है 

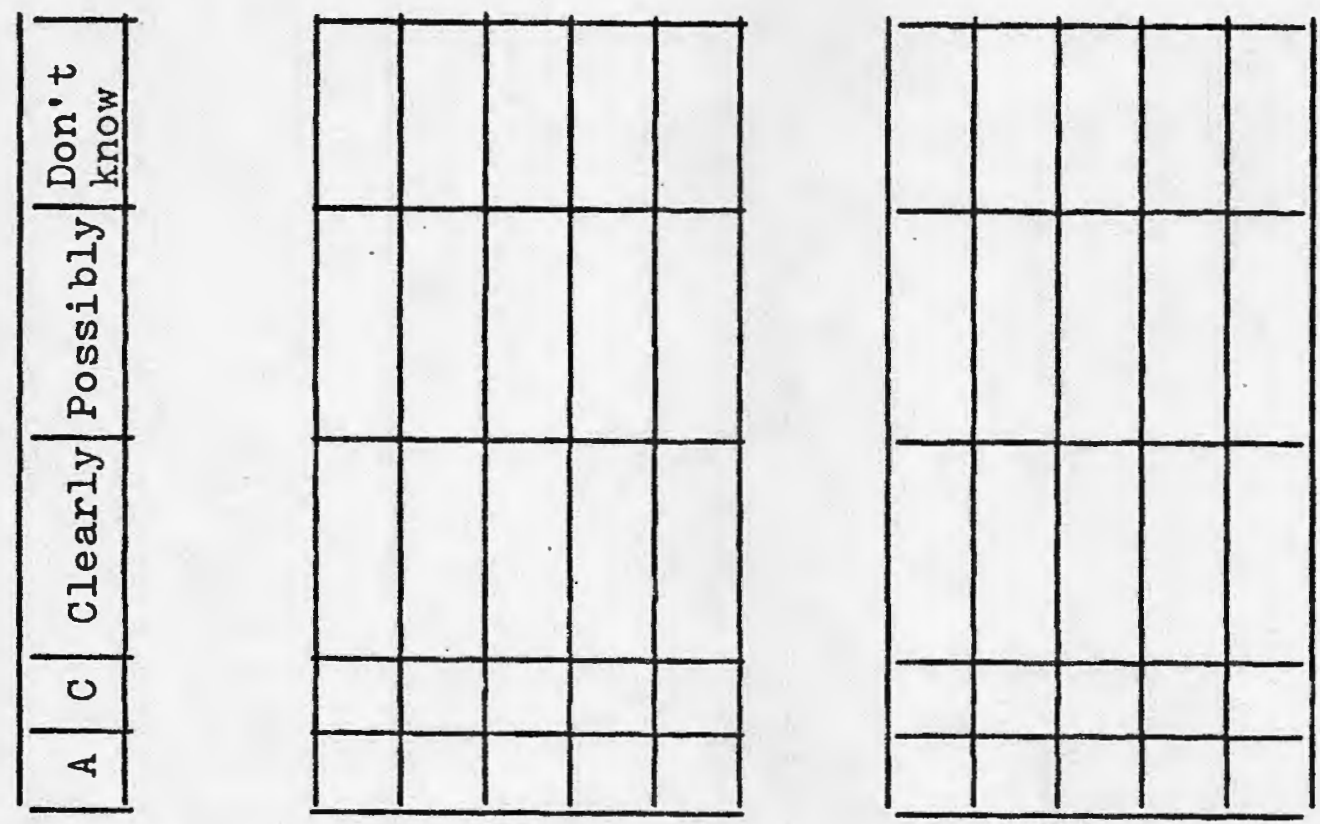

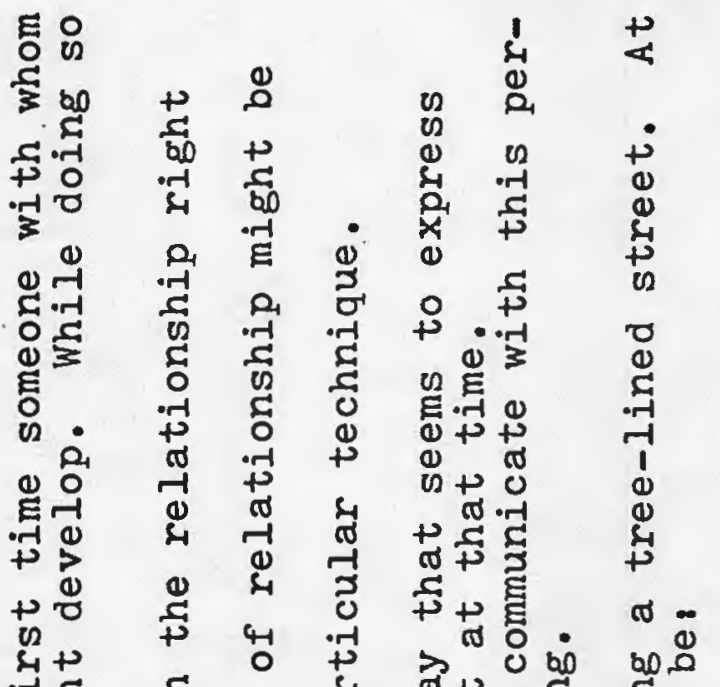

${ }_{4}^{4}$

$\rightarrow+\infty$

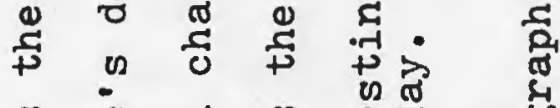

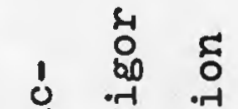

क 3 i

ข

द 0 द

$3+4$

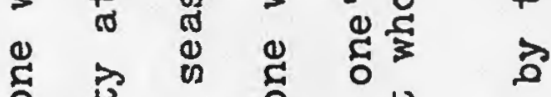

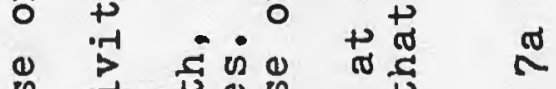

ถ तึ่

$\overrightarrow{4} 4$

4

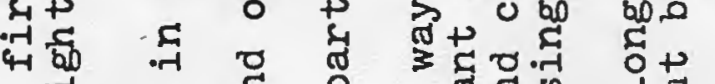

है थ है ह

过

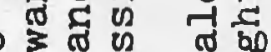

(1) 0

(1)

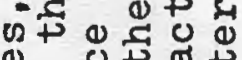

t n 0 我

ब्द है

का थ

की

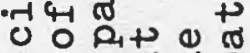

ब. $\frac{1}{b 0} \frac{d}{5}$

इ

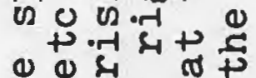

है दो

\& द्य

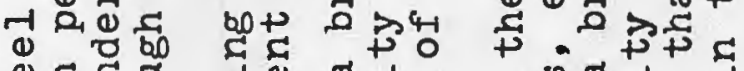

म्न 0 उ.

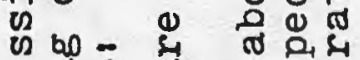

- दिए त

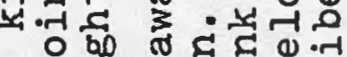

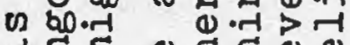

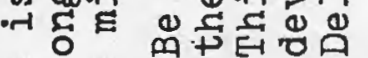

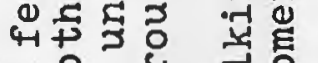

응요용 정

$+\rightarrow+\infty$

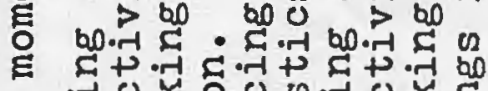

c

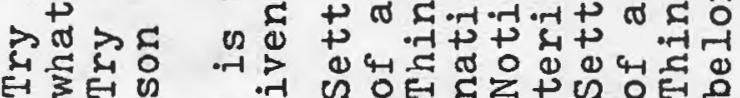

(1) 10 स

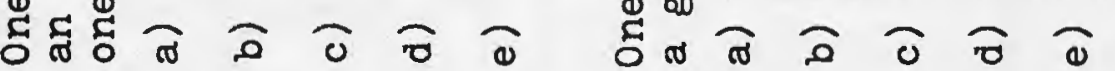

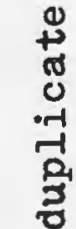

$\boldsymbol{\sigma}$

ט

E

है 

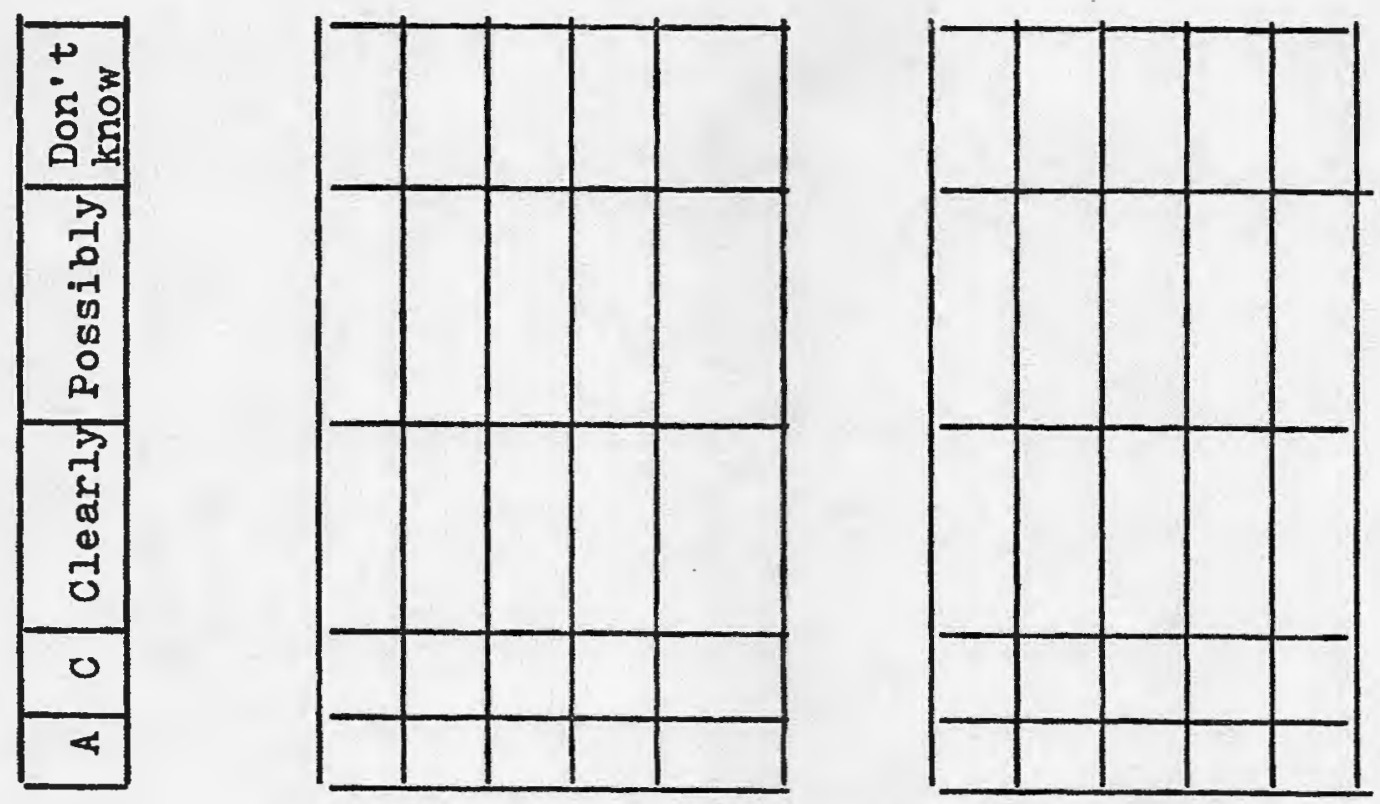

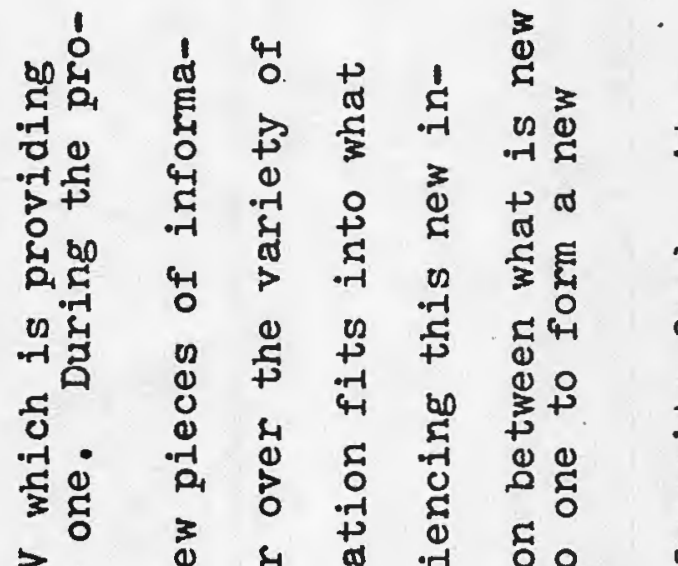

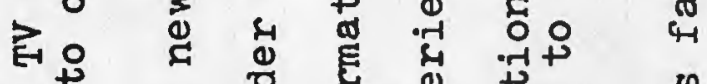

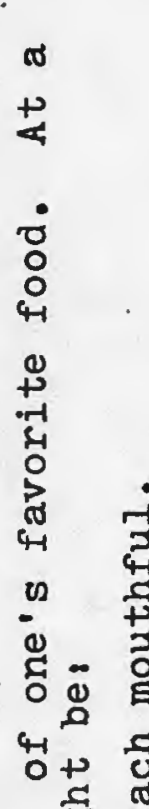

द bी

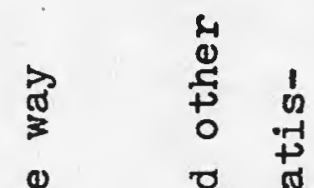

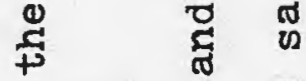

म

दे मे ट्द

ए)

듀 4 or

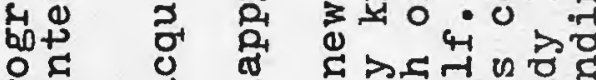

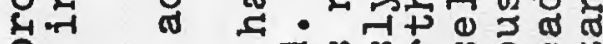

Q.

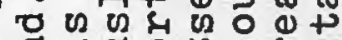

है

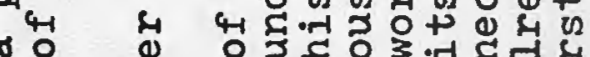

न ह है

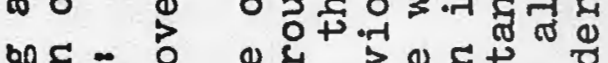

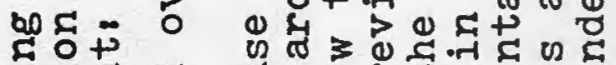

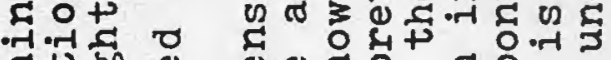

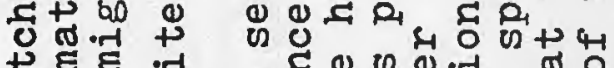

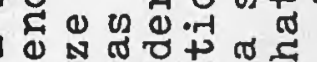

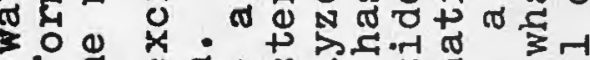

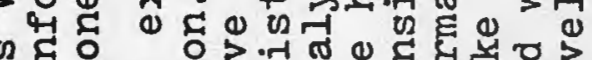

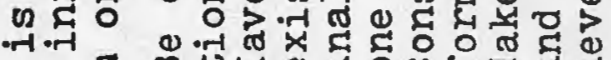

0 需 过岂

$$
\pi
$$

م

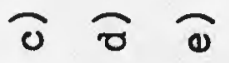

ता $\stackrel{9}{8}$

bo ?

点

if द

+ है।

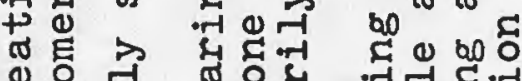

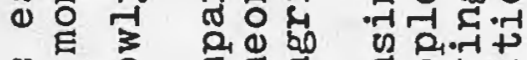

थ थ

U 2

0 红

(1) م红 4

$\infty$

a 


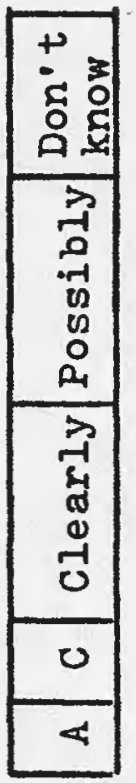
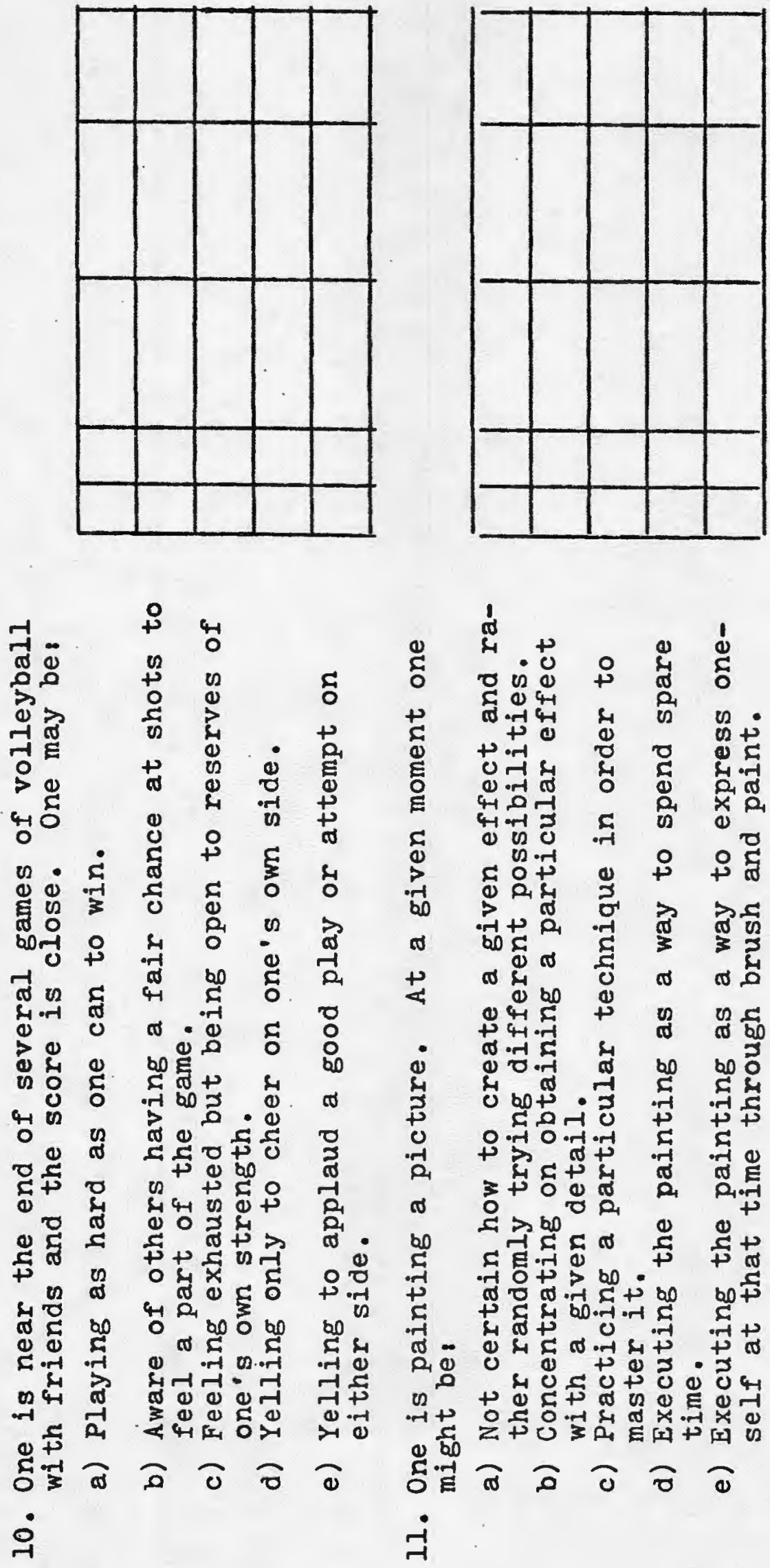

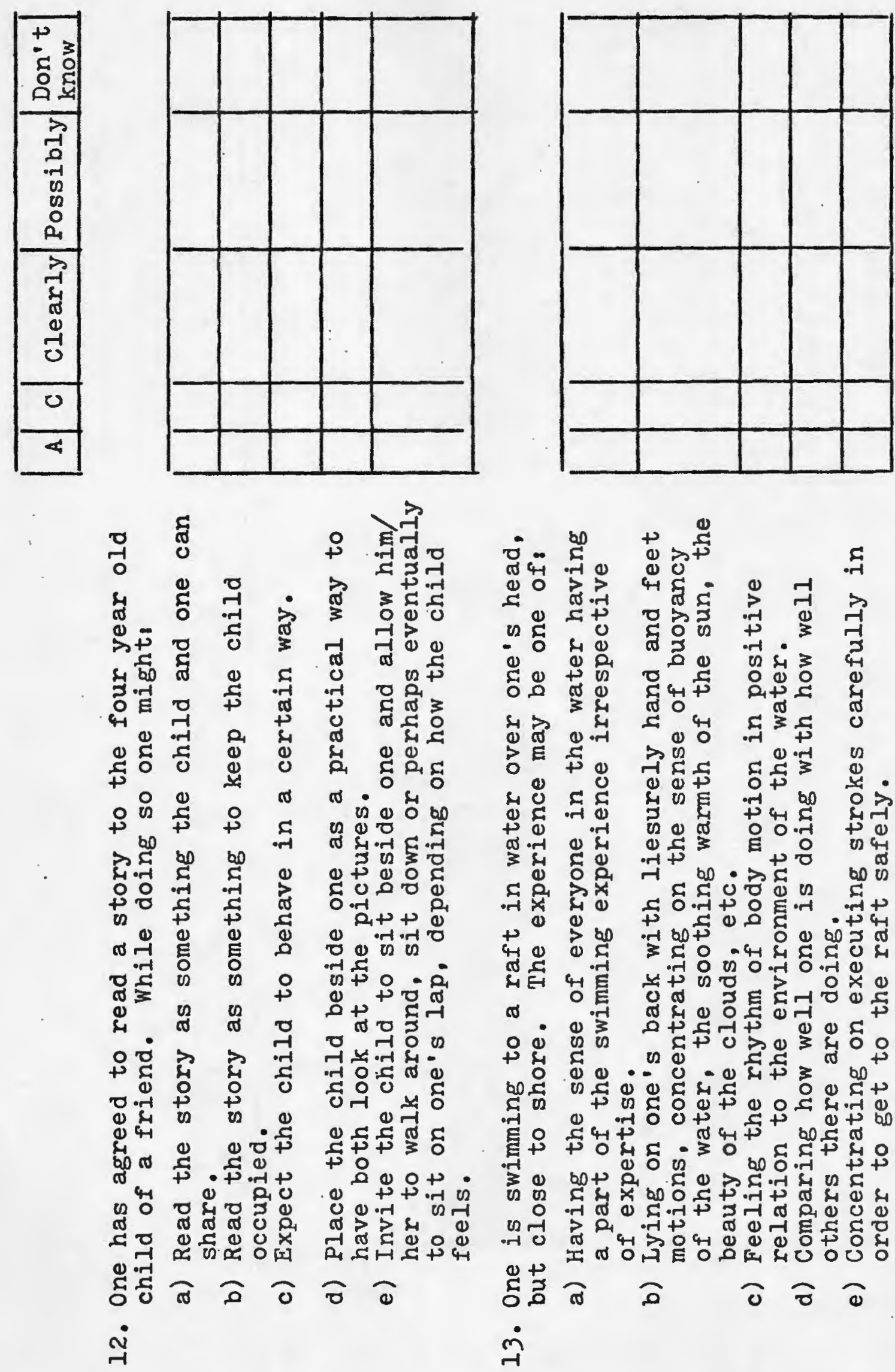

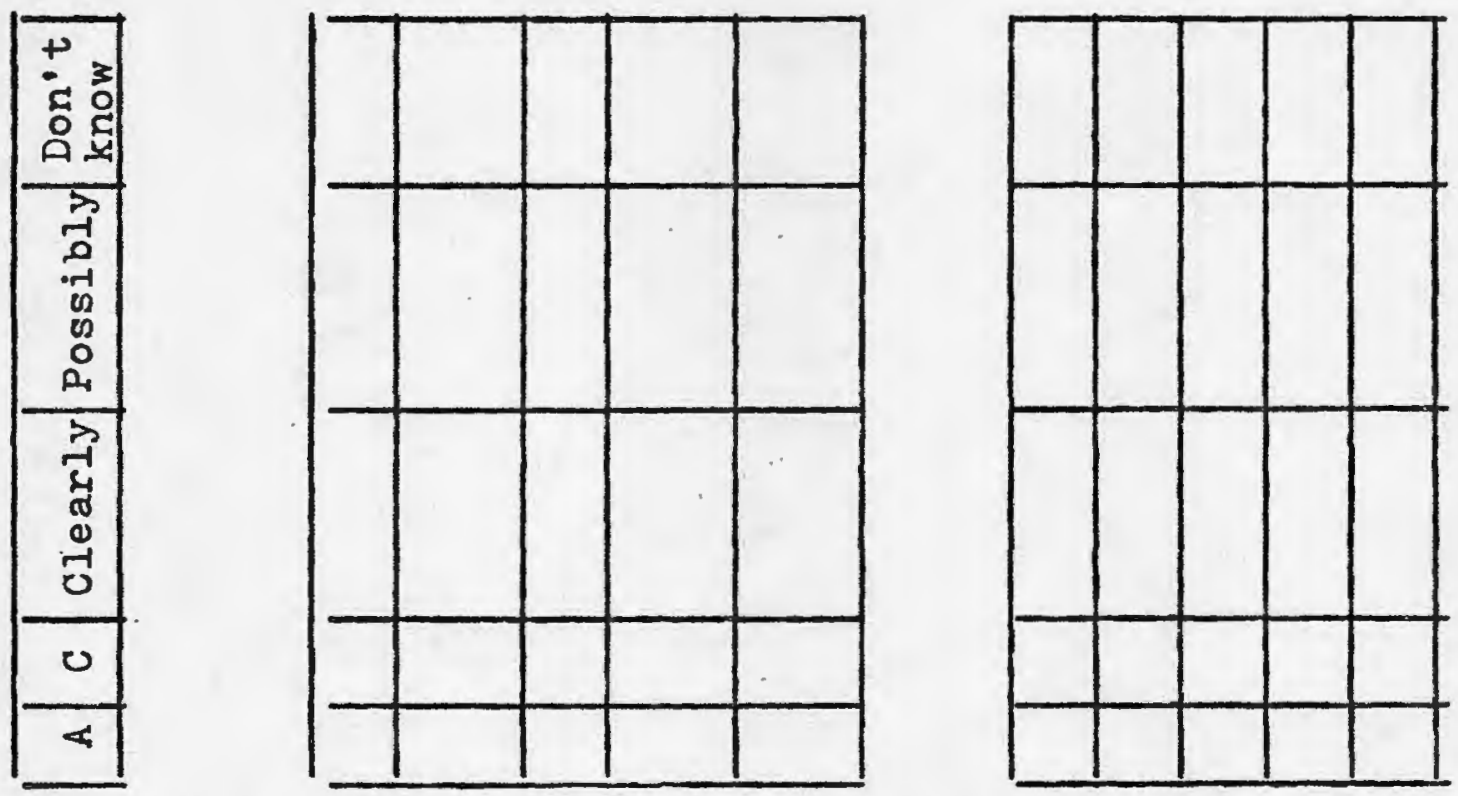

कृ

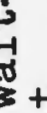

(1) की 穷

点 मे

1.

4 :

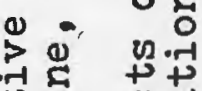

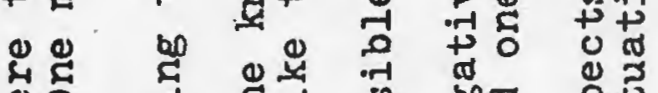

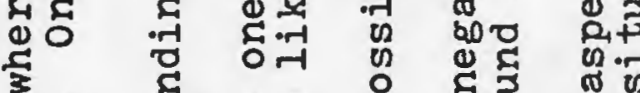

त त 0 थ

दैव

द है 0.

วิ

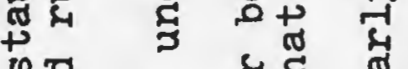

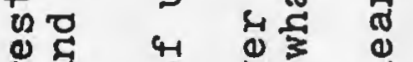

น नै 0 है ने

ब व

मधन्द क ब.न ते

$\rightarrow$ वृ

เ

वै कै 더

तี फे के

0.

$>0$ ०

Tै

\& 5

०ू मू दू

م先

के

की मू म्न.न

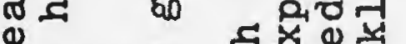

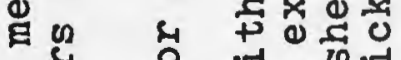

त ช

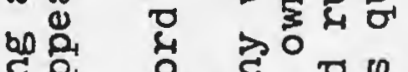

न्म

44 त 4 क

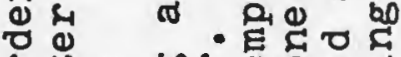

4ै

0 .

n 3 उ द्य

- ने

今. ¿ू है

निम द्न

$0+$ व

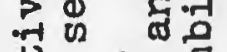

Uै 0 ن

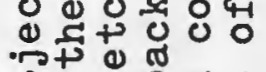

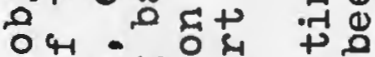

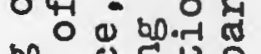

bo 0 द्व

द्व.

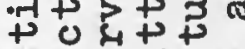

요요

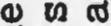

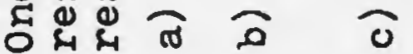

ชิ

$\begin{array}{ll}1 & \\ 41 & \\ 0 & ! \\ 4 & +\end{array}$

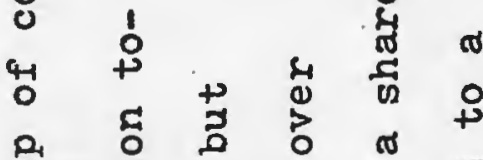

गें

๙

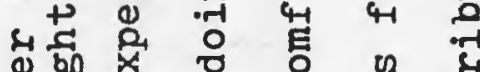

$>\cdot न$ \& 0 o की

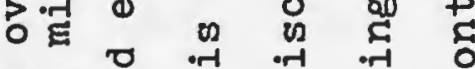

ठृ

屯

मे 0 or 0 4 a

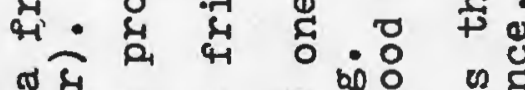

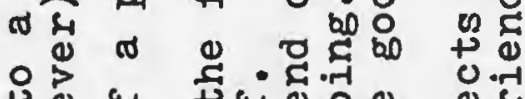

† 品

की क 400 \&

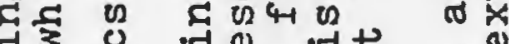

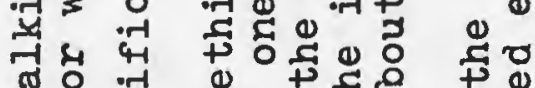

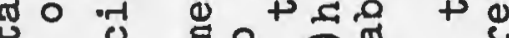

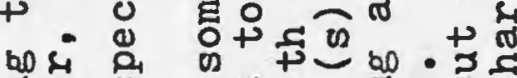

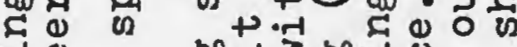

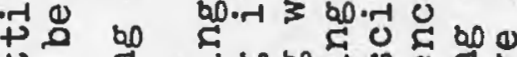

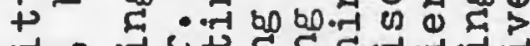

-

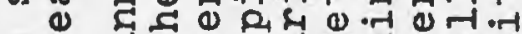

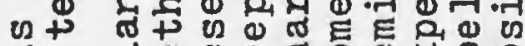

- ${ }^{-1} 0$ 过

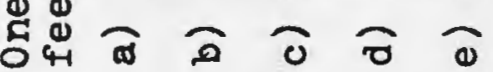

$\pm$

in 


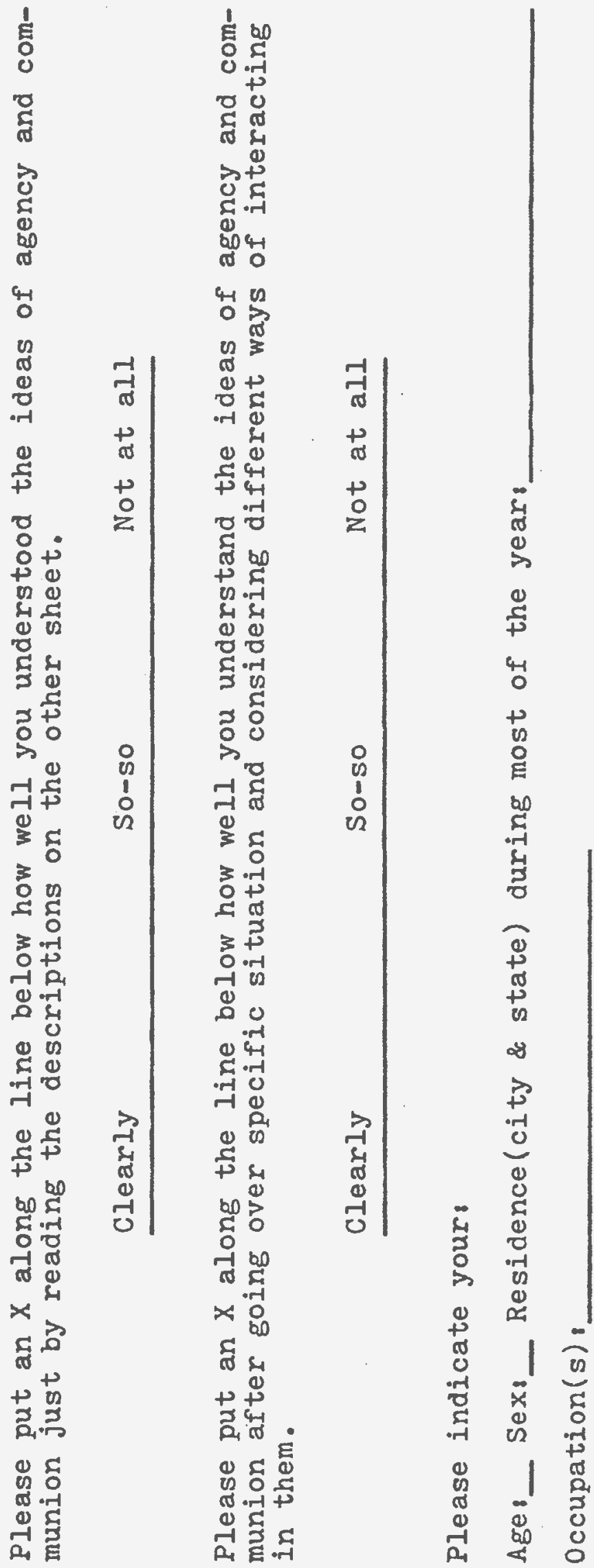




\section{APPENDIX B}

\section{What are Agency and Communion?}

Suppose there are two major ways people interact with life and situations in it. A person may use one way consistently more frequently and easily than the other, may use one more sometimes and the other more sometimes depending on the situation and inner state at the time, or may weave the two together so smoothly that unless one stops to consider what is going on, it seems like one way.

One way can be called Agency. I am Agentic at a given moment to the extent that I have a sense (a thinking/feeling awareness) of being a separate self interacting with other people, things and/or ideas.

The other way can be called Communion. I am Communal at a given moment to the extent that I have a sense (a thinking/feeling awareness) of mutuality or oneness with other people, things and/or ideạs.

The following is a table of some ways a person may manife'st Agency and Communion:

\begin{tabular}{l|l|l} 
With regard to & \multicolumn{1}{|c|}{ Agency } & \multicolumn{1}{|c}{ Communion } \\
\hline Other people & Treat impersonally & $\begin{array}{l}\text { Be in relation to as } \\
\text { another feeling being }\end{array}$ \\
\hline Emotions & $\begin{array}{l}\text { Show those that, at } \\
\text { the time keep dis- } \\
\text { tance \& make barri- } \\
\text { ers, for example, } \\
\text { anger or detachment }\end{array}$ & $\begin{array}{l}\text { ly bring those that usual- } \\
\text { together, for example, } \\
\text { empathy or caring }\end{array}$ \\
Thoughts & $\begin{array}{l}\text { Place them be analy- } \\
\text { zing or categorizing }\end{array}$ & $\begin{array}{l}\text { Allow them to move } \\
\text { about and come to- } \\
\text { gether as in intuition } \\
\text { or insight }\end{array}$ \\
\hline Art forms & $\begin{array}{l}\text { Express or respond } \\
\text { to in terms of struc } \\
\text { ture and technique }\end{array}$ & $\begin{array}{l}\text { Express or respond to going with" an in- } \\
\text { berent process }\end{array}$ \\
\hline Physical nature & $\begin{array}{l}\text { observe facts about } \\
\text { and consider condi- } \\
\text { tions as things to } \\
\text { be dealt with }\end{array}$ & $\begin{array}{l}\text { Feel a part of or one- } \\
\text { ness with conditions, } \\
\text { organic and inorganic }\end{array}$ \\
\hline Tasks & $\begin{array}{l}\text { Learn and use skills } \\
\text { as means to an end } \\
\text { or for feeling of } \\
\text { mastery over }\end{array}$ & $\begin{array}{l}\text { fo about experiencing } \\
\text { at the time, whether } \\
\text { just learning or well } \\
\text { learned }\end{array}$ \\
\hline
\end{tabular}


I am going to present to you a number of situations likely to be experienced by many people. Under each will be listed different ways to experience or behave in the situation. What I am asking you to do is to look at each alternative item and decide whether it is more Agentic or more Communal.

Here is a sample situation for you to try

Please put $A$ for more Agentic than Communal and $C$ for more Communal than Agentic in the space preceeding each alternative.

One is sitting talking to a friend over a cup of coffee (tea, beer, or whatever). One might be:

a) Planning specifics of a proposed expedition.

b) Resenting something the friend is doing.

c) Sharing with the friend one's discomfort over something (s) he is doing.

-d) Reminiscing about the good feelings from a shared experience.

-e) Speliing out the aspects that contributed to a previous experience.

f) Enjoying being together.

Now please wait for discussion of the ratings on this set of alternatives before going on. 
Instructions:

Put A for more Agentic than Communal and $\mathrm{C}$ for more Communal than Agentic in the space preceding each alternative.

1. One is teaching someone a new skill that involves some risk, for example, riding a bicycle. Different ways of doing it might be to:

a) Go over step by step what the task requires.

b) Deal with the person objectively regarding his/her trying this new experience.

c) Concentrate on the goal of teaching this skill.

d) Try to help the other person become aware of what the total experience of riding a bike is like.

e) Show some understanding of the person's feeling as (s)he tries this new experience.

f) Give attention to both persons sharing in the teaching-learning process.

2. One is performing a home task such as raking leaves or sweeping the kitchen floor. While doing so, one might,

a) Be aware of one's muscles and motions and the rake or broom as tools to be used.

b) Be aware of one's muscles and motions and the rake or broom moving together as part of a process.

c) Experience it as one way of maintaining harmony in one's homelife.

d) See how efficiently and competently one can do the job.

e) Experience it as a chore that simply is a mechanical routine.

f) Experience some warm feelings for others in the home while doing the task. 
3. One has just completed skillfully driving a car through a difficult situation, for example, avoiding having an accident during rushhour traffic with slippery conditions. One might react by:

a) Acknowledging one's successful manuevering.

b) Experiencing a closeness to those in one's car because they are unharmed.

c) Driving the rest of the way keenly aware of the experience of harmony in motion of oneself in relation to one's own vehicle and others'.

d) Driving the rest of the way keenly aware of driving conditions.

e) Having a sense of fellowship with other drivers who contributed to avoiding an accident.

f) Being angry at the poor driving habits of other drivers.

4. One is discussing one's medical problem with one's physician. One might,

a) Systemmatically provide specific information about one's symptoms and medical history.

b) Obtain information about this kind of problem from the physician.

c) While talking to the physician become aware of how the problem relates to other aspects of one's life.

d) Feel that one could share one's own ideas about the problem with that physician.

e) Deal with the physician as an authority figure.

f) Relate to the physician as someone who is a person.

5. One is listening to some music and is:

a) Aware of separate aspects, like melody, rhythm, harmony, instruments.

b) Feeling sheer pleasure from the sound itself.

c) Experiencing a particular mood or range of moods expressed in the music or associated with hearing it.

d) Sensing a rapport between oneself as listener and/or the performer and composer.

e) Acknowledging the ability of the composer in terms of his/her use of musical materials.

f) Comparing the quality of execution by the performer(s) to others previously heard playing the same piece. 
6. One is kissing for the first time someone with whom an ongoing closeness might develop. While doing so one might,

a) Be aware of the closeness in the relationship right then.

b) Think about different ways the relationship might develop.

c) Deliberately use a particular technique.

d) Try to feel out the way that seems to express what both persons want at that time.

e) Try to understand and communicate with this person through the kissing.

f) Compare the way this person kisses with that of someone else.

7. One is walking alone along a tree-lined street. At a given moment one might be:

a) Going at a brisk pace because it fits into the crispness of the day and one's mood.

b) Thinking of details of activity at one's destination.

c) Noticing separate aspects, like the species, health, seasonal characteristics, etc. of the trees.

d) Setting a brisk pace because it is considered to be good for the heart, etc.

e) Sensing that this activity fits into the rhythm of that whole day.

f) Feeling a similarity between the strength and vitality of the trees and these characteristics in oneself or someone else.

8. One is watching a program on TV which is providing new information of interest. During the program one might:

a) Deliberately store away some new pieces of information.

b) Have a sense of happy wonder over the variety of existence around.

c) Analyze how this new information compares with what one has previously known.

d) Experience this new information for itself.

e) Make a spontaneous connection between what is new and what is already known to form a new understanding.

f) Think about how one can use this information. 
9. One is eating a dish of one's favorite food. At a given moment one might be:

a) Aware of a kind of union taking place between the food and oneself.

b) Comparing the current preparation with the way the dish has been prepared before.

c) Eating it as fast as possible because one is "starved."

d) Sensing a relationship between oneself and other people also eating that same food.

e) Experiencing satisfaction over the taste in itself.

f) Trying to figure out what ingredient is responsible for a new additional flavor.

10. One is near the end of several games of volleyball with friends and the score is close. One may be:

a) Playing as hard as one can to beat the other side.

b) Aware of others having a fair chance at shots.

c) Feeling exhausted but keeping going because of feeling for the group.

d) Yelling to cheer on a teammate who is helping one to win.

e) Yelling to applaud a good play or attempt on either side.

f) Feeling exhausted but pushing on to prove one can finish.

11. One is painting a picture. At a given moment one might bes

a) "Playing" with color and texture, letting the picture emerge.

b) Concentrating on obtaining a particular visual effect with a given detail.

c) Practicing a particular technique in order to master it.

d) Mechanically painting as a way to use up spare time.

e) Painting as a way to express harmony and beauty through brush and paint.

f) Having the "flash" of an idea that seems ready to flow out of one. 
12. One has agreed to read a story to a four year old child. While doing so one might.

a) Read the story as something the child and one can share.

b) Read the story as something to keep the child occupied.

c) Expect the child to be different than one because (s) he is a child.

d) Sit next to the child for practical reasons.

e) Allow the child to walk around, sit down or perhaps to sit on one's lap depending on how the child feels.

f) Assume that the child may have some similar interest to one's own.

13. One is swimming to a raft. The experience may be one of:

a) Having the sense of everyone in the water sharing the swimming experience irrespective of expertise.

b) Lying on one's back with liesurely hand and feet motions, concentrating on the sense of buoyancy of the water, the soothing warmth of the sun, the beauty of the clouds, etc.

c) Feeling the rhythm of body motion in positive relation to the environment of the water.

d) Comparing how well one is doing with how well others are swimming.

e) Concentrating on executing strokes carefully in order to get to the raft.

f) Experiencing mastery over the water while swimming in it.

14. One is ordering a meal in a restaurant where the waitress/waiter appears harried and rushed. One might react by:

a) Giving a word or gesture of understanding to the server.

b) Feeling empathy with the server because one knows what it is like to be harried and rushed.

c) Being annoyed that one is not going to be able to order in liesurely comfort.

d) Noting objectively the different aspects of the setting, the kind of people around one, the service, etc.

e) Being aware of the aspects of the situation combining into an overall situation one is a part of.

f) Being involved in one's thoughts and interests to the extent one is not even aware of the server's situation. 
Now please examine each of the situations presented above with the intention of judging whether the situation itself appears to be more highly Agentic or Communal.

Please put A for more Agentic than Communal, C for more Communal than Agentic and $\mathrm{N}$ for Neutral in the space preceding each situation:

S) One is sitting talking to a friend over a cup of coffee (tea, beer, or whatever).

1) One is teaching someone a new skill that involves some risk, for example, riding a bicycle.

2) One is performing a home task such as raking leaves or sweeping the kitchen floor.

3) One has just completed skillfully driving a car through a difficult situation, for example, avoiding an accident during rushhour traffic with slippery conditions.

4) One is discussing one's medical problem with one's physician.

5) One is listening to some music.

6) One is kissing for the first time someone with whom an ongoing closeness might develop.

7) One is walking alone along a tree-lined street.

8) One is watching a program on TV which is providing new information of interest.

9) One is eating a dish of one's favorite food.

10) One is near the end of several games of volleyball with friends and the score is close.

11) One is painting a picture. 12) One has agreed to read a story to a four year old
child.

13) One is swimming to a raft.

14) One is ordering a meal in a restaurant where the waitress/waiter appears harried and rushed. 
Please put an $X$ along the line below to indicate how well you understood the ideas of Agency and Communion just by reading the descriptions at the beginning.

Please put an $X$ along the line below to indicate how well you understand the ideas of Agency and Communion after going over specific situations and considering different ways of interacting in them.

Clearly

So-so

Not at all

Please indicate your: Age: Sex: Occupation(s) 
WAYS OF INTERACTING QUESTIONNAIRE

I am going to present to you a number of situations likely to be experienced by many people. Under each will be listed different ways to experience or behave in the situation. What I am asking you to do is to look at each alternative item and decide how likely you would be to interact that way IF you were in that situation.

Please choose the number from the scale below that best agrees with the way you think you would be most likely to interact and place that number in the space beside that alternative on the answer sheet. Please answer for all alternatives in each situation.

\section{Answer Scale}

7. Definitely or Always

6. Very Probably or Very Frequently

5. Probably or Frequently

4. Possibly or Occasionally

3. Probably Not or Very Rarely

2. Very Probably Not or Very Rarely

1. Definitely Not or Never

We want your first reaction, not a long drawn-out thought process, so please don't linger--

And remember to give an answer for each item so that all blanks on the answer sheet are filled.

Now turn the page over and go ahead-- 
1. One is teaching someone a new skill that involves some risk, for example, riding a bicycle. Different ways of doing it might be tor

a) Go over step by step what the task requires.

b) Deal with the person objectively regarding his/her trying this new experience.

c) Concentrate on the goal of teaching this skill.

d) Try to help the other person become aware of what the total experience of riding a bike is like.

e) Show some understanding of the person's feeling as (s) he tries this new experience.

f) Give attention to both persons sharing in the teaching -learning process.

2. One is performing a home task such as raking leaves or sweeping the kitchen floor. While doing so, one might,

a) Be aware of one's muscles and motions and the rake or broom as tools to be used.

b) Be aware of one's muscles and motions and the rake or broom moving together as part of a process.

c) Experience it as one way of maintaining harmony in one's homelife.

d) See how efficiently and competently one can do the job.

e) Experience it as a chore that simply is a mechanical routine.

f) Experience some warm feelings for others in the home while doing the task.

3. One has just completed skillfully driving a car through a difficult situation, for example, avoiding having an accident during rushhour traffic with slippery conditions. one might react by:

a) Acknowledging one's successful manuevering.

b) Experiencing a closeness to those in one's car because they are unharmed.

c) Driving the rest of the way keenly aware of the experience of harmony in motion of oneself in relation to one's own vehicle and others'.

d) Driving the rest of the way keenly aware of driving conditions.

e) Having a sense of fellowship with other drivers who contributed to avoiding an accident.

f) Being angry at the poor driving habits of other drivers. 
4. One is discussing one's medical problem with one's physician. One might:
a) Systemmatically provide specific information about one's symptoms and medical history.
b) Obtain information about this kind of problem from the physician.
c) While talking to the physician become aware of how the problem relates to other aspects of one's life.
d) Feel that one could share one's own ideas about the problem with that physician.
e) Deal with the physician as an authority figure.
f) Relate to the physician as someone who is a person.

5. One is listening to some music and is

a) Aware of separate aspects, like melody, rhythm, harmony, instruments.

b) Feeling sheer pleasure from the sound itself.

c) Experiencing a particular mood or range of moods expressed in the music or associated with hearing it.

d) Sensing a rapport between oneself as listener and/or the performer and composer.

e) Acknowledging the ability of the composer in terms of his/her use of musical materials.

f) Comparing the quality of execution by the performer(s) to others previously heard playing the same piece.

6. One is kissing for the first time someone with whom an ongoing closeness might develop. While doing so one might:

a) Be aware of the closeness in the relationship right then.

b) Think about different ways the relationship might develop.

c) Deliberately use a particular technique.

d) Try to feel out the way that seems to express what both persons want at that time.

e) Try to understand and communicate with this person through the kissing.

f) Compare the way this person kisses with that of someone else. 
7. One is walking alone along a tree-lined street. At a given moment one might be:

a) Going at a brisk pace because it fits into the crispness of the day and one's mood.

b) Thinking of details of activity at one's destination.

c) Noticing separate aspects, like the species, health, seasonal characteristics, etc. of the trees.

d) Setting a brisk pace because it is considered to be good for the heart, etc.

e) Sensing that this activity fits into the rhythm of that whole day.

f) Feeling a similarity between the strength and vitality of the trees and these characteristics in oneself or someone else.

8. One is watching a program on TV which is providing new information of interest. During the program one mights

a) Deliberately store away some new pieces of information.

b) Have a sense of happy wonder over the variety of existence around.

c) Analyze how this new information compares with what one has previously known.

d) Experience this new information for itself.

e) Make a spontaneous connection between what is new and what is already known to form a new understanding.

f) Think about how one can use this information.

9. One is eating a dish of one's favorite food. At a given moment one might be:

a) Aware of a kind of union taking place between the food and oneself.

b) Comparing the current preparation with the way the dish has been prepared before.

c) Eating it as fast as possible because one 1.3 "starved."

d) Sensing a relationship between oneself and other people also eating that same food.

e) Experiencing satisfaction over the taste in itself.

f) Trying to figure out what ingredient is responsible for a new additional flavor. 
10. One is near the end of several games of volleyball with friends and the score is close. One may be:
a) Playing as hard as one can to beat the other side.
b) Aware of others having a fair chance at shots.
c) Feeling exhausted but keeping going because of feel- ing for the group.
d) Yelling to cheer on a teammate who is helping one to win.
e) Yeliing to applaud a good play or attempt on either side.
f) Feeling exhausted but pushing on to prove one can finish.

11. One is painting a picture. At a given moment one might be:
a) "Playing" with color and. texture, letting the picture emerge.
b) Concentrating on obtaining a particular visual effect with a given detail.
c) Practicing a particular technique in order to master it.
d) Mechanically painting as a way to use up spare time.
e) Painting as a way to express harmony and beauty through brush and paint.
f) Having the "flash" of an idea that seems ready to flow out of one.

12. One has agreed to read a story to a four year old child. While doing so one might:
a) Read the story as something the child and one can share.
b) Read the story as something to keep the child oc- cupied.
c) Expect the child to be different than one because (s) he is a child.
d) Sit next to the child for practical reasons.
e) Allow the child to walk around, sit down or perhaps to sit on one's lap depending on how the child feels.
f) Assume that the child may have some similar interest to one's own.


13. One is swimming to a raft. The experience may be one of:

a) Having the sense of everyone in the water sharing the swimming experience irrespective of expertise.

b) Lying on one's back with liesurely hand and feet motions, concentrating on the sense of buoyancy of the water, the soothing warmth of the sun, the beauty of the clouds, etc.

c) Feeling the rhythm of body motion in positive relation to the environment of the water.

d) Comparing how well one is doing with how well others are swimming.

e) Concentrating on executing strokes carefully in order to get to the raft.

f) Experiencing mastery over the water while swimming in it.

14. One is ordering a meal in a restaurant where the waitress/waiter appears harried and rushed. One might react by:

a) Giving a word or gesture of understanding to the server.

b) Feeling empathy with the server because one knows what it is like to be harried and rushed.

c) Being annoyed that one is not going to be able to order in liesurely comfort.

d) Noting objectively the different aspects of the setting, the kind of people around one, the service, etc.

e) Being aware of the aspects of the situation combining into an overall situation one is a part of.

f) Being involved in one's own thoughts and interests to the extent one is not even aware of the server's situation.

15. One is sitting talking to a friend over a cup of coffee (tea, beer, or whatever). One might bes

a) Planning specifics of a proposed expedition.

b) Resenting something the friend is doing.

c) Sharing with the friend one's discomfort over something ( $s$ ) he is doing.

d) Reminiscing about the good feelings from a shared experience.

e) Spelling out the aspects that contributed to a previous experience.

f) Enjoying being together. 
ANSWER BOOKLET ( 4 pages)

Answer Scale for 7. Definitely or Always Ways of Interacting

6. Very Probably or Very Frequently Questionnaire

5. Probably or Frequently

4. Possibly or Occasionally

3. Probably Not or Rarely

2. Very Probably Not or Very Rarely

1. Definitely Not or Never

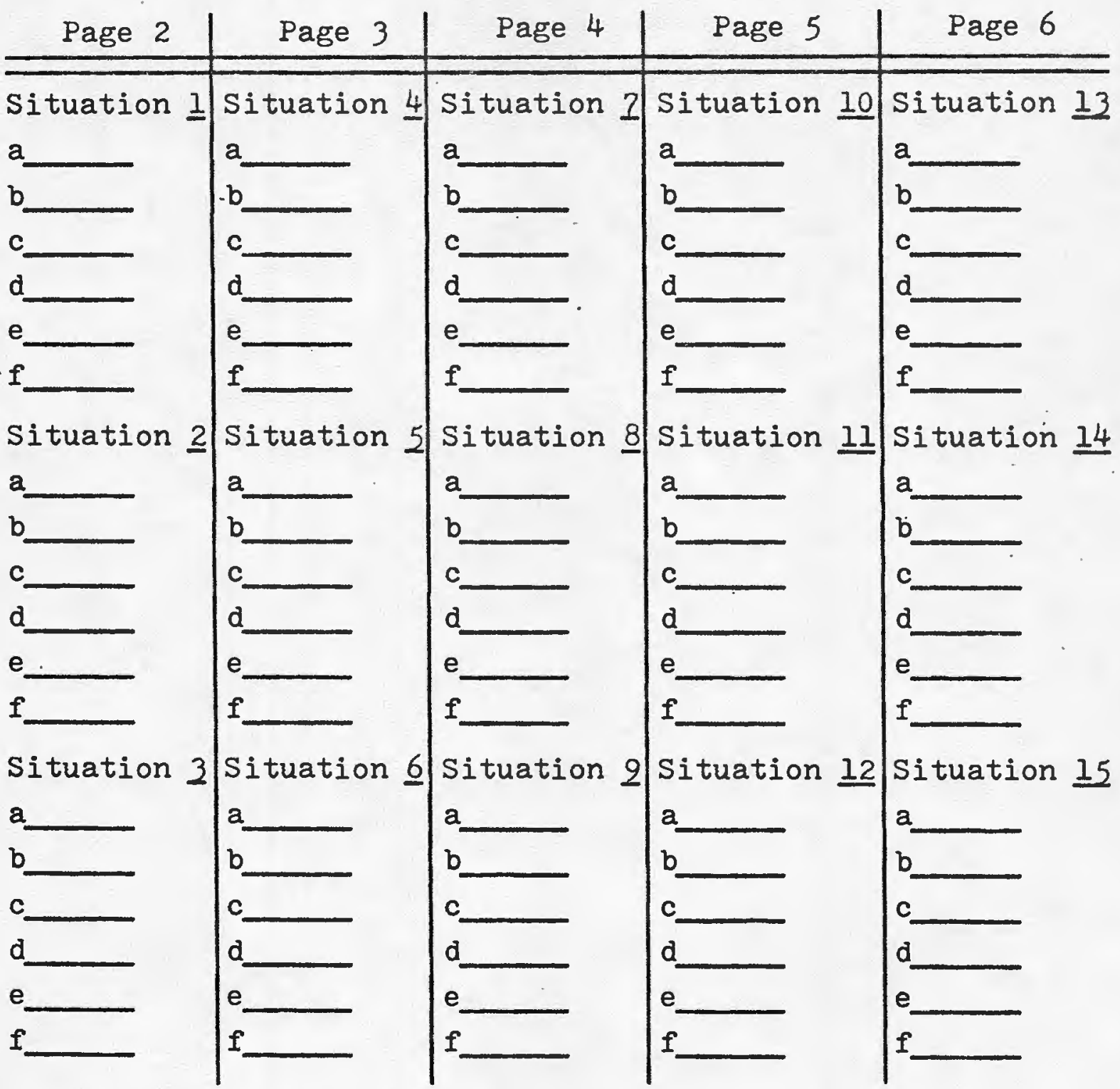

Please indicate your, Age: Sex: Major: Occupation(s) 


\section{REFERENCES}

Adl $r, A$. On the origin of the strivng for superiority and social interest. In H. I. Ansbacher \& R. R. Ansbacher (Eds.). Superiority and social interest: A collection of later writings. Evanston, Illinois: Nortinestern University Press, 1964.

Bak:in, D. The duality of human existence. Chicago: Rand McNally, 1966.

Bar: $y, H$. III, Bacon, N. K., \& Child, I. I. A cross-cultural survey of some sex differences in socialization. Journal of Abnormal and Social Psychology, 1957, 55. $327-332$.

Bem: S. Psychology looks at sex roles: Where have all the androgynous people gone? Paper presented at University of California in Los Angeles Symposium on Women, Los Angeles, May 1972.

Bem. S. The measurement of psychological androgeny. Journal of Consulting and Clinical Psychology, 1974.

Bem, S. Sex-role adaptability: One consequence of psychological androgeny. Journal of Personality and Social Psychology, $1975,31,634-643$.

Bilier, $H$. Sex role learning: Some comments and complexities from a multidimensional perspective. Symposium presented at the meeting of the American Association for the Advancement of Science, Washington, D. C., December 1972.

Block, J. H. Conceptions of sex role, Some cross-cultural and longitudinal perspectives. American Psychologist, 1973, 28, 512-526.

Broverman, D. M., Klaiber, E. I., Kobayashi, N., \& Vogel, W. Activation, inhibition and cognitive sex differences. Psychological Review, 1968, 25, 23-50.

Broverman, I. I., Vogel, S. B., Broverman, D. M., Clarkson, F. E., \& Ronsenkrantz, P. S. Sex-role stereotypes: A current Appraisal. Journal of Social Issues, 1972, 28. $59-78$. 
Brown, D., \& Marks, P. A. Bakan's bi-polar constructs: Agency and communion. Psychological Record, 1969, 12, 465-473.

Buber, M. I and Thou, (2nd ed.) New Yorkı Charles Scribner, $1 \overline{9} 5 \overline{8}$ (Originally published, 1923).

Carkhuff, R. R., \& Berenson, B. G. Beyond Counseling and Therapy, New York: Holt, Rinehart \& Winston, 1967.

Carkhuff, R. R., \& Berenson, B. G. The counselor is a man and a woman. Personnel and Guidance Journal, 1969, $48,24-28$.

Carlson, R. Sex differences in ego functioning, Exploratory studies of agency and communion. Journal of Consulting and Clinical Psychology, 1971, 37, 267-277.

Carlson, R. Understanding women: Implications for personality theory and research. Journal of Social Issues, $1972,28,17-32$.

Chesler, P. Women and madness: When is a woman mad and who is it who decides? New York: Doubleday, 1972.

Constantinople, A. Masculinity-femininity: An exception to a famous dictum? Psychological Bulletin, 1973, 80, $389-407$.

Copland, A. What to listen for in music. New York: McGraw-Hill, $\overline{19} 39$.

Cumming, J., \& Cumming, E. Ego and Wilieu. New York, Atherton Press, 1970.

Deutsch, H. The psychology of women: A psychoanalysis interpretation. Vol. 1. New York Grune \& Stratton, 1944 .

Erikson, E. H. Childhood and Society (2nd ed.) New Yorkı W. W. Norton, 1963.

Freire, P. Pedagogy of the oppressed. New York: Seabury Press, 1970.

Freud, S. Anatomy is destiny. In B. Roszak \& T. Roszak (Eds.), Masculine/Feminine: Readings in Sexual Mythology and the liberation of woman. New York: Harper Colophon, 1969. (Originally published, 1933).

Goldberg. S., \& Lewis, M. Play behavior in the year-old infant: Early sex differences. Child Development, 1969, 40, 21-31. 
Gutmann, D. Women and the conception of ego strength. Merrill Palmer Quarterly, 1965, 11, 229-240.

Hacker, H. M. Women as a minority group. Social Forces, $1951,20,60-69$.

Heilbrun, A. B. Jr. An empirical test of the modeling theory of sex role learning, Child Development, 1965, 36. 789-799.

Heilbrun, C. Toward a recognition of androgeny. New Yorks Knopf, 1973.

Horner, M. S. Toward a understanding of achievement related conflicts in women. Journal of Social Issues, 1972, 28, 157-175.

Horney, K. Feminine Psychology. New Yorks Norton, 1967.

Johnson, M. M. Sex-role learning in the nuclear family. Child Development, 1963, 24, 319-333.

Jourard, S. Mi. The transparent self. New York: Van Nostrand Reinhold, 1964.

Kaiser, H. Effective Psychotherapy. L. B. Fierman (Ed.). New York: Free Press, 1965.

Kaiser, H. F. Computer program for Varimax rotation in factor analysis. Educational and Psychological Mieasurement; $1959,19,413-420$.

Kastenbaum, R. "Running subjects", A change in editorial policy. Omega, Journal of Death and Dying. 1973, 4 , $177-179$.

Kohlberg, I. Development of moral character and moral ideology. In M. Hoffman \& I. Hoffman (Eds.), Review of child development research. Vol. 1. New Yorks Russell sage Foundation, 1964.

Kohlberg, I. A cognitive-developmental analysis of children's sex-role concepts and attitudes. In E. E. Maccoby $(E d$.$) , The development of sex differences. Stan-$ ford, Californias Stanford University Press, 1966.

Loevinger, J. The meaning and measurement of ego development. American Psychologist, 1966, 21, 195-206.

Loevinger, J., \& Wessler, R. Measuring ego development, Vol. 1. San Francisco: Jossey-Boss, 1970. 
Maccoby, E. E., \& Jackim, C. N. Sex differences and their implications for sex roles. Paper presented in a symposium at the American Psychological Association, Washington, D. C., September 1971.

Maslow, A. H. Toward a psychology of being. Princeton: Van Nostrand, 1962 .

May, R. Psychology and the human dilemma. Princeton, N. J.: Van Nostrand, 1967.

Mead, M. Sex and temperament in three primitive societies.

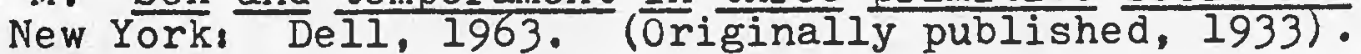

Money, J., \& Ehrhardt, A. Man and woman, boy and girl: Differentiation and Dimorphism of gender identity. Baltimore: Johns Hopkins, 1972 .

Mussen, P. H. Long term consequents of masculinity of interests in adolescence. Journal of Consulting Psychology. 1962, 26, 435-440.

Myrdal, G. In B. Roszak \& T. Boszak (Eds.), Masculine/ Feminine: Readings in sexual mythology and the liberation of women. New York Harper Colophon, 1969. Toriginally published, 1944 ).

Our own feelings about androgeny. Women. 1974, 4. 32-35.

Parsons, T. Family structure and socialization of the child. In T. Parsons \& R. F. Bales (Eds.), Family socialization and interaction process. Glencoe, Illinois: Free Press, 1955.

Piaget, J. The Origins of Intelligence in Children translated by Margaret cook. New York: International University Press, 1952. (Originally published, 1936).

Pleck, J.H. Masculinity-Femininity: Current and Alternative Paradigms. Sex Roles: A Journal of Research, 1975. $1,161-178$.

Rheingold, H. Sharing at an early age. Presidential address, Division 7. American Psychological Association, Montreal, 1973.

Rheingold, J. C. The fear of being a woman: A theory of maternal destructiveness. New Yorki Grune \& Stratton, 1964.

Rosenkrantz, P. S., Vogel, S. R., Bee, H., Broverman, I. K., \& Broverman, D. M. Sex-role stereotypes and self-concepts in college students. Journal of Consulting and Clinical Psychology, 1968, 22, 287-295. 
Sherman, J. A. Socializing for maximal female competence. Paper presented in a Symposium at the American Association for the Advancement of Science, Washington, D. C., December 1972.

Shostrom, E. L. An inventory for the measurement of selfactualization. Educational and Psychological Measurement, $1964,24,207-218$.

Spence, J. T., Helmreich, R., \& Stapp, J. The Personal Attributes Questionnaire: A heasure of Sex Role Stereotyping and Masculinity-Femininity. Journal Supplement Abstract Service Catalog of Selected Documents in Psychology, 1974, 4, 43.

Velicer, $W$. The minimum residual curve and the number of factors problem. Paper presented at the Psychometric Society at Stanford University, Palo Alto, California, Spring 1974.

Weisstein, N. Woman as nigger. Psychology Today, 1969, 3 , $5-7$.

Welling, M. A. A new androgeny measure derived from the Personality Research Form. Paper presented at a Symposium at the American Psychological Association, Chicago, August 1975.

White, R. H. Competence and the psychosexual stages of development. In i. R. Jones (Ed.), Nebraska Symposium on Motivation, 1960. Lincoln, Nebraska: University of Nebraska Press, 1960. 